\title{
Transmural clinics
}

Citation for published version (APA):

Temmink, D. (2000). Transmural clinics: a nursing innovation explored. [Doctoral Thesis, Maastricht University]. NIVEL. https://doi.org/10.26481/dis.20001124dt

Document status and date:

Published: 01/01/2000

DOI:

10.26481/dis.20001124dt

Document Version:

Publisher's PDF, also known as Version of record

\section{Please check the document version of this publication:}

- A submitted manuscript is the version of the article upon submission and before peer-review. There can be important differences between the submitted version and the official published version of record.

People interested in the research are advised to contact the author for the final version of the publication, or visit the DOI to the publisher's website.

- The final author version and the galley proof are versions of the publication after peer review.

- The final published version features the final layout of the paper including the volume, issue and page numbers.

Link to publication

\footnotetext{
General rights rights.

- You may freely distribute the URL identifying the publication in the public portal. please follow below link for the End User Agreement:

www.umlib.nl/taverne-license

Take down policy

If you believe that this document breaches copyright please contact us at:

repository@maastrichtuniversity.nl

providing details and we will investigate your claim.
}

Copyright and moral rights for the publications made accessible in the public portal are retained by the authors and/or other copyright owners and it is a condition of accessing publications that users recognise and abide by the legal requirements associated with these

- Users may download and print one copy of any publication from the public portal for the purpose of private study or research.

- You may not further distribute the material or use it for any profit-making activity or commercial gain

If the publication is distributed under the terms of Article $25 \mathrm{fa}$ of the Dutch Copyright Act, indicated by the "Taverne" license above, 


\title{
Transmural clinics:
}

\section{a nursing innovation explored}

\author{
Denise Temmink
}


Temmink, D.

Transmural clinics: a nursing innovation explored /Denise Temmink

Utrecht: Nivel

Proefschrift Universiteit Maastricht. - met lit. opg. - Met samenvatting in het Nederlands

ISBN 90-6905-488-4

Language consultant

Lay-out

Cover Design

Printed by
Stafford Wadsworth

Marcelle van der Meulen

Vincent Bus Buro voor grafische vormgeving bv

Richard van Kruysdijk

Drukkerij Anraad B.V. 


\section{Transmural clinics: \\ a nursing innovation explored}

Transmurale spreekuren:

een verpleegkundige innovatie onderzocht

\section{PROEFSCHRIFT:}

ter verkrijging van de graad van doctor aan de Universiteit Maastricht,

op gezag van de Rector Magnificus,

prof. dr A.C. Nieuwenhuijzen Kruseman

volgens het besluit van het College van Decanen,

in het openbaar te verdedigen

op vrijdag 24 november 2000 om 10.00 uur

door

Denise Temmink 
Promotoren:

prof. dr H. Huijer Abu-Saad

prof. dr J. van der Zee

Copromotor:

dr A.L. Francke

Beoordelingscommissie:

prof. $\mathrm{dr}$ C. Spreeuwenberg (voorzitter)

prof. dr C.M.A. Frederiks (Katholieke Universiteit Nijmegen)

dr I. Múr

prof. dr P. Pop

dr M.A.G. Schlösser (Stichting St. Maartensgasthuis, Venio)

The studies presented in this thesis were conducted at the Nivel foundation, Utrecht, The Netherlands. Nivel is the national institute for health services research.

The reported studies were mainly financed by the Dutch Ministry of Health, Welfare \& Sports. Additional financial support was given by Stichting Coördinatiecentrum Chronisch Zieken IKR/IKW. 


\section{Contents}

1 Overview

2 Innovations in the nursing care of the chronically ill: a literature review from an international perspective Journal of Advanced Nursing 2000; 31(6): 1449-1458

3 Dutch transmural nurse clinics for chronic patients: a descriptive study

Patient Education and Counseling 2000; 39: 177-184

$4 \quad$ Dutch nurse clinics for children with asthma: views of professionals and parents Journal of Nursing Care Quality 1999; 14(1): 63-71

$5 \quad$ Quality and continuity of care in Dutch nurse clinics for people with rheumatic diseases International Journal for Quality in Health Care 2000; 12(2): 89-95

89

6 Content and outcomes of Dutch nurse clinics for children with asthma Journal of Asthma (in press)

7 Rheumatology outpatient nurse clinics:

a valuable addition?

Submitted for publication

Summary

Samenvatting

Dankwoord 

This chapter gives an outline of the thesis. First, insight is provided into the background to the studies described. Second, the research methods employed are presented. Subsequently, the principal findings are set forth and critical reflections are given. At the end of the chapter proposals are made for practice, policy and research. The reader is referred to chapters 2-7 for more detailed methodological information and the results of the studies.

\section{THE BACKGROUND TO THE STUDY}

\section{Challenges in health care}

Health care organizations in Western industrialized countries face a number of challenges. The first relates to health (care) developments. Western populations are getting older and increasingly comprise larger numbers of people suffering from chronic complaints. Medical, technological and pharmaceutical advances have also meant a challenge to the health care system in the last two decades (Kendig et al. 1992, Raffel 1997, Saltman \& Figueras 1997). As a result of these advances, patients live longer and can be cared for at home instead of in hospital. Second, cultural developments, such as the emancipation and empowerment of patients and the increasing number of people living alone, also present health care organizations with a challenge. The emancipation and empowerment of patients has resulted in services being increasingly geared toward patients' care demands. As people in the western world more often live alone, they will make increasing demands on professional health care services and, in consequence, put pressure on health care organizations. Third, the issue of funding influences health care organizations in the industrial west. Rising health care costs, in many western countries, have led to the imposition of limits on the amount of money available for health care (Raffel, 1997; Preston et al., 1999; Ankoné, 2000). The tightening money supply forces health care organizations to work more efficiently and more effectively.

\section{Innovations}

As shown in Figure 1, health care policy in the industrialized west is anticipating the challenges specified by implementing substitution-related health care innovations. Substitution of care refers to a shift in care responsibilities and tasks in such a way that high quality care is provided by 
the most appropriate health care provider at the lowest cost level. If, for instance, responsibilities and tasks shift from medical specialists to nurses, substitution can be said to have taken place.

Figure 1: Relation between health care challenges, policy and innovations

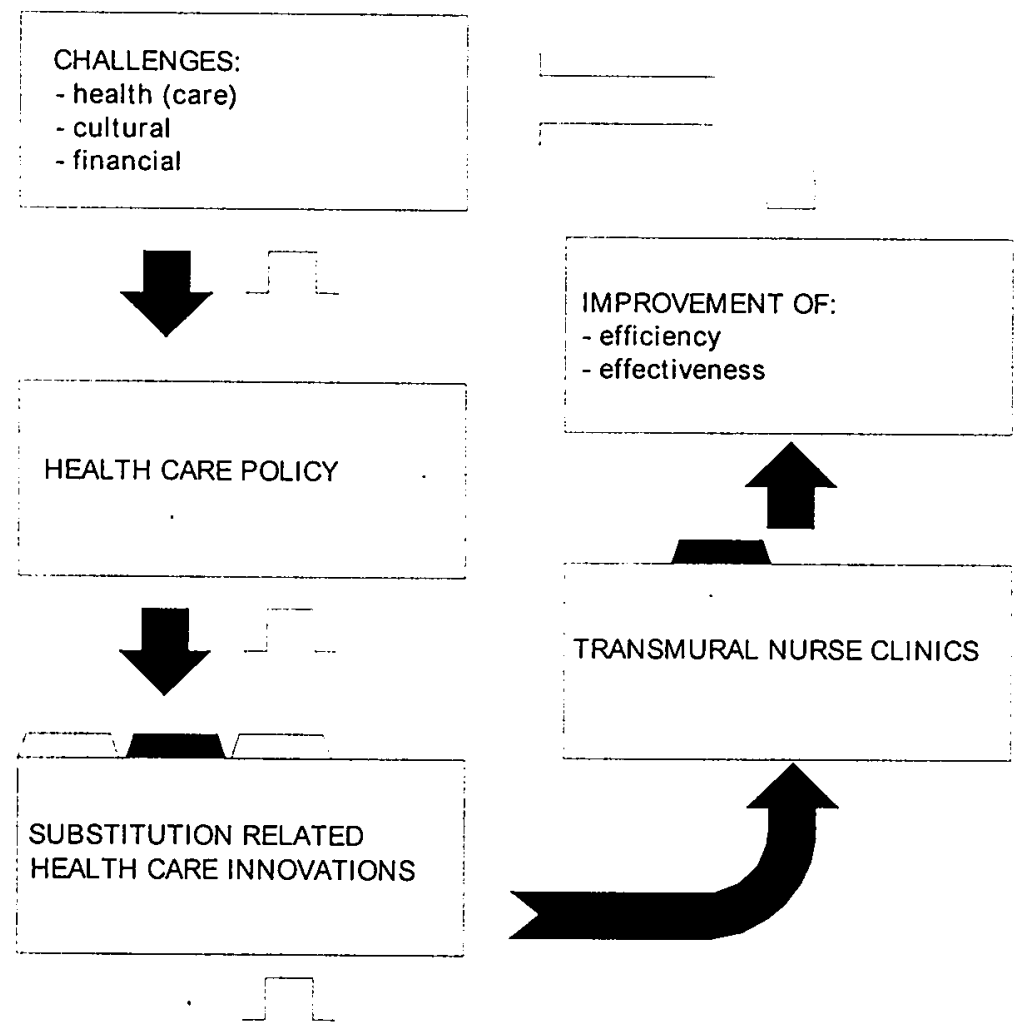

Although we speak of 'care innovations', it should be noted that some health care services in one country will be labelled as innovations, while in other countries they might be integrated into standard care services and not considered as innovations. These differences in labelling relate to the fact that despite a great deal of shared practice in the west, the organization of health care differs from one country to another. Variables include the availability of 
home and hospital care, the number of general practitioners, medical specialists and nurses and expenditure on home and hospital care (Westert, 1997; Temmink et al., 2000a).

Substitution of care, however, is a pivotal innovative element in most western industrialized countries. One type of innovative substitution is that in which care is delivered under the joint responsibility of primary and secondary health care organizations. In the international literature, several terms are used to indicate such innovations. For instance, concepts like 'integrated care', 'disease management', 'managed care', 'case management', 'shared care' and 'transmural care' are used. The impact of this type of innovation is assessed in a number of studies (Dawson \& Critchley, 1992; Campbell Haggerty et al., 1991; Witteveen, 1998; Smeenk, 1998; Häggmark \& Nilsson, 1997; Peters, 1995; Osman, 1996; Rietkerk \& Hirasing, 1997; Weinberger et al., 1996). A broad range of innovation and outcome variables are described in these studies. As a consequence, valid general conclusions about the contribution of innovation under the joint responsibility of primary and secondary care organizations in respect, for instance, of the quality and continuity of care, patient-related outcomes, and the efficiency and effectiveness of care cannot be inferred.

\section{Transmural care}

In the Netherlands, the term 'transmural care' is used to indicate substitution-related innovation which is implemented under the joint responsibility of primary and secondary care organizations. Transmural care innovation has been encouraged since the beginning of the nineties in Dutch health care policy and implies a shift from institution-based health care (with a sharp distinction between primary and secondary health care) to a more functional approach to the health care system (Tweede Kamer, 1990). In the functional approach, terms like 'care' and 'cure' replace terms like 'home care' and 'hospital care'. A range of care demands can be met in several ways and by different health care services. In anticipation of the cultural, financial and health (care) related challenges specified, it is important that this care process be directed to an improvement in the quality, efficiency and effectiveness of the care. To achieve these objectives, it is necessary to erase traditional boundaries between primary and secondary care and also have care provided jointly by primary and secondary care services (Tweede Kamer, 1991; Commissie Modernisering Curatieve Zorg, 1994; NRV/CvZ, 1995). 
The transmural care concept refers to care that breaks down the traditional boundaries between hospitals and primary care, that is tailored to patients' needs and provided on the basis of close collaboration and joint responsibility by primary care and hospital organizations (NRV/CVZ, 1995). Close collaboration implies collaboration between professionals on a formal structural basis. This collaboration may take the form of regular meetings between professionals (nurses and medical specialists) in which both patient-related subjects as well as the pre-conditions of the transmural care process are discussed. Joint responsibility refers to formal agreements about the transmural care process at an organizational level. Such agreements can be laid down in protocols or guidelines which contain information about the person or organization to assign the location for transmural care or about the agency employing the professionals providing transmural care.

\section{Transmural nurse clinics}

One example of Dutch transmural care relates to transmural nurse clinics for people suffering from chronic diseases. In 1996, 78 of such clinics were established in the Netherlands (Temmink et al., 2000b). Community nurses specializing in the care for a group of chronic patients often run transmural clinics in an outpatient department of a hospital. Most patients visiting a transmural nurse clinic are referred by their medical specialist. The main activities of the specialist nurses at the clinics is to provide illness-related information and to support patients in coping with the illness both practically and emotionally. Information can, for example, be given about how to acquire practical aids and adaptations for the living environment. The implementation of transmural nurse clinics is intended to anticipate the cultural, financial and health (care) related challenges specified by the increasing effectiveness, efficiency and continuity of quality care. 
The aim of this thesis is to provide insight into the results of a specific type of substitution-related innovation, namely the transmural nurse clinic. In order to achieve this objective, the following research question is addressed:

- What is the impact of attending a transmural nurse clinic on:

- the quality of care,

- the continuity of care,

- patients' need for information,

- patients' use of practical aids and adaptations,

- patients' use of health care facilities and

- patients' daily functioning?

In the core section of the thesis, two evaluation studies on transmural asthma and rheumatology nurse clinics (hereinafter the asthma- and rheumatology study) are presented. The reason for a focus on rheumatology clinics is that this type of transmural clinic is the most common in the Dutch health care system (Temmink et al., 2000b). Transmural nurse clinics for children with asthma are studied because asthma is the most prevalent chronic disease among children (Bur et al., 1989; Magnus \& Jaakkola, 1997; Stoffelen et al., 1999). It is also well known that children with asthma are often underdiagnosed and undertreated (Speight et al., 1983; Stoffelen et al., 1999), which provides an illustration of an inadequate care process. In the Netherlands, there are also clinics for children with asthma in a non-transmural setting, in the form of a care service provided solely by home care organizations (these are called extramural nurse clinics). This thesis will provide an answer to the question as to whether transmural nurse clinics produce different outcomes from the traditional extramural nurse clinics for children with asthma.

In the next part of this overview chapter, the research methods and major findings of the studies described in the thesis will be presented and discussed consecutively. Recommendations for practice, policy and research will also be outlined. 


\section{METHODS AND MAJOR FINDINGS}

\section{Methods}

Box 1 summarizes the studies and research methods described in this thesis. More insight into substitution-related innovation and the characteristics of transmural nurse clinics in the Netherlands is given in Chapters 2 and 3 . This overview chapter will further focus on the core of the thesis, the asthma and rheumatology study presented in Chapters 4-7.

In the quantitative part of the asthma and rheumatology study, pre-, post-, follow-up measurements and control groups were used (see Box 1). The participants' quantitative data was gathered by using structured telephone interviews. In addition, qualitative data was gathered by interviewing specialist nurses and medical specialists involved in either transmural or extramural nurse clinics. More detailed information about the research methods used in the asthma and rheumatology study can be found in Box 1 and chapters 2-7.

Box 1: The studies described in this thesis

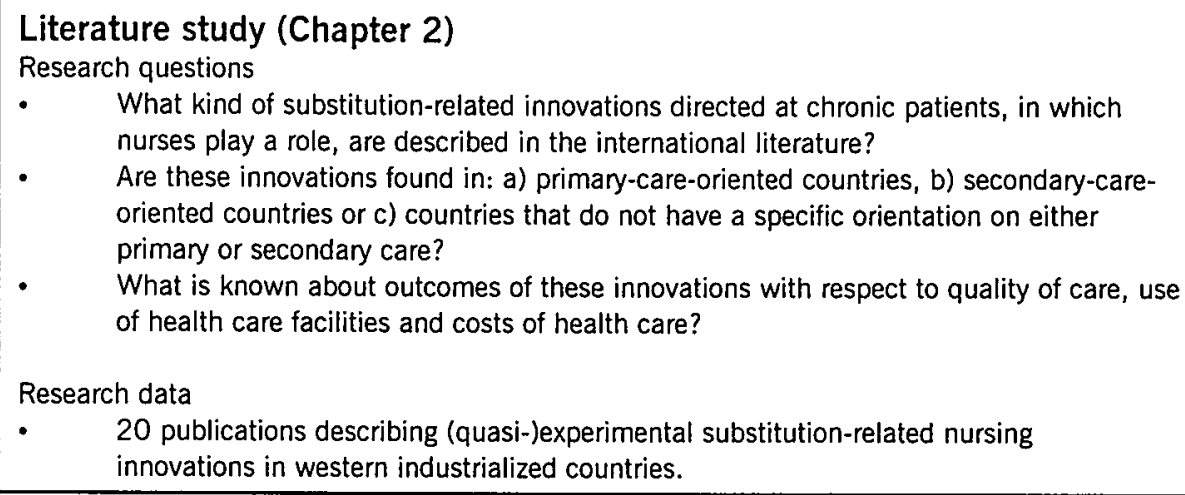




\section{Box 1 continued}

\section{Descriptive inventory study (Chapter 3 )}

Research questions

- What are structural/organizational characteristics of Dutch transmural nurse clinics for somatic patients?

- What are process characteristics of these clinics?

- Are these clinics evaluated? If so, what methods are used and what outcome characteristics are described?

\section{Research data}

- $\quad 35$ project plans, annual reports or evaluation reports presenting information about the characteristics and/or outcomes of a transmural nurse clinic;

- 27 questionnaires completed by specialised nurses running a transmural nurse clinic.

\section{The asthma-study (Chapters 4 and 6)}

Intervention

Children with asthma attended the clinics (with their parents) an average of 2.4 times during the research period of six months. Main activities of the specialist asthma nurses were to provide illness related information and psycho-social support.

\section{Research questions}

- What are specialist asthma nurses' perceptions about transmural and extramural nurse clinics in the Netherlands? What are pediatricians' perceptions about transmural nurse clinics in the Netherlands?

- Do parents' perceptions about the quality and continuity of care reveal a difference in the assessment of transmural and extramural nurse clinics in the Netherlands?

- Do transmural and extramural nurse clinics differ with regard to: the characteristics of the attending asthmatic children and their parents or the nursing care provided? What is the effect of visiting a nurse clinic on (parents of) asthmatic children: need for information and use of health care services?

Is there a difference in outcomes between transmural and extramural nurse clinics with regard to: parents' need for information or asthmatic children's use of health care services?

Research data

- $\quad$ questionnaires completed by 139 parents of children with asthma attending a transmural nurse clinic questionnaires completed by 63 parents of children with asthma attending an extramural nurse clinic 4 specialist asthma nurses and 5 pediatricians involved in transmural nurse clinics and 2 specialist asthma nurses heading an extramural nurse clinic provided qualitative interview data 
chapter 1

\section{Box 1 continued}

\section{Measurement points and research conditions}

\begin{tabular}{|c|c|c|c|c|}
\hline & \multicolumn{2}{|c|}{$\begin{array}{l}\text { Parents and children attending a } \\
\text { transmural nurse clinic }\end{array}$} & \multicolumn{2}{|c|}{$\begin{array}{l}\text { Parents and children attending an extramural nurse } \\
\text { clinic }\end{array}$} \\
\hline Week 0 & \multicolumn{2}{|c|}{$\begin{array}{l}\text { Pre-test; } 1-4 \text { days betore the first } \\
\text { contact with the specialized nurse } \\
\text { at the clinic }\end{array}$} & \multicolumn{2}{|c|}{$\begin{array}{l}\text { Pre-test: } 1-4 \text { days before the first contact with the } \\
\text { specialized nurse at the clinic }\end{array}$} \\
\hline Week 6 & \multicolumn{2}{|l|}{ Post-test } & \multicolumn{2}{|l|}{ Post-test } \\
\hline Week 26 & \multicolumn{2}{|l|}{ Follow-up } & \multicolumn{2}{|l|}{ Follow-up } \\
\hline \multicolumn{5}{|c|}{ Variables measured and instruments used } \\
\hline Variables & $\begin{array}{l}\text { Measurement } \\
\text { instruments }\end{array}$ & \multicolumn{2}{|c|}{ Measurement points } & Major findings \\
\hline $\begin{array}{l}\text { Specialist asthma } \\
\text { nurses' and } \\
\text { pediatricians } \\
\text { perceptions } \\
\text { (Chapter 4) }\end{array}$ & In-depth interviews & \multicolumn{2}{|c|}{$\begin{array}{l}\text { At the end of the research } \\
\text { period }\end{array}$} & $\begin{array}{l}\text { Positive; no difference between } \\
\text { research conditions }\end{array}$ \\
\hline $\begin{array}{l}\text { Quality of care } \\
\text { (Chapter } 4 \text { ) }\end{array}$ & QUOTE & \multicolumn{2}{|c|}{ Pre-test and post-test } & $\begin{array}{l}\text { Positive; no difference between } \\
\text { research conditions }\end{array}$ \\
\hline $\begin{array}{l}\text { Continuity of care } \\
\text { (Chapter 4) }\end{array}$ & QCC & \multicolumn{2}{|c|}{ Pre-test and post-test } & $\begin{array}{l}\text { Positive; no difference between } \\
\text { research conditions }\end{array}$ \\
\hline $\begin{array}{l}\text { Characteristics of } \\
\text { asthmatic children } \\
\text { and their parents } \\
\text { (Chapter 6) }\end{array}$ & $\begin{array}{l}\text { Pre-structured } \\
\text { questions }\end{array}$ & \multicolumn{2}{|l|}{ Pre-test } & $\begin{array}{l}\text { Differences between research } \\
\text { conditions with respect to the } \\
\text { severity of asthma }\end{array}$ \\
\hline $\begin{array}{l}\text { The nursing care } \\
\text { provided } \\
\text { (Chapter 6) }\end{array}$ & $\begin{array}{l}\text { Nurse registration } \\
\text { form }\end{array}$ & \multicolumn{2}{|c|}{ During the research period } & $\begin{array}{l}\text { Differences between research } \\
\text { conditions with respect to: } \\
\text { referral to the clinic, duration of } \\
\text { contacts, care demands and care } \\
\text { activities }\end{array}$ \\
\hline $\begin{array}{l}\text { Need for asthma } \\
\text { related information } \\
\text { (Chapter } 6 \text { ) }\end{array}$ & $\begin{array}{l}\text { Pre-structured } \\
\text { questions }\end{array}$ & \multicolumn{2}{|c|}{$\begin{array}{l}\text { Pre-test, post-test and } \\
\text { follow-up }\end{array}$} & $\begin{array}{l}\text { Decline in information needs is } \\
\text { greater in transmural condition }\end{array}$ \\
\hline $\begin{array}{l}\text { Use of health care } \\
\text { facilities } \\
\text { (Chapter } 6 \text { ) }\end{array}$ & $\begin{array}{l}\text { Pre-structured } \\
\text { questions }\end{array}$ & \multicolumn{2}{|c|}{ Pre-test and Follow-up } & $\begin{array}{l}\text { No differences between research } \\
\text { conditions }\end{array}$ \\
\hline
\end{tabular}




\section{Box 1 continued}

\section{The rheumatology-study (Chapter 5 and 7)}

Intervention

Rheumatic patients attended a transmural nurse clinic about three times on average during the research period of six months. Main activities of the specialist rheuma nurses were providing

illness related information and psycho-social support.

\section{Research questions}

- Are there, in the view of people with rheumatic diseases, quality or continuity of care aspects which need to be improved in Dutch transmural nurse clinics?

What positive or negative factors, in the view of specialist rheumatology nurses and rheumatologists involved in Dutch transmural nurse clinics (such as organizational or social factors) had affected the quality or continuity of care?

What is the effect of attending a transmural nurse clinic in addition to the regular care provided for rheumatic patients on the: need for information, use of practical aids and adaptations, use of health care services and daily functioning?

\section{Research data}

- $\quad$ questionnaires completed by 128 people with a rheumatic disease attending a transmural nurse clinic questionnaires completed by 81 people with a rheumatic disease receiving regular care only

6 specialist rheumatology nurses and 4 rheumatologists involved in transmural nurse clinics provided qualitative interview data

Measurement points and research conditions

\begin{tabular}{|c|c|c|c|}
\hline & $\begin{array}{l}\text { Patients attending a transmural } \\
\text { nurse clinic. }\end{array}$ & \multicolumn{2}{|c|}{ Patients receiving regular care only } \\
\hline Week 0 & $\begin{array}{l}\text { Pre-test; } 1-4 \text { days after consulting } \\
\text { the rheumatologist }\end{array}$ & \multicolumn{2}{|c|}{ Pre-test: 1-4 days after consulting the rheumatologist } \\
\hline Week 6 & Post-test & \multicolumn{2}{|l|}{ - } \\
\hline Week 26 & Follow-up & \multicolumn{2}{|l|}{ Follow-up } \\
\hline \multicolumn{4}{|c|}{ Variables measured and instruments used } \\
\hline Variables & Measurement instruments & Measurement points & Major findings \\
\hline $\begin{array}{l}\text { Specialist } \\
\text { theumatology } \\
\text { nurses' and } \\
\text { rheumatologists' } \\
\text { perceptions* } \\
\text { (Chapter 5) }\end{array}$ & In-depth interviews & $\begin{array}{l}\text { At the end of the research } \\
\text { period }\end{array}$ & Positive \\
\hline $\begin{array}{l}\text { Quality of care* } \\
\text { (Chapter } 5 \text { ) }\end{array}$ & QUOTE & Pretest and post-test & Positive \\
\hline
\end{tabular}


Box 1 continued

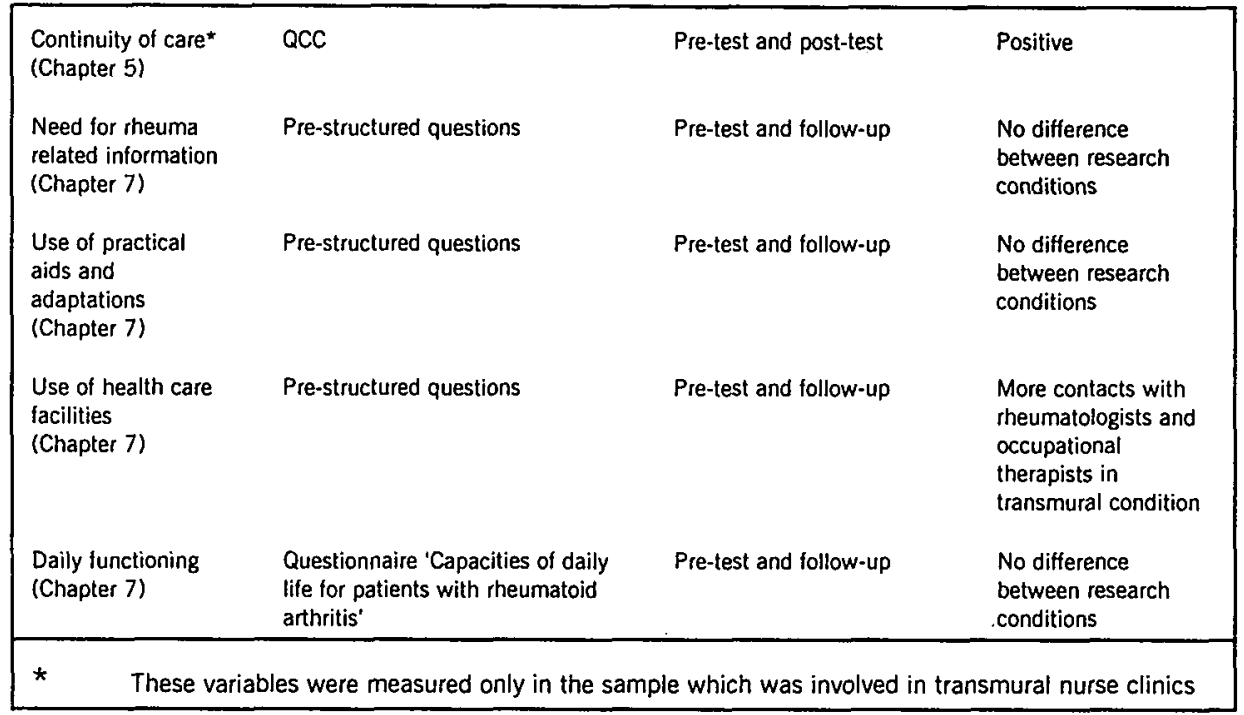

The aim of this thesis is to provide insight into the results of one type of substitution-related innovation, namely the transmural nurse clinic. In achieving this aim, the description of the results of the studies forms a starting point. It is vital that the research results be translated into conclusions and recommendations for practice, policy and research. In this section, a start is made on this translation process by discussing the major findings of the asthma and rheumatology study under three headings: 1) The principal conclusions, 2) Methodological considerations and 3) Recommendations for practice, policy and research.

\title{
PRINCIPAL CONCLUSIONS
}

\author{
What can be concluded on the basis of this thesis? \\ Quality and continuity of care \\ Parents of children with asthma, people with a rheumatic disease and health \\ care professionals participating in the asthma and rheumatology study made a \\ very positive assessment of the quality and continuity of care in transmural \\ nurse clinics.
}

Other studies concluded that people suffering from a rheumatic disease or asthma who only received standard medical care often felt that they had not received enough information (Bendtsen \& Bjurulf, 1993; Nocon \& Booth, 
1990; Jans, 1999). Daltroy (1993) observed in addition that, when patients only make use of standard medical services there is inadequate doctor-patient communication. Furthermore, patients are often dissatisfied with the fact that medical outpatient clinics do not provide unscheduled access (Hill et al., 1992), patients are critical about waiting time when attending medical outpatient clinics and about the co-ordination of care given by medical specialists (Hill et al., 1992; Van Campen et al., 1998; Van Campen et al., 1997). In the asthma and rheumatology study described in this thesis, virtually no negative judgements were made on the quality and continuity of care. Consequently, further implementation of nurse clinics would seem appropriate where the improvement of the quality and continuity of care is an objective.

However, the asthma study described in this thesis also reveals that the positive judgements on the quality and continuity of care did not differ between participants attending an innovative transmural nurse clinic or a traditional extramural clinic. These results are supported by Garvican et al. (1998) and Hill et al. (1992) who also concluded that nurse clinics are a meaningful intervention, but that the organizational background (i.e. transmural vs. extramural) of nurse clinics does not influence the perceived quality and continuity of care. This result may be explained by the fact that patients do not attach much importance to the organization of the care provided, but focus mainly on the content of the care process. As transmural and extramural nurse clinics do not differ in this respect, it is not surprising that differences between the quality and continuity of care in the two kinds of clinics was not perceived.

\section{Characteristics of asthmatic children and their parents}

It can be assumed that the population of asthmatic children in regions in which a transmural or extramural clinic is available are comparable. However, the asthma study showed that children attending extramural nurse clinics suffered from less severe asthmatic conditions. Furthermore the nurses running extramural nurse clinics often did not know the severity of childrens' asthma. Children visiting an extramural nurse clinic are also more often referred to the clinic by a general practitioner or have contacted the specialist nurse at their own initiative. The combination of these findings indicates that in those areas where only extramural nurse clinics are available, children suffering from severe asthma may not be receiving the nursing care they need. The suggestion is that there may be insufficient co-operation between medical doctors and specialist community nurses. This finding is in line with the conclusion drawn by Jans (1999). She concluded that Dutch general practitioners perceive barriers in referring asthmatic patients to a community nurse. 


\section{Need for information}

The nursing care provided in transmural and extramural clinics mainly provides patients with information about their disease and how to deal with it on an everyday basis. It would therefore seem obvious that the asthma study presented in this thesis would show a decline in the need for asthma-related information on the part of the parents after they had attended a nurse clinic. However, it transpired that the decline in the parental information requirement was greater in the transmural than in the extramural clinics. These results indicate that both transmural and extramural clinics meet the parental information requirement. It would appear, however, that the transmural clinics make a better job of it than the extramural ones.

This improved supply of information to parents in the transmural setting can be attributed to a difference in organization between transmural and extramural nurse clinics. In transmural nurse clinics, health care professionals (i.e. medical specialists and specialist nurses) work closely together in a multi-disciplinary setting. This provides the advantage of up-to-date information on asthma care in general and the care process for individual patients in particular. In contradiction, the nurses running extramural clinics involved in the asthma study, did not have structural contact with other professionals (medical specialists or general practitioners).

In the rheumatology study, a comparison was made between patients who attended a transmural nurse clinic and those who received regular health care only. The results of this study showed that rheumatic patients' need for rheumatology-related information declined under both research conditions and no significant differences between the two groups were found. A plausible explanation for this is that where rheumatologists do not have the opportunity to refer patients to a nurse clinic, they do, in fact, provide patients with adequate information about the disease. It is of course equally possible that in case rheumatologists can refer to a transmural nurse clinic, the demarcation of educational tasks between rheumatologists and nurses remains unclear.

\section{Use of health care facilities}

With respect to patients' use of health care services, the asthma study showed that after patients had attended a nurse clinic, they made less use of other health care services. More specifically, it appeared that parents of children with asthma were less likely to take their child to the general practitioner after they had attended a transmural or extramural nurse clinic. No differences were found between those attending transmural and extramural nurse clinics in respect of this result.

The rheumatology study indicated that patients attending a transmural nurse clinic contacted their rheumatologists and occupational therapists more often 
than patients only receiving regular care. A possible reason for this might be that a specialist rheumatology nurse provides a more extensive specification of patients' care problems and is required to provide optimal care coordination. This can lead to care demands requiring the competence of other professionals such as a rheumatologist or occupational therapist and, consequently, to referrals.

In the international literature several authors describe that where patients received care in which patient education played a central role, a decrease in health care consumption occurred (Blake et al., 1990; Beck et al., 1997; Mazzuca et al., 1996; Colland, 1993; Taggart et al., 1991; Mesters, 1993; Ghosh et al., 1998; Maslennikova et al., 1998; Osman et al., 1996; Campbell Haggerty et al., 1991; Schlösser, 1992). An increase of health care consumption as a result of providing care in which education plays a pivotal role, was only found in the study by Weinberger et al. (1996).

\section{Use of practical aids and daily functioning}

On the basis of the rheumatology study it can be further concluded that the use of practical aids and adaptations and daily functioning does not differ between people who receive regular care and people who attend a transmural nurse clinic. A reason for not finding a difference with respect to rheumatic patients' use of practical aids and adaptations might be that the procedure for requesting aids and adaptations often takes more than the six month period allowed in the rheumatology study. On the one hand, this has to do with the fact that patients often have to get used to the idea that their condition is worsening and that they therefore need various aids. On the other hand, such aid requirements involve considerable red tape, which means that the whole process can take more than six months to complete.

The rheumatology study finding that attending a transmural nurse clinic did not influence rheumatic patients' daily functioning was found in other studies too. On the basis of the results of the rheumatology study described in this thesis and the studies of Vliet Vlieland (1996) and Riemsma (1998), it seems clear that education-oriented intervention alone cannot influence the functional abilities of people with rheumatic diseases positively. 


\section{METHODOLOGICAL CONSIDERATIONS}

\section{Was the appropriate intervention used?}

In evaluation research, the intervention tested is often specially developed for the research on the basis of existing theory and the literature. An advantage of using such an intervention is that an ideal, uniform, intervention, from which considerable effect is expected, will be tested. However, in the asthma and rheumatology study another approach was chosen. This involved the evaluation of the existing transmural nurse clinics. An advantage of this approach is that the clinics included in this thesis had already been implemented on a large scale in the current health care context instead of only within the organizations involved in the study itself. This makes the study automatically relevant to practice. The exact dose of the intervention (i.e. transmural nurse clinics) was not predetermined in the asthma and rheumatology study. However, by making an inventory of transmural nurse clinics before starting an evaluation study and using nursing registration forms to indicate the nursing care provided, insight was gained into the actual intervention provided.

\section{Did we use the proper design and methods for the study?}

In both the asthma and the rheumatology study, a quasi-experimental design with one pre-test and two post-tests was used. The term 'quasi-experimental' refers to the fact that the participating subjects were, for ethical and practical reasons, not allocated to one of the study-groups involved on a random basis. We chose to compare settings rather than randomize within settings, because the health care professionals involved in the studies thought it unethical to withhold the option of attending a transmural nurse clinic from patients. In addition, it appears to be very difficult, if not impossible, to avoid contaminating results within settings. Even if it had been chosen to randomize patients on, for instance, a weekly basis, it would not have been possible to avoid contaminating results within settings. Patients will talk with one another in the waiting rooms and will soon know of the presence of a specialist nurse and ask to consult her.

A post-test after six weeks and a follow-up measurement after six months was considered appropriate. However, it might have been useful to have an additional follow-up measurement after twelve months. This extended follow-up measurement period might have provided more reliable insight into the effect of attending transmural nurse clinics on participants' use of practical aids and adaptations. Furthermore, not all variables were measured at all three measurement points. The rationale for this was that it did not seem reasonable to expect short-term effects (that is after six weeks) on outcomes such as the use of health care services and daily functioning. In the rheumatology study, patients' information needs were only measured at the 
pre- and follow-up measurement. As a result, insight into the short-term effects of transmural nurse clinics on rheumatic patients information requirement is lacking. However, most rheumatic patients contacted a specialist nurse running a transmural nurse clinic in the first two months of the research period of six months. It is therefore plausible that effects on patients' information needs occurred shortly after their first contact with the nurse. These effects may have faded away at the six-month measurement point.

In the studies, patients were not stratified on the basis of the severity or duration of their disease and, as a consequence, sub-group analyses could not be performed due to the small number of patients per sub-group.

Nevertheless, the biasing effects of possible differences between research conditions are taken into account in the statistical analyses used. It would seem logical for attendance at transmural nurse clinics to lead to different outcomes when there is a difference in the severity or duration of the disease. As regards the rheumatology study, it also seems possible that the outcomes of the intervention differ in terms of the kind of rheumatic disease.

The research data were gathered by using structured telephone interviews. These interviews were conducted by an independently trained pollster and lasted from about fifteen to forty minutes. The choice of structured telephone interviews resulted in a high response rate and a reliable data set with a minimal number of missing values. However, it should be borne in mind that telephone interviews are much more time-consuming and accordingly more expensive than using postal questionnaires (Van Campen et al., 1998).

Some of the questionnaires used focused directly on experience with the care provided. Consequently the pollster, carrying out the telephone interviews, knew participants' research condition and was thus not blinded. However, to avoid biased results as a consequence of the use of an open study design, the pollster was trained for the interviews and used the precise wording of the structured questionnaire format. It is assumed that this way of avoiding biased results was adequate.

\section{Did we use the proper instruments?}

Well-established and internationally current instruments were selected for the collection of quantitative data in the asthma and rheumatology study when available. The instruments used require further comment. 


\section{Nursing care provided}

During the six-month research period, of the asthma and rheumatology study, the specialist nurses running a nurse clinic, completed a registration form for each participant in the study. The specialist nurses registered characteristics of the nursing care provided to individual respondents, these included the number and duration of nursing contacts and the care demands made upon the nurse. This method was useful in gaining insight into the actual nursing care provided and appeared to be a sound solution for evaluating a 'black box'. Other options would have been the use of video- or participant-observation. However, such methods are much more time-consuming and expensive.

\section{Quality of care}

Questionnaires entitled Quality of Care through the Patient's Eyes for asthma and COPD and QUOTE for rheumatic patients (Van Campen et al., 1997 \& 1998) were used to examine participants' perceptions of the quality of care. Using QUOTE at pre-test measurement, participants were asked to rate the importance of health care indicators, for example as follows: 'Health professionals should understand my problems'. At the post-test measurement, patients were requested to rate perceived performance for each indicator, for example as follows: 'The specialist nurse understands my problems'. Scores based on these pre- and post-test data were calculated indicating either positive or negative scores for specific quality indicators.

QUOTE has proved reliable and valid for use in a population of children with asthma and for people with rheumatic disease (Van Campen et al., 1997 \& 1998). The advantage of using QUOTE, was that this instrument anticipates the difficulties of measuring the quality of care as perceived in other studies. Patient views of the quality of care have often only been assessed using post-measurement patient satisfaction questionnaires. However, such questionnaires often produce highly skewed scores and absolute scores unrelated to respondents' individual levels of expectations and need ( $V$ an Campen et al., 1998). This difficulty is avoided by using QUOTE, because data is not only collected on patient experience, but also on their needs and expectations. Another advantage of using QUOTE is that this instrument is specific enough to provide direction for daily health care practice. Data collected via QUOTE indicates those practical factors that might be relevant in the improvement of the quality of care in future.

\section{Continuity of care}

The Questionnaire on Continuity of care from the Clients' perspective (QCC) was used to measure the continuity of care (Casparie et al., 1998). This instrument has been shown to be reliable and valid in assessing the continuity of health care services from the perspective of patients (Casparie et al., 1998). The QCC used in this thesis has a comparable structure to QUOTE and also 
comprises pre- and post-measurements in which patients' importance and perceptions are measured. It should be noted that the definitive version of QCC only measures patient perceptions. Despite this it was decided to use importance scores as well in the asthma and rheumatology study, because this provides an opportunity to reveal participants' experience and to give practical advice on improving the continuity of care. As a result, QCC as used in this thesis has advantages comparable with those described for QUOTE; i.e., more reliable insight and specificity in directing daily health care practice.

\section{Need for disease-related information}

In order to gain insight into the need for information, patients were asked what topics they required disease-related information about. The response categories used were: none, I have enough information; about my disease in general; about dealing with the disease in daily life; about the correct use of medication; about side-effects of medication; about requesting practical aids or adaptations; about other subjects. This pre-structured question was derived from a sub-part of QCC (see above) and provided good insight into the development of the participants' information need during the six-month research period.

\section{Daily functioning}

The Dutch version of the English language Health Assessment Questionnaire (HAQ), [Vragenlijst Dagelijks Functioneren' (VDF)], was used at pre- and follow-up measurement to measure rheumatic patients daily functioning. In the VDF, patients are asked to rate their level of dependency in terms of twenty daily activity indicators such as: 'Were you able to get on and off the toilet?' Response categories used in the VDF range from 0 (=completely dependent) to 3 (=independent). VDF has been shown to be valid and reliable (Bijlsma et al., 1990). HAQ and VDF are often used in international and national research (Liang et al., 1985; Bijlsma, 1990) and VDF seemed most eligible for this research.

\section{Use of practical aids and adaptations}

The number and kind of aids and adaptations used was determined by asking rheumatic patients, at pre- and follow-up measurement 'What practical aids or adaptations do you use in daily life?' Fifteen response categories each representing an aid or adaptation (like a height-adjusted toilet, adjusted taps or handles in the bathroom) were presented to the patient. This question was derived from a sub-part of the VDF questionnaire (see above) and was useful in detecting changes in rheumatic patients' use of aids and adaptations. In the rheumatology study, this variable was only measured at pre-test and follow-up. However, procedures for requesting practical aids and adaptations often take longer than the six-month period allowed for the study. 
At first the plan was to measure the use of practical aids and adaptations in the asthma study too. However, during the research it transpired that parents with asthmatic children often did not consider devices such as adapted bed-covers or curtains as adaptations. Consequently, the limited data gathered on this variable was judged to be irrelevant and not included.

\section{Use of health care facilities}

In order to determine participants' use of health care facilities, they were asked, at pre-test and follow-up measurement, to list the number of disease related contacts with health care professionals during the previous six months. Participants were also asked to rate their admissions to hospital or other health care institutions during the previous six months. In other research too, patients' use of health care facilities is measured by using patient self-reports (Jaarsma, 1999; Van den Bos, 1995; Blake et al., 1990). The danger in using this data is that patients might not recall their use of health care services, or they might confuse it with use related to complaints other than asthma or rheumatic disease. In the asthma and rheumatology study, this problem is partly overcome by the use of telephone interviews instead of postal questionnaires. During the telephone interviews, the pollster has the option of asking further questions where patients are uncertain about their use of health care services. Nevertheless, a six-month period turned out to be a very long time for some patients to remember their exact use of health care service, especially in the rheumatology study. It might therefore have been useful to use patient diaries in combination with medical and nursing records to gain more reliable insight into patients' use of health care services.

\section{Specialist nurses' and medical specialists perceptions}

In-depth interviews with specialist nurses and medical specialists were used to gain insight into their experience with and perceptions about nurse clinics. This qualitative research technique was used because only a relatively small number of professionals was involved in the studies. The use of semi-structured interviews appeared to be valuable, because it provided the option to ask further questions when necessary and for gathering in-depth information. However, using a combination of qualitative and quantitative research methods might have been appropriate. This type of combination might have had the advantage of making the interviewees feel more comfortable about expressing negative experience or perceptions. However, reliable and valid questionnaires providing information about professionals' perceptions are not yet available.

Interviews with professionals were audiotape-recorded and analysed by using qualitative research techniques. Although this process of data gathering and analysis was time-consuming, it appeared to provide valuable information. Furthermore, personal interviews with medical specialists turned out to 
provide a positive stimulus for involving them in the study; it encouraged them to recruit patients for the study.

\section{What other relevant variables could have been measured?}

In this study, participants' need for information was measured. It might have been valuable, if we had collected data on patients' knowledge of the disease and their self-care behaviour or compliance as well. The literature about nursing innovations, in which education plays a central role, produces contradictory results with regard to its influence on patients' knowledge. For instance, Mesters (1993) evaluated a multidisciplinary education protocol for primary care professionals (general practitioners, community nurses, asthma nurses and doctors in child health centers). In this experimental study it was concluded that when the protocol was used, parents' knowledge about asthma improved significantly. Research in hospital settings also indicated positive effects of asthma-related information given by specialist nurses. Donaghy (1995) compared a group of asthmatics who only received instruction from a doctor with a comparable group who received an additional individual education program conducted by an asthma nurse specialist. The latter study demonstrated that additional asthma education, provided by a nurse specialist improves the patients' understanding of asthma.

With respect to nursing education for people with a rheumatic disease, some studies indicated positive effects on patients' knowledge, while in other studies effects did not occur. For instance, in Hill (1997) and Hill et al. (1994) after consulting a rheumatology nurse practitioner, rheumatic patients knew significantly more about their disease than patients attending a rheumatologist's clinic. Riemsma (1998) studied the effect of an educational program for people with rheumatoid arthritis. During a six-month period, patients received disease-related information from nurses, rheumatologists, general practitioners and physiotherapists by discussing chapters from a self-help guide during their regular consultations with the patients. Riemsma (1998) concluded that the individual education program had no effect on rheumatic patients' knowledge of the disease.

If patients' knowledge of their disease were to increase as a result of attending a transmural nurse clinic, it seems plausible that their self-care behaviour and adherence to medical treatment would improve. Jaarsma (1999) found that extra education and support given by a specialist nurse improved the self-care behaviour of patients with heart failure. However, in the study by Van Es (1999), adolescents with asthma received normal care from a pediatrician, supplemented by individual and group education sessions with an asthma nurse, and were compared with a control group receiving only normal pediatric care. Van Es (1999) concluded that the intervention did not influence adherence to the asthma medication regime. It might be useful in 
gaining insight into the effect of attending a transmural nurse clinic on patients' knowledge, self-care behaviour and their adherence in the future.

Measuring medical outcomes like fatigue, the kind of medication used or the number of exacerbations has been considered. However, the intervention of transmural nurse clinics consisted mainly in providing patient education about the disease and giving psychosocial support. It did therefore not seem plausible that a transmural nurse clinic would influence such medical outcomes. Also, on the basis of a literature study by Vrijhoef et al. (2000) it was concluded that nursing-related interventions were not specific and intensive enough to affect medical outcomes. In addition, the study of the literature by Ketelaars (1996) shows that the majority of previous intervention studies in the field of specialized nursing asthma care could not establish beneficial effects on outcomes directly related to physical health.

Finally, because transmural care in general and transmural nurse clinics in particular are initiated to reduce health care costs, it would have been useful to perform an additional study which determined the cost-effectiveness of transmural nurse clinics. We tried to provide some insight into cost-effectiveness by using the 'use of health care facilities' variable in this thesis. However, a reliable cost-effectiveness study not only measures patients' use of health care facilities, but examines the effectiveness of an intervention in terms such as years-of-life-saved or quality-adjusted life years produced (Douglas et al., 1995). Although full cost-effectiveness assessment requires consideration of all costs, including indirect costs as side effects of treatments, the cost of extended life, and additional costs of medical care in later years, this degree of comprehensiveness is rarely possible or required in clinical evaluations (Douglas et al., 1995). It would therefore seem necessary to determine which method is the most eligible in measuring health care costs of substitution-related health care innovations.

\section{Were the statistical methods used adequate?}

Multivariate statistics were used, with correction for base-line scores and background characteristics to compare the control and intervention groups. Including base-line scores as covariates provided an opportunity to correct for what are called 'ceiling and basement effects'; people who have the highest/lowest score at baseline cannot score higher/lower at post-measurement (Cook \& Campbell, 1979). In addition, the inclusion of base-line scores and background characteristics as covariates in the analyses implied a correction for possible differences between the research groups at the start of the research.

The use of multi-level analysis techniques for the data was considered. A reason for not using such statistical methods was that differences at the 
organizational level (i.e. differences between organizations within the same research condition) were not expected, on the basis of the descriptive inventory study carried out and the content of the information gathered by using the nurse registration forms. In addition, multi-level analysis techniques are only useful in research designs in which a sufficient number of organizations are involved. In the asthma and rheumatology study six and nine locations were involved respectively, which is too small to make meaningful estimates of variation among organizations (Bryk \& Raudenbush, 1992).

\section{RECOMMENDATIONS}

As stated in the previous section, in the asthma and rheumatology study, randomization and stratification procedures were absent. However, proper instruments were used at several measurement moments, control groups were available and adequate statistical analyses were carried out. It is therefore possible to formulate recommendations for practice, policy and research.

\section{Recommendations for practice and policy}

The results of the asthma and rheumatology study indicate that, where improvement of quality or continuity of care is pursued, it is useful to implement nurse clinics on a broader scale. In comparison with studies in which the quality and continuity of regular medical care was determined (Bendtsen \& Bjurulf, 1993; Nocon \& Booth, 1990; Jans, 1999; Daltroy, 1993; Hill et al., 1992; Van Campen et al., 1998; Van Campen et al., 1997) patients attending a transmural or extramural nurse clinic assessed the quality and continuity of care very highly. However, no differences were found between the perceptions of patients attending a transmural and patients attending an extramural nurse clinic. This indicates that the organizational background of nurse clinics does not especially have to be a transmural one, but could also be an extramural or possibly even an intramural (hospital) one.

Where the objective is to reduce patient consumption of health care services, improve their daily functioning or change the use of practical aids and adaptations, the transmural nurse clinic does not seem to be an obvious solution. As regards the reduction of the patient information needs, the thesis produced some contradictory results. Both the asthma and rheumatology study show that attendance at a transmural nurse clinic meets patients' information needs. However, regular medical care provided also satisfied the patients' information needs. Transmural nurse clinics seemed to be better than extramural clinics as regards meeting the information needs. The results pose the question of whether it is more worthwhile to implement transmural nurse clinics or whether it would not be just as useful to improve information flow to the patient in traditional care. 
It has also been indicated that children attending extramural nurse clinics suffer from less severe asthma than those attending a transmural clinic. The nurses in the extramural clinics were often not aware of the severity of the asthma and children attending these clinics were more often referred by a general practitioner or contacted the specialist nurse at their own initiative. These findings indicate that where only extramural nurse clinics are available, children suffering severe asthma may not receive the nursing care they need. Consequently, it might be relevant to implement transmural nurse clinics on a larger scale. Other options for improving the extramural care process for asthmatic children might more readily be found in supporting the traditional care process. Although this thesis did not focus directly on adaptations in the regular care process, the introduction of elements, such as protocols or additional training courses for extramural nurses running extramural nurse clinics, might be a solution to the improvement of the extramural care process for asthmatic children. The introduction of protocols in general can be helpful in solving problems of tuning the care process. Multidisciplinary protocols in particular, might improve the structural co-operation and coordination of care between physicians and specialized community nurses. The option of developing and implementing such multidisciplinary protocols seems worthy of further exploration. Furthermore, additional training courses for community nurses might be, to some extent, a replacement for the multidisciplinary contacts which transmural nurses have. In these courses, the focus can be on the severity of the chronic disease and the nursing care needed for each level of severity. New developments in the field of asthma and individual patient cases can also be discussed in additional training courses. Such courses would be likely to facilitate the implementation of multidisciplinary protocols as well, since other health care professionals, like general practitioners, might be more convinced of the skills and knowledge of the nurses who had followed additional training courses.

The transmural nurse clinics as described in this thesis were additional to the standard care for people with chronic diseases; substitution of tasks between medical specialists and specialized nurses was not an element in the design of the transmural clinics. In the rheumatology study no differences were found in patients' need for rheumatology-related information. This might indicate that the demarcation of educational tasks between medical specialists and specialist nurses is not always clear. It would therefore seem relevant to develop task profiles with guidelines for information to be given by either medical specialists or specialist nurses. It also seems possible that where there is a substitution with some medical tasks going to specialist nurses, the impact of transmural nurse clinics on patients' use of health care facilities will be strengthened. 
Several suggestions for restructuring an institution-based health care to allow for a more functional approach have been made over the last decade (Tweede Kamer, 1990, 1991 \& 1995; NRV, 1993; Commissie Modernisering Curatieve Zorg, 1994; RvZ, 1998). In addition to the implementation of transmural nurse clinics, the introduction of practice nurses (Welling et al., 1997) and regional care-networks (RvZ, 1998; Tweede Kamer, 1999a; Tweede Kamer, 1999b) are suggested as possible solutions in dealing with current financial, cultural and health (care) related challenges. As was also the case with regard to transmural clinics, before implementing innovations like practice nurses and care-networks, limited evidence is available about their effectiveness and efficiency. Obviously, the encouragement and implementation of innovation will be more effective and efficient where it is based on empirical findings. It is therefore recommended that reliable insight into the impact of innovations be obtained before they are implemented on a large scale.

\section{Recommendations for research}

The transmural nurse clinics described in this thesis were additional to the regular medical care provided. It would seem useful in future research to study the effects of transmural nurse clinics in which tasks are transferred from medical specialists to specialist nurses. In such research insight can be obtained into whether substitution of medical tasks results in outcomes (i.e. regarding patients' needs for information, use of health care services or medical outcomes) other than those found in the studies described in this thesis.

Different results were found in the asthma and rheumatology study. This indicates that innovations such as transmural nurse clinics cannot be seen independently of their target patient group. It would therefore seem useful to carry out future research in which the impact of transmural nurse clinics on other patient groups is assessed. The focus could be on other groups of the chronically ill, such as those with diabetes. Another area of focus could be sub-groups of patients who have a comparable level of disease-severity or, in the case of rheumatics, a comparable type of rheumatic disease. Studies in which patients are stratified allowing for conclusions per sub-group would be useful.

Subsequently, it might be worthwhile to do research into the influence of transmural nurse clinics on other outcome measures; for instance, on outcomes such as patients' knowledge, self-care behaviour, adherence to regimes and cost-effectiveness. In measuring such outcomes both short and long term measurement points are recommended. As regards determining cost-effectiveness, it would seem relevant to cooperate with health economists who are able to compare the costs of regular and innovative care processes. It 
would seem sensible to gain insight into the most adequate method for measuring health care costs, before carrying out a cost-effectiveness study.

In addition, further insight is required into the effectiveness of substitution-related innovation other than transmural nurse clinics. On the basis of such research, insight will be obtained into differences in outcomes of other substitution-related innovations. Consequently, a better assessment can be made of which innovations, or which combination of innovations, provide the optimal solution for the cultural, financial and health (care) related challenges to be faced. 


\section{REFERENCES}

Ankoné A. Overheidsbeleid doorgaans niet evidence-based. [Government policy often not evidence-based]. Medisch Contact 2000;55(2):56-58.

Beck A, Scott J, Williams P, Robertson B, Jackson D, Gade G, Cowan P. A randomized trial of group outpatient visits for chronically ill older HMO members: the cooperative health care clinic. J Am Geriatirics Soc 1997;45:543-549.

Bendtsen $P, B$ Burulf $P$. Perceived needs and patient satisfaction in relation to care provided in individuals with rheumatoid arthritis. Qual Assur Health Care 1993;5:243-253.

Bijlsma JWJ, Oude Heuvel CHB, Zaalberg A. Development and validation of the Dutch questionnaire capacities of daily life (VDF) for patients with theumatoid arthritis. J Rehabilitation Sciences 1990;3:71-74.

Blake RL, Vandiver TA, Braun S, Bertuso DD, Straub V. A randomized controlled evaluation of a psychosocial intervention in adults with chronic lung disease. Fam Med 1990;22:365-370.

Bos GAM van den. The burden of chronic diseases in terms of disability, use of health care and healthy life expectancies. Eur J Public Health 1995;5:29-34.

Bryk AS, Raudenbush SW (1992). Hierarchical Linear Models: Applications and Data Analysis Methods. California: Sage Publications, Inc.

Burr ML, Butland BK, King S, Vaughan-Williams E. Changes in asthma prevalence: two surveys 15 years apart. Arch Dis Child 1989;64:1452-1456.

Campbell Haggerty $M$, Stockdale-Woolley $R$, Nair S. Respi-care, an innovative home care program for the patient with chronic obstructive pulmonary disease. Chest 1991;100(3):607-612.

Campen van C, Sixma HJ, Kerssens JJ and Peters L. Assessing Noninstitutionalized Asthma and COPD Patients' Priorities and Perceptions of Quality of Health Care: The development of the QUOTE-CNSLD Instrument. J Asthma 1997;34( 6):531-538.

Campen $C$ van, Sixma HJ, Kerssens JJ, Peters $L$ and Rasker JJ. Assessing patients' priorities and perceptions of the quality of health care: the development of the QUOTE-Rheumatic-patients instrument. Br J Rheum 1998;37:362-368.

Casparie AF, Foets M, Raaijmakers MF. Bakker DH de, Schneider MJ, Sterkenburg PS, Janssen CGC, Bijman-Schulte AM, Bakker RH, Moorer P, Dassen THWN and Suurmeijer NCG. (1998). Vragenlijst Continuiteit van zorg vanuit Cliënt perspectief (VCC) Handleiding en vragenlijsten. [Questionnaire continuity of care from the clients' perspecitive]. Utrecht/Amsterdam/Groningen: NIVEL, VU, RUG.

Colland VT (1993). Leren omgaan met astma. Interventiemethoden voor kinderen en ouders. [Learning to cope with asthma. Intervention programs for children and parents]. Ph.D-thesis. Amsterdam: Universiteit van Amsterdam. 
Commissie Modernisering Curatieve Zorg (1994). Rapport Gedeelde Zorg: betere zorg. [Report Shared Care: better care]. Zoetermeer: Hageman bv.

Cook TD, Campbell DT. (1997). Quasi-experimentation. Chicago: Raud McNally.

Daltroy LH. Doctor-patient communication in rheumatological disorders. Baillieres Clin Rheumatol 1993;7:221-239.

Dawson JL, Critchley L. (1992) Community-hospital partnerships. The Quick Response Team. J Nurs Admin 1992;22(11):33-39.

Donaghy D. The asthma specialist and patient education. Prof Nurse 1995;11:160-162.

Douglas S, Daly $B$, Rudy $E$, Song $R$, Dyer MA, Montenegro $H$. The cost-effectiveness of a special care unit to care for the chronically critically ill. JONA $1995 ; 25(11): 47-53$.

Es, SM van (1999). Adherence to asthma medication in adolescents. PhD-thesis. Amsterdam: Vrije Universiteit.

Garvican L, Grimsey E, Littlejohns P, Lowndes S, Sacks N. (1998). Satisfaction with clinical nurse specialists in a breast care clinic: questionnaire survey. BMJ;316:976-977.

Ghosh CS, Ravindran P, Joshi M, Stearns SC. Reductions in hospital use from self-management training for chronic asthmatics. Soc Sci Med 1998;8:1087-1093.

Häggmark C, Nilsson B. Effects of an intervention programme for improved discharge-planning. The frequency of re-admissions, problems and treatments of cancer patients receiving repeated treatments in hospital. Vård I Nord 1997;17:4-8.

Hill J. Patient satisfaction in a nurse-led rheumatology clinic. J Adv Nurs 1997;25:347-354.

Hill J, Bird HA, Harmer R, Wright V, Lawton C. An evaluation of the effectiveness, safety and acceptability of a nurse practitioner in a rheumatology outpatient clinic. $\mathrm{Br} J$ Rheumatol $1994 ; 33: 283-288$.

Jaarsma T (1999). Heart failure: nurses care. Ph.D thesis. Universiteit Maastricht: Maastricht.

Jans M (1999).Care for asthma and COPD patients in general practice. Phd-thesis. Vrije Universiteit: Amsterdam.

Kendig HL, Hashimoto A, Coppard LC (1992). Family support for the elderly. The international experience. Oxford University Press, Oxford/New York/Tokyo.

Ketelaars C (1996). Aftercare and specialized community nursing: Implications for patients with chronic obstructive pulmonary disease. PhD-thesis. Maastricht: Rijksuniversiteit Limburg.

Liang MH, Larson MG, Cullen KE, Schwartz JA. Comparative measurement efficiency and sensitivity of five health status instruments for arthritis research. Arthritis and Rheum 1985;28(5): 542-547. 
Magnus $P$, Jaakkola JJ. Secular trend in the occurrence of asthma among children and young adults: critical appraisal of repeated cross sectional surveys. BMJ 1997;314:1795-1799.

Maslennikova GY, Morosova ME, Salman NV, Kulikov SM, Oganov RG. Asthma education programme in Russia: educating patients. Pat Educ Couns 1998;33:113-127.

Mazzuca, SA, Brandt KD, Katz BP, Hanna M, Chambers M, Byrd DJ. Self-care education reduces health care utilization and costs for patients with osteoarthritis (OA) of the knee. Arthritis and Rheum 1996;39 (Supplement 9):S168.

Mesters I (1993). Infants with asthma. Towards a multidisciplinary education protocol for primary care. Ph.D-thesis. Maastricht: Rijksuniversiteit Limburg.

Nationale Raad voor de Volksgezondheid (1993). Beleid op maat: een achtergrondstudie over de bestuurlijke vernieuwing in de gezondheidszorg. [Tailored policy: a background study concerning governmental innovations in health care]. Zoetermeer: NRV.

Nationale Raad voor de Volksgezondheid \& College voor Ziekenhuisvoorzieningen (1995). Transmurale somatische zorg: Advies van de Nationale Raad voor de Volksgezondheid en het College voor Ziekenhuisvoorzieningen. [Somatic Transmural Care: Advise of the National Council for Public Health and the National Board for Hospital Facilities]. Zoetermeer: NRV/CvZ.

Nocon A, Booth T. The social impact of Asthma. Fam Prac 1990;8(1):37-41.

Osman LM, Abdalla MI, Russel IT, Fiddes J, Friend JAR, Legge JS, Douglas JG (1996) Integrated care for asthma: matching care to the patient. Eur Resp J 1996;9:444-448.

Peters $P$ (1995). Liaisonverpleegkundige schakel tussen ziekenhuis en thuiszorg. [Liaison nurse. A link between hospital and home care). VU, Amsterdam.

Preston C, Cheater F, Baker R, Hearnshaw H (1999). Left in limbo: patients' views on care across the primary/secondary interface. Quality in health care 1999;8:16-21.

Raad voor de Volksgezondheid \& Zorg (1998). Redesign van de eerste lijn in transmuraal perspectief. [Redesign primary health care in transmural perspective]. Zoetermeer: RvZ.

Raad voor de Volksgezondheid \& Zorg (1998). Transmurale zorg: redesign van het zorgproces. [Transmural care: redesign of the care process]. Zoetermeer: RvZ.

Raffel MW (1997) Dominant issues: convergence, decentralization, competition, health services. In: Health care and reform in industrialized countries (Raffel M.W, ed.), The Pennsylvania State University Press, Pennsylvania, pp. 291-302.

Riemsma $R$ (1998) Challenging arthritis. The role of self-management, formal and informal care. Ph.D-thesis. Enschede: Universiteit Twente.

Rietkerk MG, Hirasing RA (1997) Effect-evaluatie TASK-project. Transmurale Astmaverpleegkundige voor Kinderen in Gouda. [Effect-evaluation TASK-project. Transmural asthma nurse for children in the town Gouda]. TNO Preventie en Gezondheid, Leiden. 
Saltman RB, Figueras J (1997). European health care reform. Analysis of current strategies. WHO, Copenhagen.

Schlösser, MAG (1992). Self-management and asthma. Ph.D-thesis. Leiden University, Leiden.

Smeenk FWJM (1998). Transmural care of terminal cancer patients. An evaluation study in the Eindhoven region. Ph.D-thesis. Universiteit Maastricht, Maastricht.

Speight AN, Lee DA, Hey EN. Underdiagnosis and undertreatment of asthma in childhood. BMJ 1983;286:1253-1256.

Stoffelen H, De Schampheleire L, Van Peer W. Astma bij kinderen: Aanbeveling voor goede medische praktijkvoering. [Asthma in children: recommendation for good medical practice]. Huisarts $\mathrm{Nu}$ 1999;9:351-373.

Taggart VS, Zuckerman AE, Sly RM, Steinmueller C, Newman G, O'Brien RW, Schneider S, Bellanti JA. You can control asthma: evaluation of an asthma education program for hospitalized inner-city children. Pat Educ Couns 1991;17:35-47.

Temmink D, Francke AL, Hutten JBF, Van der Zee J, Huyer Abu-Saad H. Innovations in the care of the chronically ill: an international perspective. J Adv Nurs 2000;31(6):1449-1458.

Temmink D, Francke AL, Kerkstra A, Huyer Abu-Saad H. Dutch transmural nurse clinics for chronic patients: a descriptive study. Pat Educ Couns 2000;39:177-184.

Tweede Kamer (1990). Werken aan zorgvernieuwing: Actieprogramma van het beleid voor de zorgsector in de jaren negentig. [Action programme of the health care policy in the nineties]. SDU uitgeverij: Den Haag.

Tweede Kamer (1991). Chronisch-ziekenbeleid: Chronische patiënten niet buiten spel. [Policy for chronically ill: chronic patients at play]. SDU uitgeverij: Den Haag.

Tweede Kamer (1995). Modernisering curatieve zorg: Standpunt op het advies van de Commissie modernisering curatieve zorg. (Modernization curative care: Viewpoint on the advice of the Committee modernization curative care]. SDU uitgeverij: Den Haag.

Tweede Kamer (1999). Curatieve zorg, Kamerstuk 23619, nr.17. [Curative care]. SDU uitgeverij: Den Haag.

Tweede Kamer (1999). Zicht op zorg: modernisering AWBZ. [View on care: modernization AWBZ]. SDU uitgeverij: Den Haag.

Vliet Vlieland TPM (1996). Multidisciplinary team care in rheumatoid arthritis. Ph.D-thesis. Leiden: Rijksuniversiteit Leiden.

Vrijhoef HJM, Diederiks JPM, Spreeuwenberg C. Effects on quality of care for patients with NIDDM or COPD when the specialised nurse has a central role: a literature review. Pat Educ Couns (in press). 
Welling BJM, Delnoij DMJ, Bakker de DH (1997). De praktijkverpleegkundige in Nederland. [Practice nurses in the Netherlands]. NIVEL: Utrecht.

Weinberger $M$, Oddone EZ, Henderson WG. Does increased access to primary care reduce hospital admissions? N Engl J Med 1996;334:1441-1447.

Westert GP. State control and the delivery of health care: a preliminary study in eleven European countries. Environment and Planning C: Government and Policy 1997;15:219-228.

Witteveen $E$ (1998). Home care technology for patients with cancer or serious infections.

Ph.D-thesis. Universiteit Utrecht, Utrecht. 
chapter 1 


\section{INNOVATIONS IN THE NURSING CARE OF THE}

CHRONICALLY ILL: a literature review from an international perspective

D. Temmink, A.L. Francke, J.B.F. Hutten, J. van der Zee,

H. Huijer Abu-Saad

Journal of Advanced Nursing 2000; 31(6): 1449-1458

\section{ABSTRACT}

This literature study focuses on substitution-related innovations in the nursing care of chronic patients in six western industrialized countries. Differences between primary and secondary care-orientated countries in the kind of innovations implemented are discussed. Health care systems are increasingly being confronted with chronic patients who need complex interventions tailored to their individual needs. However, it seems that today's health care professionals, organizations and budgets are not sufficiently prepared to provide this kind of care. As a result, health care policy in many countries targets innovations which reduce health care costs and, at the same time, improve the quality of care. Frequently, these innovations are related directly to the 'substitution of care' phenomenon, in which care is provided by the most appropriate professional at the lowest cost level, and encompass advanced nursing practice, hospital-at-home care and integrated care. The main conclusion of this paper is that integrated care innovations are implemented in both primary care as well as in secondary care-orientated countries. However, innovations in hospital-athome care and advanced nursing practice are primarily implemented in primary care-orientated countries. Whether these innovations positively influence the quality of care, costs of care or patients' use of health care facilities remains rather unclear.

Keywords: chronic patients, health care orientation, substitution, innovations, nursing, primary care, secondary care, advanced nursing practice, hospital-at-home, integrated care, health economics, management 
chapter 2 


\section{INTRODUCTION}

Ageing Western populations and the increasing numbers of the chronically ill are challenging health care policy in Western industrialized countries [Kendig et al. 1992, Raffel 1997, Saltman \& Figueras 1997]. In addition to the ageing of the population and the increase in chronic diseases, the demand for health care is influenced by other socio-demographic or cultural changes. People more often live alone and consequently require professional care more frequently [Organization for Economic Co-operation and Development, OECD 1996]. People also insist on good quality health care and impose a greater burden on health care professionals [Steering Committee on Future Health Scenarios 1993]. In addition, technological developments like advanced medical technology, electrically adjustable beds, personal lifting devices and staircase elevators provide a challenge to health care systems. Such developments are among those that make it possible to substitute home care for hospital care.

As a consequence, current western health care policy is anticipating increasing health care demand from chronic patients. In most industrialized countries, government policy focuses on the improvement of the quality of care by encouraging ongoing and patient-tailored care. Further, health care policy often stresses the importance of reducing health care costs [OECD 1994]. However, good quality, affordable care for chronic patients is often difficult to provide owing to organisational gaps in health care systems. In most western industrialized countries, traditionally there have been strong organizational and financial boundaries between (generalist) primary and (specialist) secondary care services. These boundaries have often resulted in a lack of cooperation between these settings and consequently it is difficult to provide care tailored to the needs of the chronically ill [Bringewatt 1996, Trimpka et al. 1996, Brodsky \& Habib 1997, Etzwiler 1997]. New forms of health care organization are therefore desirable.

Nurses play a pivotal role in the care for chronic patients [Borst-Eilers 1997]. in consequence, innovations relating to the nursing practice and care for chronic patients are being implemented in many countries to produce new forms of health care. These innovations often aim to break through the barriers mentioned and are often directly related to the 'substitution of care' phenomenon. Substitution of care means a shift of care responsibilities and tasks in such a way that qualitatively good care is provided by the most 
appropriate health care provider at the lowest cost level. If, for instance, responsibilities and tasks shift from medical specialists to nurses, then substitution can be said to be taking place.

In this paper, the assumption is made that characteristics of substitutionrelated innovations differ between countries because their health care systems differ. Health care systems can be distinguished on the basis of organizational and financial indicators. On the basis of such indicators, three categories of health care system will be distinguished. The first category includes countries which, traditionally, have a strong emphasis on (generalist) primary care while the second category consists of countries which are, traditionally, orientated towards (specialist) secondary care. The third category consists of countries that do not have a specific orientation towards either primary or secondary care.

The purpose of this paper is to shed more light on to important substitutionrelated care innovations for chronic patients in the three categories of countries mentioned. Accordingly, the following research questions have been addressed:

1. What kind of substitution-related innovations directed at chronic patients, in which nurses play a role, are described in the international literature?

2. Are these innovations found in: (a) primary care-orientated countries, (b) secondary care-orientated countries or (c) countries that do not have a specific orientation on either primary or secondary care?

3. What is known about outcomes of these innovations with respect to quality of care, use of health care facilities and costs of health care?

\section{METHODS}

Searches were carried out in three computerized databases: Nursing and Allied Health Literature (1982- August 1998), Medline (1990- August 1998) and the literature database of the Netherlands Institute of Primary Health Care (NIVEL) (1985-1998). The combination of keywords used in these searches was: chronic disease and (innovation, transmural care, disease management, case management, shared services, managed care programmes, discharge planning, integrated care delivery, collaborative practice, partnerships, hospital-based home care, l'hospitalisation à domicile, specialization or 
substitution). In addition to the databases mentioned, references in articles and books were used to gather relevant literature.

The titles found in these sources have been scanned and only those publications were included that described:

1. substitution-related innovations in western industrialized countries,

2. innovations for chronic patients like patients suffering rheuma, asthma or diabetes,

3. a (quasi-)experimental evaluation study (in the sense that a pre-test post-test and/or a control group design was used) and

4. nursing care as part of the innovation.

A total of 20 publications met the criteria mentioned and were used for answering the research questions. These publications covered six countries, namely Sweden, the United States, the Netherlands, Canada, the United Kingdom and Ireland. Health care systems of the six countries mentioned were categorized following the method used by Starfield [1994] and Westert [1997]. These authors distinguished indicators reflecting primary and/or secondary health care services. When combining these indicators, the health care orientation (primary vs. secondary health care) of countries can be compared.

In this study, the availability of generalist primary services per country was measured using three indicators, namely:

1. the number of general practitioners (GPs) per specialist doctor,

2. expenditure on home care and

3. the function of GPs as gatekeeper (see Appendix 1).

In addition to this, the supply of specialist secondary health services in a country was measured using the following five indicators:

1. the percentage of practising specialist doctors to the total number of physicians,

2. the percentage of total expenditure on acute care to the total expenditure on healths,

3. the number of available acute care beds,

4. the ratio of admissions per year to available acute care beds and

5. the number of acute care bed days per capita (see Appendix 2).

To make a categorization between the three types of health care systems, each country was ranked on every indicator. Further, mean scores at generalist primary care indicators as well as at specialist secondary services indicators 
were calculated (see Appendices 1 and 2). On the basis of these two means, a matrix in which the three kinds of health care systems were distinguished was constructed (Figure 2.1). It is important to mention that this meant only relative distinctions between countries. The final position of a country depended to a large extent on other countries included and the indicators used in the analysis.

Figure 2.1 Health care orientation matrix

Supply of specialist secondary services

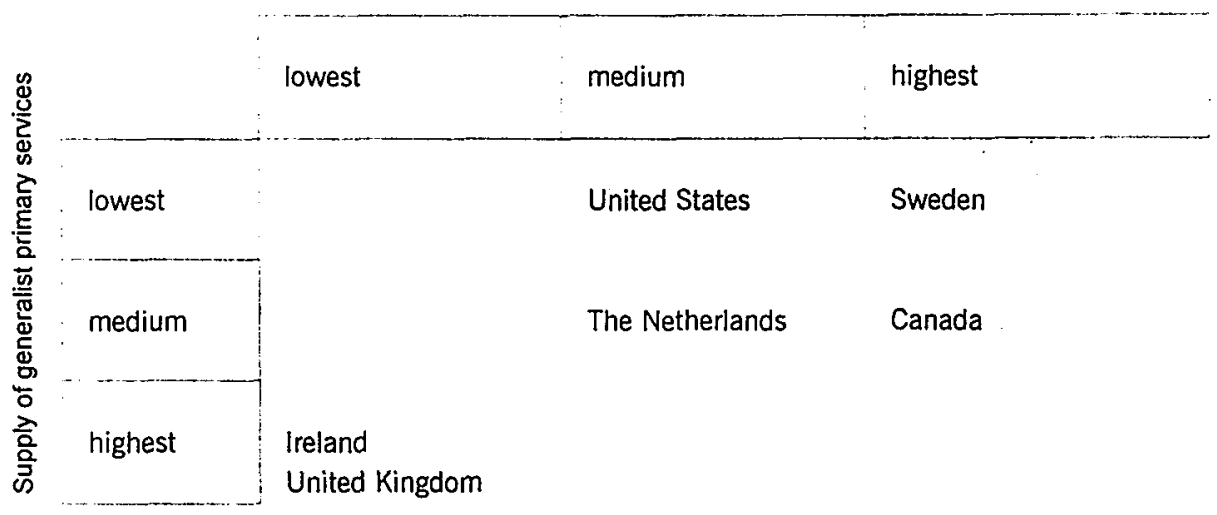

\section{DISTINCTIONS AMONG HEALTH CARE SYSTEMS}

The three horizontal rows in Figure 2.1 classify the countries on the 'supply of generalist primary services' dimension, based on the mean ranking scores as displayed in Appendix 1 . In the three vertical columns the same was done for the level of supply of specialist secondary services (see Appendix 2). The combination of rows and columns gives insight into overall care supply patterns per country. Countries which are orientated towards generalist primary care services occupy the lower shaded area of Figure 2.1: in these three cells, a country ranks higher in terms of generalist primary services compared with specialist secondary services. The countries occupying the upper shaded areas rank higher on specialist secondary services instead of generalist primary services. The country in the middle of the matrix, the Netherlands, is assumed to supply both generalist primary services and 
specialist secondary services at an average level.

From the analysis, it can be concluded that countries like Ireland and the UK focus relatively more on generalist primary health care. Countries which are relatively more orientated towards specialist secondary health care are the USA, Sweden and Canada.

\section{INNOVATIONS IN THE CARE FOR CHRONIC PATIENTS}

The 20 publications describing innovations following the inclusion criteria mentioned, were divided into three main types of innovation: advanced nursing practice, hospital-at-home and integrated care. These three types of innovation are not entirely mutually exclusive. Each type of innovation will be described in the following sections.

\section{Innovations regarding advanced nursing practice}

Advanced nursing practice is a way to meet the changing and complex care demands of chronic patients. In addition, advanced nursing practice is often important in achieving substitution. If, for instance, a nurse specializes in the care for patients with chronic obstructive airway disease (COPD), part of the responsibility and work of the (child) pulmonologist may be shifted to this nurse. In the field of advanced nursing practice, six publications concerning quasi-experimental evaluation studies were found [Hill et al. 199, Donaghy 1995, Grahame \& West 1996, Ketelaars 1996, Hill 1997, Ridsdale et al. 1997]. Most of these six innovations were implemented in (generalist) primary care systems: the UK and Ireland. One innovation described was implemented in the Netherlands.

Three of these six articles concerned nursing care for rheumatic patients in the UK. In the 1997 study of Hill, patients with rheumatic arthritis were randomly allocated to either the hospital-based clinic of a specialist rheumatology nurse practitioner (RNP) or of a rheumatologist. The patients of the RNP recorded significantly more satisfaction with their care than the patients who visited the rheumatologist. They were, for example, more satisfied with the provision of information and continuity of care. In the 1994 study of Hill et al., the same comparison was made between patients attending a hospital-based RNP clinic and patients at an outpatient rheumatology clinic. This study showed that, in patients managed by the RNP, pain, morning stiffness, psychological status, patient knowledge and satisfaction had 
improved significantly, while these improvements were not mirrored by the rheumatologist cohort. The aim of the project described by Grahame and West [1996] was to explore the possibility of conferring the skills and knowledge of a RNP upon others. A trained and experienced RNP paid a series of regular visits to general practices. Interactive sessions involving the RNP, practice nurse (PN) and patients were set up with a view to (1) instructing the PNs in the role of the RNP in the education and care of patients, and (2) educating patients about their disease and its treatment. On the basis of a quasi-experimental evaluation study, Grahame and West [1996] concluded that both PNs as well as patients' knowledge improved following the RPN visits.

In addition, the positive impact of specialist asthma nurses has been shown. Ketelaars [1996] performed a quasi-experimental evaluation study on specialist nursing for COPD patients in the Netherlands. It was established that specialized nurses paid more attention to psychosocial problems, while general community nurses focussed on practical issues. The quality of the nursing report was higher in specialist nurses than in general ones. Effects on patients' health-related quality of life, coping strategies, compliance and hospitalization were not found. However, patients in the experimental group were more satisfied with the care provided by specialist community nurses. Donaghy [1995] compared a group asthmatics who received instruction from a doctor with a comparable group who received an additional individual education programme conducted by an asthma nurse specialist in Ireland. This study demonstrated that asthma education provided by a nurse specialist improves inhaler technique and understanding of asthma.

Finally, in a randomized clinical trial performed in the UK, Ridsdale et al. [1997] tested the feasibility and effect of nurse-run epilepsy clinics in primary care. In this trial, the intervention group was offered an appointment with a nurse with special training in epilepsy at what was called a neurology clinic. Patients in the control group received standard care delivered by a general practitioner or specialist. Ridsdale et al. [1997] concluded that nurse-run clinics for patients with epilepsy were feasible and well attended. Furthermore, such clinics could significantly improve the level of advice and drug management recorded.

\section{Hospital-at-home innovations}

Substitution of tasks and responsibilities between care providers and organisations is often realized within the framework of hospital-at-home 
innovations. Hospital-at-home is a generic term referring to home-based nursing and rehabilitation services which target early hospital discharge or prevention of hospital admissions [Coast et al. 1998]. The main object of the hospital-at-home is to provide efficient complex care of good quality by meeting patient needs in the home setting [Munsterman 1993]. Hospital-athome is, for instance, put in practice by teams of hospital nurses who deliver complex (often technological) care to patients who have recently been discharged from hospital.

Innovations in hospital-at-home care for chronic patients were found in literature from the UK and Canada. The UK was classified as a (generalist)primary care-orientated country; while Canada was classified as (specialist)secondary care-orientated country (see Figure 2.1).

Six publications that met the criteria were included. Richards et al. [1998] compared the effectiveness and acceptability of early discharge by providing hospital-at-home to elderly patients in a randomized clinical trial with routine hospital care in the UK. They concluded that there were no differences in mortality, functional ability, quality of life and most measures of satisfaction at follow-up. The main significant difference between the forms of care was the length of stay. This was in the group who received routine hospital care for significantly shorter periods.

Shepperd et al. [1998a] performed a randomized clinical trial which also compared the effect of hospital-at-home delivered to both chronic and acute patients (elderly patients, patients with COPD, patients recovering from hip replacement, knee replacement and hysterectomy) with routine hospital care. Their results also suggest that there are no major differences in patients' health outcomes. However, patients preferred hospital-at-home to hospital care.

The quasi-experimental Canadian study performed by Tin et al. [1995] described a community-based respiratory therapy for patients with COPD. In this innovation, a respiratory rehabilitation programme incorporating education was offered by a hospital-employed respiratory therapist (presumably with a nursing background). Upon referral by a physician, inpatients at the hospital were seen for assessment, diagnostic screening and education and discharge planning was initiated. Further, in-home visits for assessment were made and education was given by the respiratory therapist [Tin et al.1995]. Based on their quasi-experimental research, Tin et al. [1995] concluded that, for patients suffering from COPD, respiratory therapy provided at patients' home had no significant effect on either hospital readmission rate or number of 
hospital days spent. However, Tin et al. [1995] concluded also that COPD patients visited their physicians less frequently while they were receiving care from the respiratory therapist. In addition, patients' knowledge of the illness increased.

Also some (quasi-) experimental cost analyses of hospital-at-home were recently performed in the UK [Hensher et al. 1996, Coast et al. 1998, Shepperd et al. 1998b]. Coast et al. [1998] and Hensher et al. [1996] concluded that hospital-at-home, delivered to elderly patients and orthopaedic patients, is less costly per day than care in the hospital. However, Hensher et al. [1996] remark that in hospital-at-home, the total duration of care episodes increases, so that total costs of hospital-at-home are higher. Shepperd et al. [1998b], however, could detect no differences in total health care costs between hospital-at-home and routine hospital care for elderly patients. According to Shepperd et al. [1998b] hospital-at-home significantly increased health care costs for patients with COPD. Moreover, their study showed that hospital-at-home significantly increased general practitioners' costs for elderly patients and for those with COPD.

\section{Innovations regarding integrated care settings}

Substitution of care also takes the form of innovations in which care settings are integrated. In the international literature, several terms are used to indicate innovations concerning integrated care settings. For instance, concepts like disease management, managed care, case management, shared care and transmural care are used.

Integrated care innovations were found in all three categories of countries distinguished and can be divided into three main types [Persoon et al. 1996]. Firstly, integrated care delivered by a combination of hospital professionals and primary care professionals is identified. This type includes, for instance, hospital-at-home-care delivered by a team of hospital and home care professionals instead of care delivered only by hospital professionals, as described in the previous paragraph.

A second type of integrated care is care delivered by primary care professionals during admission to and discharge from hospital. This type includes, for example, liaison nursing, in the sense that home care nurses are working in a hospital in which they are responsible for the coordination of care when patients transfer from hospital to home care and vice versa.

A third type is integrated care delivered by primary care professionals who are supported by hospital professionals. Integrated care with this characteristic 
can be practised by, for instance, community nurses who run outpatient clinics in a hospital and who work closely together with a medical specialist [Temmink et al. 1998].

In four publications [Campbell Haggerty et al. 1991, Dawson \& Critchley 1992, Smeenk 1998, Witteveen 1998], an innovation in which care is delivered by a combination of hospital professionals and primary care professionals is assessed. Dawson and Critchley [1992] describe a Quick Response Team (QRT) in Canada. This QRT targeted the health needs of frail elderly people with multiple social, emotional, physical and medical problems who were at risk of a custodial admission to acute care. The QRT required collaboration in health policy decision-making between community health and acute hospital organizations and arranged emergency home support services. These services included 24-hour services such as home nursing care, short respite care, adult day care and counselling. In the QRT community nurses worked together with emergency room physicians and family physicians. The nurses arranged all services before the patient left the emergency room to ensure that the support sources were established and provided within ten minutes to half an hour of the patients' return home. Based on findings of the performed quasi-experimental evaluation study, Dawson and Critchley [1992] concluded that the accessibility improved and provision of care was shorter due to the QRT. The cost of care was also much less in the QRT situations compared with the control group patients who received standard hospital care. Further, it was found that, due to the QRT, the client waiting list for placement in a long-term facility was extremely decreased [1992].

Campbell Haggerty et al. [1991] described an innovative home care program for patients suffering COPD in the USA. In this innovation, a contractual arrangement between a hospital and a public health nursing agency provided a link between these services. A hospital-based pulmonary clinical nurse specialist coordinated the program, with a pulmonologist serving as medical advisor. The service included nursing home visits every week, respiratory therapy and social service visits every 2 weeks. Other services available to patients included physical and occupational therapy, dietary, home health aid and a home volunteer program. In addition to the scheduled visits, a 24-hour on-call coverage by respiratory and nursing personnel was available [Campbell Haggerty et al. 1991]. To evaluate this innovation Campbell Haggerty et al. [1991] used a pre-test--post-test control group design. It was concluded that the innovation resulted in a reduction of hospitalizations, hospital days, emergency room visits and costs.

Smeenk [1998] in the Netherlands investigated the effects of a transmural 
hospital-based home-care program for terminal cancer patients. Main elements of the program were: coordination of care by a specialist cancer nurse, a transmural hospital-based home-care team which delivers a 24-hour telephone service for home care professionals; and the implementation of a home care dossier and transmural care protocols. This research showed that the transmural home care program reduced hospital admissions and had a positive influence on patients' physical functioning. A significant positive effect on relatives' quality of life was established.

Finally, Witteveen [1998] in the Netherlands, performed a quasi-experimental evaluation study of transmural home care technology for patients with cancer or serious infections. In this innovation GPs and community nurses were trained by a medical oncologist and two specialist hospital nurses to use various medical technology interventions correctly in patients' homes. The medical oncologist and specialist nurses also prepared protocols, were responsible for the coordination of the supply logistics and, as a 24-hour support team, were prepared to make home visits if required. Witteveen [1998] concluded that this innovation improved patients' quality of life and resulted in lower health care costs. However, the participation of volunteers or relatives was a factor missing from the calculation of costs and should therefore be kept in mind especially when treatment periods are prolonged [Witteveen 1998].

Two quasi-experimental evaluation studies concerning integrated care during admission to and discharge from a hospital delivered by primary care professionals were found in the literature. Häggmark \& Nilsson [1997] conducted an experimental study in which the effects of a Swedish intervention programme for improved discharge planning for cancer patients were described. The integrated care character of this programme implied that hospital and home care professionals collaborated closely and made appointments on how to deliver patient care. Before hospital discharge, a district nurse and a GP received information about the patient and they visited the patient in the hospital. During this hospital visit, the district nurse and the GP received information from the nurse and the doctor in the hospital ward about the patient's disease and treatment. The patient received information from the district nurse and GP regarding the kinds of help and support they could give. This study did not show significant effects on re-admissions to the hospital [Häggmark \& Nilsson 1997].

Peters [1995] described a Dutch innovation in which a transmural liaison nurse was responsible for discharge planning for elderly patients. Based on a quasi-experimental evaluation study Peters [1995] concluded that patients 
and hospital nurses were satisfied with discharge planning, continuity of care and aftercare received. Further, it was concluded that the quality of discharge planning had improved.

In addition, two publications were found on a (quasi-) experimental evaluation study of primary care professionals supported by hospital professionals.

Osman et al. [1996] compared asthma patients in the UK who received care from their GP with asthma patients who received care from an integrated care service. Patients in the integrated care innovation program were reviewed by their GP every 3 months, with review data being returned to the clinic to be seen by the referred clinician. At any time, patients could be referred back to the full hospital clinic, where nurses were employed, if the GP felt it appropriate. After 1 year, all patients were reviewed at the hospital outpatient clinic. This randomized trial found no difference between the integrated and conventional specialist review groups in clinical outcomes such as: hospital admissions, lung function, morbidity measures and acute episodes. Further, no difference was found with respect to quality of life outcomes. However, patients in integrated care were more likely to feel they were 'in control' of their asthma.

Rietkerk \& Hirasing [1997] described a Dutch transmural innovation in which a community nurse runs clinics at the outpatient department of a hospital for patients with chronic non-specific lung diseases. At this clinic, the nurse gave information and education about the disease, the use of inhalers and how to deal with the illness. Children with asthma and their parents who did receive support from the specialist nurse reported fewer hospital admissions, fewer visits at the medical outpatient clinic and less exacerbation of the problem compared with children/parents receiving routine care.

\section{CONCLUSIONS AND DISCUSSION}

This literature study describes types of substitution-related innovations for chronic patients in which nursing practice plays a part. It describes. differences between primary and secondary care-orientated countries with respect to the kind of innovation implemented. Further, findings of (quasi-) experimental evaluation studies concerning innovations for chronically ill are discussed.

It appeared that three kinds of substitution-related innovations occur in the 
international literature. The first kind of innovation is advanced nursing practice. The innovations described in the literature were mainly conducted in countries which were orientated towards (generalist) primary care. Based on (quasi-) experimental research performed, there are some indications that these innovations do improve the quality of care; some studies reported improvement of patient and professional satisfaction, knowledge, physical or psychosocial functioning. Whether innovations concerning advanced nursing practice influence patients' use of health care facilities or the costs of care is unclear from the literature studied.

Hospital-at-home care was the second kind of substitution-related innovation described. This kind of innovation was mainly reported in publications from primary care-orientated countries. (Quasi-) experimental evaluation studies performed do not suggest that there are differences between hospital-at-home care and standard hospital care with respect to the quality of care. On the basis of the cost analyses of hospital-at-home care programs it also seems that this kind of innovation does not reduce today's costs of health care for chronic patients and chronic patients' use of health care facilities.

The third kind of substitution-related innovation described concerned integrated care settings which are implemented in both (generalist) primary care-orientated health care systems and (specialist) secondary-orientatedhealth-care systems. The small number of (quasi-) experimental evaluation studies described in the international literature focus on a rather broad range of integrated care innovations. This inhibits deriving conclusions about the effectiveness of integrated care in general. However, based on the commonalities between the described integrated care innovations (e.g. concerning integrated care for chronic patients in which substitution takes place and nurses play a central role) it is possible to conclude that integrated care settings may lead to a decrease in costs and hospital admissions. However, whether integrated care innovations result in better quality of care remains unclear. Still, there are some indications that integrated care innovations in which complex care is transferred from a hospital to a home care setting may influence patients' physical functioning and relatives' quality of life positively.

In general, it can be concluded that many initiatives are being launched in western industrialized countries to solve problems in organization, finance and expertise with regard to the care of chronic patients. In both primary careorientated as well as in secondary care-orientated countries, a process of 
integration between generalist and specialist health care services is ongoing. In addition, in primary care-orientated countries a tendency for meeting specialist health care needs of chronic patients in the primary care setting is arising. Primary care-orientated countries are anticipating the specialist health care needs of chronic patients by implementing hospital-at-home innovations and innovations in which advanced nursing practice plays a central role. The number of evaluation studies found in this study was, compared to the variety of innovations described, low. Consequently, it is difficult to derive general conclusions about the effectiveness of substitution-related innovations in the nursing care for chronic patients. Therefore, it is recommended that future research should be carried out that gives insight into whether such innovations lead to better quality of care and/or a decline in patients' use of health care services and health care costs. Based on such research it should be decided whether broader implementation might be gainful.

It is important to realize that this paper did not intend to give a complete survey of nursing-related innovations for chronic patients in each country. This limitation is related to the inclusion criteria of the literature ((quasi-) experimental evaluation studies regarding substitution-related innovations for chronically ill patients in which nurses play a central role) and the categorization of countries on the basis of primary and secondary care orientation. The health care orientation matrix used, indicated relative distinctions between countries and has an explorative character. The indicators used could have been extended with several other indicators like the availability of advanced nurse practitioners. However, internationally comparable data on, for instance, the latter indicator is very scarce. Therefore, the method used to compare countries on the basis of the indicators described in this article seems the most eligible. Another advantage is that this method is previously used by others [see Starfield 1994, Westert 1997]. Furthermore, a limitation of our study is that comparisons between countries and innovations could only be made on a national level instead of a provincial or local level. Therefore, it is possible that conclusions drawn about a specific country does not count completely for every province in that specific country. However, it can be assumed that the data used for making the categorization of countries reflects the average situation in a country.

As stated previously, this paper is based on innovations for chronic patients described in the international literature. Further, only those innovations which were evaluated by using a (quasi-) experimental design were included. Therefore a publication and selection bias may exist. It is plausible that 
substitution-related innovations are implemented in more countries than those included in this article. For instance, in France, innovations known as 'L'hospitalisation à domicile' are implemented on a large scale. Two reasons for not finding publications about (quasi-) experimental evaluations concerning innovations in countries like France can be that these innovations do not often aim at the chronically ill [Raffy-Pihan 1994] or that innovations and their outcomes are not published in international sources and, consequently, are not available to international colleagues. It is therefore recommended that outcomes of research should be published in international accessible sources. This will give insight in developments throughout the world that can be used by professionals, researchers and policy makers to face today's challenges in health care. 


\section{REFERENCES}

Boerma W.G.W. \& Fleming D.M. (1998) The role of general practice in primary health care. The Stationery Office/WHO Regional Office for Europa, St Crispins.

Borst-Eilers E., Minister for Health \& Welfare and Sports, The Netherlands (1997) Government policy on the chronically ill. In Proceedings of the Key-Note Lectures of the 2 nd European Nursing Congress 5-8 October 1997, pp. 2-7

Bringewatt R.J. (1996) Integrating care for people with chronic conditions. Creative Nursing 2, 7-9

Brodsky J. \& Habib J. (1997) New developments and issues in home care policies. Disability and Rehabilitation 19, 150-154.

Campbell Haggerty M., Stockdale-Woolley R. \& Nair S. (1991) Respi-care, an innovative home care, program for the patient with chronic obstructive pulmonary disease. Chest 100 , 607-612

Coast J., Richards S.H.,Peters T.J. et al . (1998) Hospital at home or acute hospital care? A cost minimisation analysis. British Medical Journal 316, 1802-1806.

Dawson J.L. \& Critchley L. (1992) Community-hospital partnerships. The Quick Response Team. Journal of Nursing Administration 22, 33-39.

Donaghy D. (1995) The asthma specialist and patient education. Professional Nurse 11, 160-162.

Etzwiler D.D. (1997) Chronic care: a need in search of a system. The Diabetes Educator 23, 569573.

Grahame R. \& West J. (1996) The role of the rheumatology nurse practitioner in primary care: an experiment in the further education of the practice nurse. British Journal of Rheumatology $35,581-588$.

Häggmark C. \& Nilsson B. (1997) Effects of an intervention programme for improved dischargeplanning. The frequency of re-admissions, problems and treatments of cancer patients receiving repeated treatments in hospital. Vard I Norden $17,4-8$.

Hensher M., Fulop N., Hood S. \& Ujah S. (1996) Does hospital-at-home make economic sense? Early discharge versus standard care for orthopaedic patients. Journal of the Royal Society of medicine $89,546-551$.

Hill J., Bird H.A., Harmer R., Wright V. \& Lawton C. (1994) An evaluation of the effectiveness, safety and acceptability of a nurse practitioner in a rheumatology outpatient clinic. British journal of Rheumatology 33, 283-288. 
chapter 2

Hill J. (1997) Patient satisfaction in an nurse-led rheumatology clinic. Journal of Advanced Nursing 25, 347-354.

Hutten J.B.F. \& Kerkstra A. (1996) Home Care in Europa. A Country-Specific Guide to its Organization and Financing. Arena, Hants/Nermont.

Kendig H.L., Hashimoto A. \& Coppard L.C. (1992) Family Support for the Elderly. The International Experience. Oxford University Press, Oxford.

Ketelaars C. (1996) Aftercare and specialised community nursing. Implications for patients with chronic obstructive pulmonary disease. PhD thesis, Rijksuniversiteit Limburg, Maastricht.

Munsterman D.K. (1993) De ontwikkeling van ziekenhuisverplaatste zorg in Nederland (The development of hospital based home care in the Netherlands). Ziekenhuis Management Magazine 12, 284-290.

Organisation for Economic Co-operation and Development (OECD) (1994) Health policy Studies No. 4. Health: Qaulity and Choice. OECD, Paris.

Organisation for Economic Co-operation and Development (OECD) (1996) Caring for Frail Elderly People: Policies in Evolution. OECD, Paris.

Organisation for Economic Co-operation and Development (OECD) (1998) Health Data. OECD, Paris.

Osman L.M., Abdalla M.I.,Russel U.T. et al. (1996) Integrated care for asthma: matching care to the patient. European Respiratory Journal 9, 444-448.

Persoon A., Francke A., Temmink D. \& Kerkstra A. (1996). Transmurale Zorg in Nederland: Een Inventarisatie Op Basis Van Bestaande Gegevensbestanden. NIVEL, Utrecht.

Peters P. (1995) Liaisonverpleegkundige Schakel Tussen Ziekenhuis En Thuiszorg (liaison nurse. A Link between hospital and home care). VU, Amsterdam.

Raffel M.W. (1997) Dominant issues: convergence, decentralization, ompetition, health service. In Health Care and Reform in industrialized Countries (Raffel M.W. ed.), The Pennsylvania State University Press, Pennsylvania, pp. 291-302.

Raffy-Pihan N. (1994) L'hospitalisation A Domicile: Un Tour D'horizon En Europe, Aux Etats-Unis et Au Canada. CREDES, Paris.

Richards S.H., Coast J., Gunnell D.J., Peters T.J. \& Pounsford J. (1998) Randomised controlled trail comparing effectiveness and acceptability of an early discharge, hospital at home scheme with acute hospital care. British Medical Journal 314, 1796-1801. 
Risdale L., Robins D., Cryer C. \& Williams H. (1997) Feasibility and effects of nurse run clinics for patients with epilepsy in general practice: randomised controlled trail. British Medical Journal 314, 120-122.

Rietkerk M.G. \& Hirasing R.A. (1997) Effect-Evaluatie TASK-Project. Transmurale Astmaverpleegkundige Voor Kinderen in Gouda (Effect-evaluation TASK-project Transmural asthma nurse for children in the town Gouda). TNO Preventie en Gezondheid, Leiden.

Saltman R.B. \& Figueras J. (1997) European Health Care Reform. Analysis of Current Strategies. WHO, Copenhagen.

Shepperd S., Harwood D., Jenkinson C. et al. (1998a) Randomised controlled trail comparing hospital at home care with inpatient hospital care. l: three month follow up of health outcomes. British Medical Journal 316, 1786-1791.

Shepperd S., Harwood D., Gray A., Vessey M. \& Morgan P. (1998b) Randomised controlled trail comparing hospital at home care with inpatient hospital care. II: cost minimisation analysis. British Medical Journal 316, 1791-1796.

Smeenk F.W.J.M. (1998) Transmural care of terminal cancer patients. An evaluation study in the eindhoven region. PhD thesis, Universiteit Maastricht, Maastricht.

Starfield B. (1994) Is primary care essential? Lancet 344, 1129-1133.

Steering Committee on Future Health Scenarios (STG) (1993) Primary Care and Home Care Scenarios 1990-2005. STG, Rijswijk.

Temmink D., Francke A.L. \& Kerkstra A. (1998) Over spreekuren gesproken. Een inventarisatie verpleegkundige spreekuren in Nederland (Spoken about clinic. An inventarisation of transmural nurse clinics in the Netherlands). Elsevier/De Tijdstroom, Maarssen.

Timpka T., Svensson B. \& Molin B. (1996) Development of community nursing: analysis of the central services and practice dilemmas. International Journal of Nursing Studies 33 , 297-308.

Tin K., Keller G. \& Kaufman E. (1995) The effect of community-based respiratory therapy on hospital readmission rates for patients with chronic obstructive pulmonary disease. Canadian Journal of Respiratory Therapy 31, 68-73.

Weekers S. \& Pijl M. (1998) Home and Care Allowances in the European Union. A-D druk/NIZW, Zeist/Utrecht.

Westert G.P. (1997) State control and the delivery of health care: a preliminary study in eleven European countries. Environment and Planning C: Government and policy 15, 219-228. 
chapter 2

Witteveen E. (1998) Home care technology for patients with cancer or serious infections. PhD thesis, Universiteit Utrecht, Utrecht. 


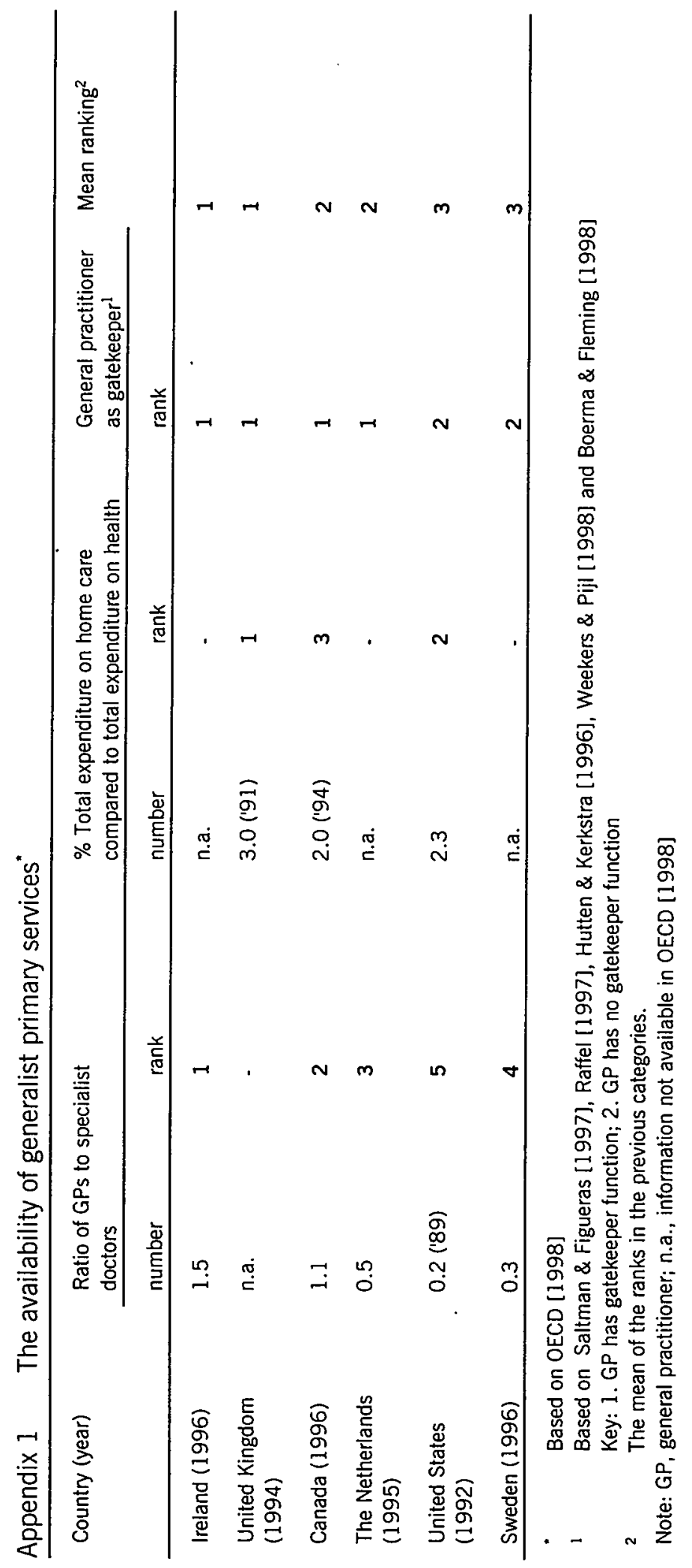




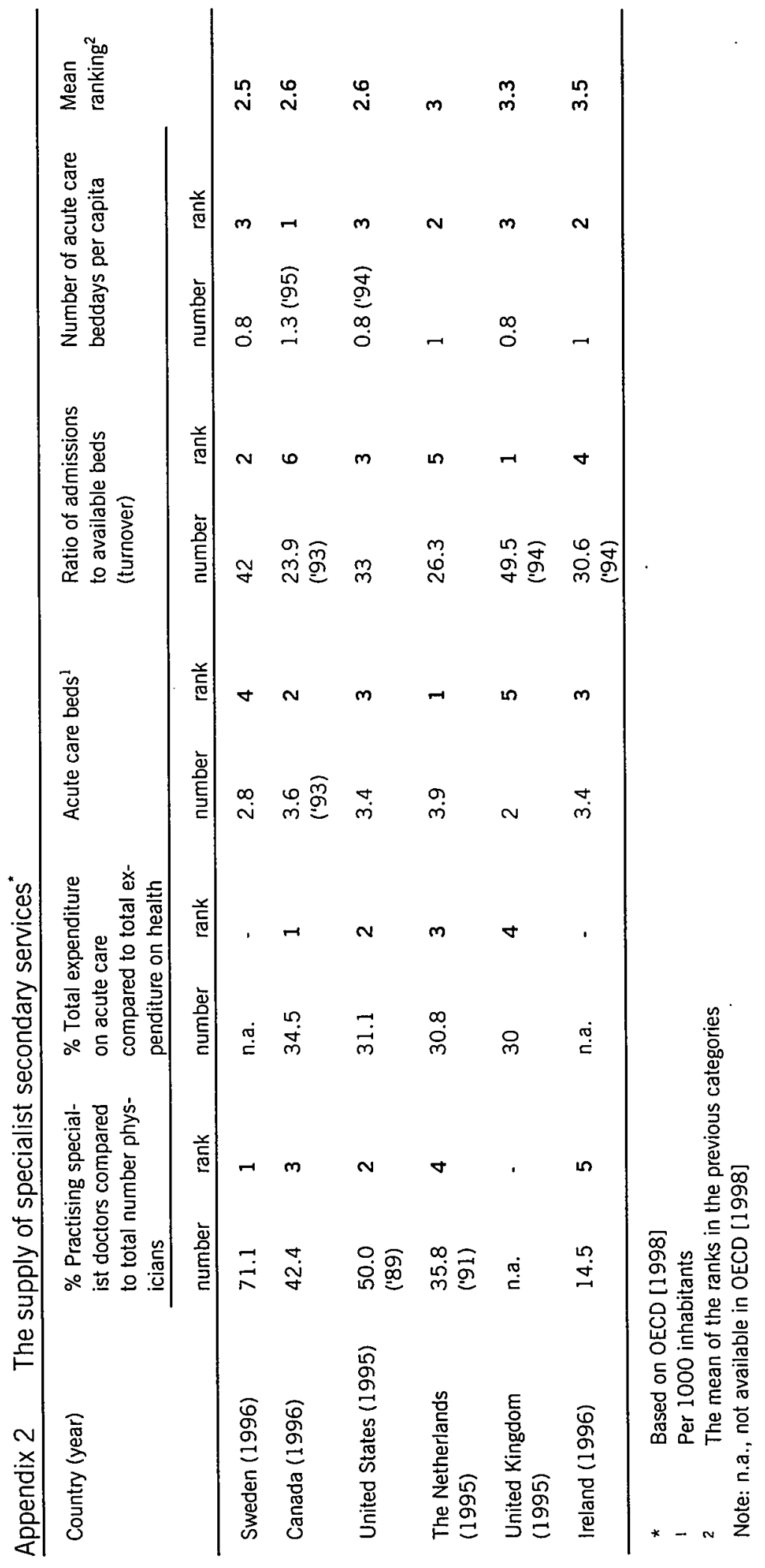




\title{
3 DUTCH TRANSMURAL NURSE CLINICS FOR CHRONIC
} PATIENTS: a descriptive study

\author{
D. Temmink, A.L. Francke, A. Kerkstra, H. Huijer Abu-Saad \\ Patient Education and Counseling 2000; 39: 177-184
}

\section{ABSTRACT}

'Transmural care' can be defined as patient-tailored care provided on the basis of close collaboration and joint responsibility between hospitals and home care organizations. One form of transmural care is transmural nurse clinics for chronically ill. This study describes 62 transmural nurse clinics in the Netherlands. It was established that most of these nurse clinics are held by a specialized community nurse at a hospital outpatient clinic. The principal tasks of the specialized nurse at the clinic are providing illnessrelated information and supporting patients in dealing with the illness. Only a few unpublished evaluations of Dutch transmural nurse clinics have been conducted. Future research has to provide more insight into the impact of transmural nurse clinics on the quality and continuity of care.

Keywords: $\quad$ chronically ill - collaboration - consultation - nurse clinics transmural care 
chapter 3 


\section{INTRODUCTION}

'Transmural care' is a new concept in Dutch health care which was introduced at the beginning of the 1990 s and has been a rapidly growing field since then [1]. The concept refers to care which breaks down the traditional walls between hospital and primary care, is tailored to patients' needs and provided on the basis of close collaboration and joint responsibility by primary care and hospital organizations [2]. Close collaboration means collaboration between professionals on a formal structural basis which can, for instance, be seen in regular meetings in which both patient-related subjects as well as preconditions of the transmural care process are discussed. Joint responsibility refers to formal agreements about the transmural care process at an organizational level. Such agreements can be written down in protocols or guidelines which, for instance, contain information about who, or what organization, assigns the location for transmural care or who organizes professionals providing transmural care.

Transmural objectives are to improve co-operation and phasing between hospital and primary care organizations. Transmural care is considered an important innovation, particularly in the care for chronic patients, since the chronically ill are often confronted with disabilities in their daily life and require help from several health care professionals in different settings [3]. The expectation is that in transmural care, hospital and primary care professionals will collaborate more than is the case in traditional care and make more reciprocal use of expertise. In addition, it is expected that transmural care will result in better quality and continuity of care for chronic patients [2].

The transmural care concept is not often used outside the Netherlands. However, in the United Kingdom the related concept of 'shared care' is an important issue on the health care policy agenda [4]. This English language concept is primarily used to indicate the integration of general practitioner care and home care services. Secondly, shared care encompasses cooperation between primary and hospital care. This second aspect of shared care, in particular, is comparable with the Dutch transmural care concept. In other European countries, the integration of primary and hospital care has also received a lot of attention. For instance, Sweden is also oriented towards a more integrated form of health care organization in which primary and hospital care services co-operate [5]. However, the way in which primary and hospital care are integrated can vary from one country to another. Outside the 
Netherlands, integration is often achieved by reorganization of the system of funding and management of the organizations involved [4]. In the Netherlands, the care needs of a specific chronic patient group often form the point of departure for transmural care innovation [4].

Three main categories of transmural care can be distinguished in Dutch health care [6]. First, transmural care delivered by specialist hospital and generalist primary care providers together is identified. This category can, for instance, be made operational by delivering hospital-based-home-care in close co-operation with a home care organization. A second category of transmural care is transmural care during admission to and discharge from a specialized care organization (e.g. a hospital), delivered by generalist primary care professionals. Within this category of transmural care, liaison nurses are often involved. In the Netherlands, these nurses are frequently employed by a home care organization, but work in a hospital in which they are responsible for the transfer of patients from hospital to home and vice versa. A third category is transmural care delivered by generalist primary care professionals who are supported by specialist hospital professionals. Transmural care with this characteristic can be practised by, for instance, specialized community nurses who hold outpatient clinics in a hospital and who work closely together with a medical specialist. In such transmural nurse clinics both the hospital as well as the home care organization are responsible for matters such as: the content of the clinic, the tasks of nurses holding the clinic and the inter- and intradisciplinary collaboration between professionals. Transmural nurse clinics are often implemented to meet patients demands for education and counseling; these are care activities which often receive insufficient attention during medical outpatient clinics.

Despite the Dutch interest in transmural care in general and transmural nurse clinics in particular, a systematic overview of the characteristics of these clinics is not available. This article aims to shed more light upon the structural/organizational, process and outcome characteristics of transmural nurse clinics. On the basis of the information in this article, policy makers and health professionals, both in, as well as, outside the Netherlands, will be better able to judge whether transmural nurse clinics may also be useful in their situation. In addition, this article may function as the impetus to starting transmural nurse clinics and research in the field. 
The following research questions are addressed in this article:

1. What are the structural/organizational characteristics of Dutch transmural nurse clinics for somatic patients?

2. What are process characteristics of these clinics?

3. Are these clinics evaluated? If so, what methods are used and what outcome characteristics are described?

Before answering the research questions posed, we first present the methods used for tracking down transmural nurse clinics and the procedures for processing and analysing the data.

\section{METHODS}

Sources and data collection

The following Dutch sources were studied in the period January-June 1996 to track down names and telephone numbers of contacts in transmural nurse clinics:

1. Innovative Care Projects Database [7]

2. Registered Scientific Research Database [8]

3. Research and Development Database [9]

4. Inventarization of Research and Development projects in home care [10]

5. Member list of the transmural network [11]

6. Member lists of nursing organizations, that is:

a) association of Dutch rheumatology nurses,

b) association of Dutch Chronic Non Specific Lung Disease (CNSLD) nurses

c) transmural nurses employed by a regional co-ordination centre for chronic illnesses.

In addition to the sources mentioned, the 'snowball method' was used:

contacts at transmural nurse clinics (often the specialized nurse who held the clinic or a nursing manager) were asked whether they knew other persons or organizations involved in transmural nurse clinics.

A total of 103 persons were contacted by telephone. To judge whether a nurse clinic had a transmural character, the contact was asked whether the services at the relevant clinic were provided on the basis of close collaboration and 
joint responsibility, as defined in the introduction to this article, between a hospital and home care organization. If both close collaboration and joint responsibility were used, the contact was asked whether he/she had any reports (e.g., project plans, annual reports or evaluation reports) that could provide information about the structure/organization, process or outcome characteristics of the transmural clinic. Structural/organizational characteristics are relatively stable characteristics like collaborating and funding organizations. Process characteristics encompass, for instance, target groups, goals and nursing activities that go on within and between care providers and patients. Outcome characteristics refer to a change in a patient's current and future health status that can be attributed to antecedent health care [12].

When respondents did not have any reports that could provide a valid picture of the characteristics of the clinic, a questionnaire developed by the researchers was sent covering the same items as mentioned above. Sixty-five of the 103 telephone contacts were involved with 78 transmural nurse clinics (some people were involved with more than one clinic). The other 38 were not involved in transmural nurse clinics, but in other transmural innovations or in non-transmural nurse clinics.

Information on 35 of the 78 transmural nurse clinics was provided by reports and on 27 by postal questionnaire. Sixteen of the 78 clinics tracked down provided either nothing or incomplete data; ten of these clinics had either just or had not yet started, contacts from five clinics did not respond and one clinic started was no longer operational. Accordingly, the results presented are based on the information available from 62 operational transmural nurse clinics for chronic patients.

\section{Procedures for processing and analysing the data}

The information gained from the reports and questionnaires was summarized by the researchers separately for each transmural nurse clinic. This transmural nurse clinic summary was sent to the contact who was requested to make corrections or changes, as needed. The changes made were then coded and stored in SPSS/PC, which is a Statistical Package for the Social Sciences. Descriptive statistics were used to analyze the data. Subsequently, a draft report of the results was sent to all respondents who were again asked to respond if their clinic was not correctly described. These latter adjustments were integrated in the final analyses and report. 


\section{RESULTS}

\section{Structural/organizational characteristics}

Collaboration, employment institution and financing

The 62 transmural nurse clinics described all started post 1988, but most clinics $(n=42)$ started in the last two years. As is inherent in the transmural . character of the clinics, formal agreements about collaboration and responsibilities for the care delivered from one or two home care organizations and one or two hospitals were made for all 62 transmural nurse clinics. All clinics were run under joint responsibility of the hospital(s) and home care organization(s). In four of the 62 transmural nurse clinics, respondents also mentioned a regional co-ordination centre for chronic illnesses as a collaborating partner, while in three of the 62 transmural nurse clinics general practitioners were also involved.

Fifty-four out of the 62 transmural nurse clinics were held at a hospital outpatient clinic. Three clinics were run in a home care building and three others were held alternately at a hospital outpatient clinic and in the building of a home care organization. Two transmural clinics were held at a practice of a general practitioner.

Close collaboration and joint responsibilities for the clinics was, for instance, expressed in the employment of nurses running the clinics and the location of the clinics. In more than a half of the clinics $(n=36)$ the specialist nurses who head them were officially employed by a home care organization. In a quarter of the transmural nurse clinics $(n=18)$, the specialist nurse was employed by both a home care agency and a hospital. In seven other clinics the specialist nurse was employed by the hospital alone. Despite the fact that the hospital was the sole employer in these clinics, we do regard them as transmural clinics. In these situations, agreements about collaboration and joint responsibility between the hospital and home care organization are evidenced in regular meetings between employees of the home care organization and the hospital. The fact that the nurse who heads the clinic can make use of the facilities of the home care organization and visit patients at home illustrates the transmural character of these clinics as well.

Half of the transmural nurse clinics $(n=31)$ were only funded by the regular budgets of the organizations involved; often both the home care organization and the hospital funded the clinic. In about one third of the transmural nurse clinics $(n=19)$ external organizations (e.g. insurance companies, Dutch Ministry of Health or National Centre for Nursing \& Care) also funded the 
clinic. Three clinics were only funded by the hospital; two only by an external organization and two others only by a home care organization. No information on funding was available from five of the clinics.

\section{Professional background}

About $80 \%$ of the transmural nurse clinics were held by nurses who, following their basic training, had followed a ten-day course in nursing care for a specific patient group (for instance rheumatics or diabetics). Three transmural nurse clinics were held by nurses who had followed an 18 months certified post-basic nurse specialist program after basic nursing training. The remaining transmural nurse clinics were held by a nurse who had not followed any specific additional course.

\section{Process characteristics}

\section{Target groups}

All 62 clinics targeted patients with chronic disease. On the basis of the medical diagnosis, four types of clinics could be distinguished:

1. clinics for rheumatics,

2. clinics for diabetics,

3. clinics for patients with CNSLD and

4. 'other' clinics (see Table 3.1). This last type includes clinics which were for patients with a colostomy, stroke, cancer, multiple sclerosis, cystic fibrosis or parkinson's disease.

Table 3.1 Types of transmural nurse clinics distinguished by medical diagnosis

All four types of clinics were oriented towards patients who had a need for information about their disease or its consequences in daily life. Patients who found it difficult to accept their illness or had more practical questions, e.g. about financial compensation for adapting their homes, were also able to visit 
the clinic.

Clinics for rheumatics, diabetics and the 'other clinics' were mostly for adults, while transmural nurse clinics for patients with CNSLD were more often only for children.

\section{Goals of the clinics}

Goals of the transmural nurse clinics were often formulated as improving the quality or continuity of care. For example, the quality of care could be improved because the medical specialist who referred patients to the transmural clinic, now made more use of the expertise of the specialist (community) nurse, and vice versa. The continuity of care could, for instance, be improved because the transmural nurse clinic was situated at the same outpatient clinic in which the medical specialist provided patient consultations. Visits to the medical specialist and the specialist nurse could then be arranged on the same day.

A more specifically formulated goal mentioned by respondents of rheumatology-, CNSLD and 'other' clinics was 'improving patient education'. At a transmural nurse clinic, the specialist nurse could give patients information additional to the information given by the specialist.

In addition to 'improving quality of care', respondents from diabetes clinics often mentioned 'preventing hospitalization' and 'improving interdisciplinary cooperation' as goals of the transmural nurse clinic. During the clinic, the specialist nurse gave patients information about foot inspection, which could reduce incidence of hospitalization. As the nurses were employed by both a home care organization and a hospital they are able to contact care providers of both organizations, this may lead to a better interdisciplinary co-operation.

\section{Referra/s}

In all transmural nurse clinics, a majority of the patients were referred by medical specialists. Fifty per cent of the respondents mentioned that the transmural nurse clinic was also attended by patients who come on their own initiative. About $40 \%$ of the respondents, in rare cases, mentioned a general practitioner as having referred them. Health care providers in general, nurses and dieticians were also mentioned (in 26,21 and $5 \%$ of clinics respectively) as referrers to clinics.

The tasks of the specialist nurse at the transmural nurse clinic Two most frequently reported nursing tasks were giving patient education and counseling to patients. Patient education was specified as a nursing task in almost all transmural nurse clinics (see Table 3.2). Practical aids and adapting 
the home were the main topics on which patients received information. For example, rheumatics received information about how to request a special chair or special footwear, while parents of asthmatic children received information about how to use inhalers. Respondents from diabetes clinics frequently mentioned teaching patients to use a blood-testing kit for bloodglucose during a consultation at the clinics. During a transmural nurse clinic, nurses can reduce patient anxiety about using these kits, by telling them of the importance of monitoring these values themselves.

Giving counseling or psychosocial support was reported in more than $40 \%$ of the transmural nurse clinics (see Table 3.2). Often, the specialist nurse functions as a' sympathetic listener' for the patient. This can, for instance, be important in creating acceptance of the illness and in dealing with increasing dependence on the partner, family or professionals.

Table 3.2 Tasks of the specialist nurse at the transmural nurse clinic

\begin{tabular}{|c|c|c|c|c|c|}
\hline Tasks & $\begin{array}{l}\text { Rheuma } \\
\text { Clinics } \\
(n=24)\end{array}$ & $\begin{array}{l}\text { Diabetes } \\
\text { clinics } \\
(n=16)\end{array}$ & $\begin{array}{l}\text { CNSLD } \\
\text { clinics } \\
(n=11)\end{array}$ & $\begin{array}{l}\text { Other } \\
\text { clinics } \\
(n=11)\end{array}$ & $\begin{array}{l}\text { Number of } \\
\text { clinics for } \\
\text { which the } \\
\text { task is } \\
\text { reported } \\
(n=62)^{\star}\end{array}$ \\
\hline Patient education & 22 & 14 & 11 & 8 & $55(89 \%)$ \\
\hline Counseling & 15 & 5 & 2 & 5 & $27(43 \%)$ \\
\hline $\begin{array}{l}\text { Assessment of problems } \\
\text { and care needs/history } \\
\text { taking }\end{array}$ & 10 & 4 & 3 & 4 & $21(34 \%)$ \\
\hline $\begin{array}{l}\text { Referring and guiding } \\
\text { to other professionals / } \\
\text { organizations }\end{array}$ & 8 & 0 & 0 & 4 & $12(19 \%)$ \\
\hline $\begin{array}{l}\text { Supporting the medical } \\
\text { treatment }\end{array}$ & 0 & 1 & 0 & 3 & $4(6 \%)$ \\
\hline Foot inspection & 0 & 4 & 0 & 0 & $4(6 \%)$ \\
\hline $\begin{array}{l}\text { Others (tasks which are } \\
\text { mentioned at one clinic) }\end{array}$ & 2 & 4 & 1 & 3 & $10(16 \%)$ \\
\hline
\end{tabular}

* Often more than one task was mentioned for a clinic. 
Careful assessment of the patients' problems and care needs was mentioned in one third of the transmural nurse clinics as one of the tasks of the specialist nurse (see Table 3.2). Often by using a standard history form, the nurse first assessed the patients' physical and psychosocial problems. In about twenty per cent of the clinics, the specialist nurse can refer patients to other health care professionals and guide them through the web of health care organizations and institutions.

Table 3.2 shows that the 'foot inspection' is mentioned in a quarter of the diabetes clinics. Particularly older diabetes patients frequently have problems with their circulation, so foot tissue damage can be a problem. Structural check of the patients' feet may prevent tissue damage.

\section{Additional tasks}

In all cases, the specialist nurse had other tasks in addition to the consultations at the transmural nurse clinic. Six categories of additional tasks can be distinguished (see Table 3.3):

1. direct patient care outside the clinic,

2. improving the competence of professionals,

3. the co-ordination and organization of care,

4. innovation and health care management,

5. research and

6. other tasks

Most of the additional tasks mentioned were related to 'direct patient care outside the clinic'. For example, specialist nurses visit patients at home or give consultations by telephone. Before nurses can give patients advice about adapting the home, they need to know this environment. By visiting the patient at home, the nurse is able to give advice which is better suited to the patients needs.

Another frequently reported additional task for the specialist nurse was to improve the competence of other professionals. Specialist nurses who head transmural nurse clinics, for example, also give lectures and provide consultations to hospital and community nurses. 
Table 3.3 Additional tasks of the specialist nurses (besides the transmural nurse clinic)

\begin{tabular}{|c|c|c|c|c|c|}
\hline Additional tasks & $\begin{array}{l}\text { Rheumatology } \\
\text { nurses } \\
(n=24)\end{array}$ & $\begin{array}{l}\text { Diabetic } \\
\text { nurses } \\
(n=16)\end{array}$ & $\begin{array}{l}\text { CNSLD } \\
\text { nurses } \\
(n=11)\end{array}$ & $\begin{array}{l}\text { Other } \\
\text { nurses } \\
(n=11)\end{array}$ & $\begin{array}{l}\text { Number of nurse } \\
\text { clinics for which } \\
\text { the task is } \\
\text { reported }(n=62)^{*}\end{array}$ \\
\hline $\begin{array}{l}\text { Direct patient care } \\
\text { outside the clinic }\end{array}$ & 14 & 8 & 7 & 6 & $35(56 \%)$ \\
\hline $\begin{array}{l}\text { Improvement of } \\
\text { competence of } \\
\text { professionals }\end{array}$ & 17 & 8 & 2 & 6 & $33(53 \%)$ \\
\hline $\begin{array}{l}\text { Co-ordination and } \\
\text { organisation of } \\
\text { care }\end{array}$ & 16 & 4 & 5 & 3 & $28(45 \%)$ \\
\hline $\begin{array}{l}\text { Innovation and } \\
\text { health care } \\
\text { management }\end{array}$ & 12 & 6 & 1 & 5 & $24(39 \%)$ \\
\hline Research & 6 & 3 & 2 & 2 & $13(21 \%)$ \\
\hline $\begin{array}{l}\text { Other additional } \\
\text { tasks (tasks which } \\
\text { are mentioned at } \\
\text { one clinic) }\end{array}$ & 1 & 3 & 0 & 0 & $4(6 \%)$ \\
\hline
\end{tabular}

* Often more than one goa! is formulated for a clinic.

Co-ordination of care was mentioned as additional task in 28 transmural nurse clinics (see Table 3.3). Co-ordination is important because chronic patients are often treated by several care providers and coordination makes clear who is to do what. Consequently, a lot of nurses who head the clinics have regular, interdisciplinary meetings with medical specialists, occupational therapists, physiotherapists, etc.

A fourth additional reported task concerns 'innovation and health care management'. About forty per cent of the contacts reported that the specialist nurse who headed the clinic also developed care protocols and ensured optimal conditions for the transmural nurse clinic involved. 


\section{Outcome characteristics}

According to the respondents, 21 of the 62 transmural nurse clinics presented have been evaluated. However, four of those respondents provided no information about the evaluation conducted, so we have insight into 17 evaluations. The evaluation outcomes presented by respondents indicate positive effects on the quality or continuity of care or effects on the use of health care facilities. These outcomes are often formulated in terms of satisfaction of clients or professionals. However, since satisfaction judgements will always be determined by what is a social desirable response, only asking about satisfaction does not give a valid picture of the quality or continuity of care. Moreover, shortcomings in the design of the evaluations make it difficult to interpret reported outcomes. In almost all of the evaluations $(n=16)$ a research design with post-tests only was used, while in only one case a pretest was carried out. Control groups or validated measurement instruments were not used in any of the evaluations.

\section{CONCLUSIONS AND DISCUSSION}

In several western industrialized countries, innovations are introduced into the care of chronic patients $[4,5]$. In such innovations, primary and secondary care services are often integrated. This kind of integrated care is often called 'transmural care' in the Netherlands. The present descriptive study gives insight into characteristics of 62 Dutch transmural nurse clinics. The nurse clinics are considered 'transmural' since they are provided on the basis of close collaboration and joint responsibility by hospitals and home care organizations.

Firstly, the structural/organizational characteristics of transmural nurse clinics were described. It appeared that transmural nurse clinics were most often held at a hospital outpatient clinic and were mostly financed by the regular budgets of the organizations involved (e.g. a home care organization and a hospital). The professional background of nurses heading a transmural nurse clinic differs. These nurses have different professional backgrounds ranging from nurses who did not follow any specific training course for the patient group involved, after their basic nursing training, to nurses who followed an extended eighteen month programme of training. More insight into the appropriate background for nurses heading transmural nurse clinics seems needed to direct the training of these nurses. 
Secondly, process characteristics of Dutch transmural nurse clinics have been described. The clinics were oriented towards rheumatic patients, diabetics, patients with CNSLD and other chronic patients (for instance patients with cancer, multiple sclerosis or Parkinson's disease). This orientation towards the chronically ill is not surprising; a lot of chronic patients are confronted with disabilities in their daily life and require help from several health care professionals [3].

Patients are most often referred to a transmural nurse clinic by a medical specialist. This indicates that collaboration within the framework of the transmural nurse clinics is often limited to medical specialists only and the specialist nurses heading the clinics. On the basis of the results of our descriptive study, it can be concluded that general practitioners seldom have a role in transmural nurse clinics.

In almost all transmural nurse clinics, patient education is specified as a nursing task. In addition to this, during a consultation at the transmural clinic, the specialist nurses give counseling or psychosocial support to patients, which is helpful in dealing with the illness. Apart from the tasks at the transmural nurse clinic, the specialist nurses provide, when necessary, direct patient care outside the clinic (e.g. by home visits or consultations by telephone). This fact that nurses perform tasks in the hospital outpatient clinic as well as in the home setting, might be important in improving the communication, cooperation and match between professionals in the two settings mentioned. Patients might also have better quality and continuity of care because they receive care both in and outside the hospital from one specialist nurse who is familiar with their individual situation and problems.

Finally, evaluations and outcomes of transmural nurse clinics have been the subject of this descriptive study. Despite the positive expectations of transmural nurse clinics on, for instance, continuity and quality of care, evaluation studies with methodological qualities supporting these expectations are lacking. Few uncontrolled evaluations of Dutch transmural nurse clinics have been conducted and the effects on continuity and quality of care are still rather unclear. This is to a large extent due to methodological weaknesses; pre-tests, validated measurement tools and control groups often being absent. Consequently, future scientific research is needed to gain insight into effects of Dutch transmural nurse clinics on quality and continuity of care. Results of such future research will give insight in the desirability of implementing transmural nurse clinics on a large scale both in and outside the Netherlands. 


\section{REFERENCES}

[1] Linden, van der BA. Transmural care. Facts and future. In: Health and health care in the Netherlands. Utrecht: De Tijdstroom, 1997; 181-188.

[2] Nationale Raad voor de Volksgezondheid \& College voor Ziekenhuisvoorzieningen. Transmurale somatische zorg: Advies van de Nationale Raad voor de Volksgezondheid en het College voor Ziekenhuisvoorzieningen (Somatic Transmural Care: Advise of the National Council for Public Health and the National Board for Hospital Facilities). Zoetermeer: NRV/CVZ, 1995.

[3] Bos, van den GAM. The burden of chronic diseases in terms of disability, use of health care and healthy life expectancies. Eur J Public Health 1995; 5; 29-34.

[4] Julius Centrum voor Patiëntgebonden Onderzoek. Congres-folder 'Transmurale zorg, managed care, disease management en integrated care vergeleken' (Congress-brochure 'Transmural care, managed care, disease management and integrated care compared'). Utrecht: Universiteit van Utrecht, 1998.

[5] Häggmark C, Nilsson B. Effects of an intervention programme for improved discharge-planning. The frequency of re-admissions, problems and treatments of cancer patients receiving repeated treatments in hospital. Vård I Nord 1997;17:4-8.

[6] Francke, AL. Transmurale zorg: begrippen, beleidsontwikkelingen en basisvormen. In: Jaarboek Verpleegkunde 1997. Thema: Transmurale zorg. (Transmural care: concepts, policy developments and primary forms. In: Nursing yearbook 1997. Theme: Transmural care). Dwingeloo: Kavanah, 1997; 17-35.

[7] NIVEL, Trimbos-instituut \& NZi. Innovatie in de zorgsector, jaarboek 1996 (Innovation in care, yearbook 1996). Utrecht: Uitgeverij De Tijdstroom BV, 1996.

[8] NIVEL. Registratie Wetenschappelijk Onderzoek eerstelijnsgezondheidszorg '95-'96 (Registration Scientific Research '95-'96). nr. 24. Utrecht: NIVEL, 1996.

[9] Landelijk Centrum Verpleging \& Verzorging. Databank Onderzoek \& Ontwikkeling (Research and Development Database). Utrecht: LCVV, 1996.

[10] Landelijke Vereniging voor Thuiszorg \& Stichting Onderzoek en Ontwikkeling Maatschappelijke gezondheidszorg. Inventarisatie Onderzoeks- \& Ontwikkelingsprojecten Thuiszorg (Inventarization of Research- and Development projects in home care). Bunnik: LVT, 1996.

[11] Linden, B van der, Spithoven, E. Ledenlijst en projectomschrijvingen van het netwerk voor transmuraal werkenden (Member list of the transmural network). Utrecht:

Rijksuniversiteit Utrecht, 1996. 
chapter 3

[12] Donabedian, A. The definition of quality and approaches to its assessment. Michigan: University of chigan, 1980. 
4 DUTCH NURSE CLINICS FOR CHILDREN WITH ASTHMA: views of professionals and parents

D. Temmink, J.B.F. Hutten, J. van der Zee, H. Huijer Abu-Saad Journal of Nursing Care Quality 1999; 14(1): 63-71

\section{ABSTRACT}

In the Netherlands there are two kinds of nurse clinics for asthmatics.

Extramural nurse clinics are run under the sole responsibility of a home care organization, while transmural nurse clinics are run under the joint responsibility of a home care organization and a hospital. This article gives insight into the opinions of professionals and parents of asthmatic children about the care given at these clinics. The conclusion is that organizational differences between the clinics do not influence parents' (positive) perceptions about the quality and continuity of care provided at the clinics.

Keywords: asthma - continuity of care - nurse clinics - quality of care transmural care 
chapter 4 


\section{INTRODUCTION}

The care of persons with asthma, as with people with other chronic conditions, involves a variety of health care professionals and services in both primary and secondary care settings $[1,2]$. The quality of asthma care can vary and may result in poor treatment in both hospitals and home care settings. In the first place, asthmatics often need more information about their disease and its treatment. Patients and parents of asthmatic children want to know more about possible causes of the disease, the management of worsening conditions, how to decide when to summon medical help, the nature of the drugs and their side-effects and the likely prognosis [3]. Parents of asthmatic children also request information on how to deal with their asthmatic child at school, during holidays and in every day life. In the Netherlands, it also appears that health care for asthmatic patients is poor in regard to waiting time at the primary care provider's or lung specialist's office. The coordination of care given by these professionals also is regarded as poor [4].

Foreseeing the problems in the care for asthmatics, nurse-run asthma clinics have been established in the United Kingdom and the Netherlands [2,5-9]. At these clinics, nurses give patients information about topics like inhaler techniques and asthma preventers and relievers $[8,9]$. In addition, they support patients in how to deal with their asthma in daily life [9]. The organization of Dutch asthma clinics can vary from clinics run under the sole responsibility of a home care organization (so-called extramural nurse clinics) to clinics that are run under the joint responsibility of a home care organization and a hospital (called transmural nurse clinics). Patient and professional demands for good, quality health care are expected from both types of clinic. Transmural nurse clinics are also expected to improve the continuity of care and cooperation between home care and hospital professionals (for example, community nurses and pediatricians). Whether these expectations actually are met is as yet unknown. Consequently, this article will target specialist nurses' and pediatricians' assessment of transmural and extramural nurse clinics for asthmatic children. The object is also to give insight into the perceptions of the parents of asthmatic children about the quality and continuity of care received at transmural and extramural nurse clinics. 
The following research questions are addressed in this article:

1. What are specialist asthma nurses' perceptions about transmural and extramural nurse clinics in the Netherlands? What are pediatricians' perceptions about transmural nurse clinics in the Netherlands?

2. Do parents' perceptions about the quality and continuity of care reveal a difference in the assessment of transmural and extramural nurse clinics in the Netherlands?

\section{METHOD}

\section{Sample}

The study was conducted at six locations in the Netherlands. At four locations, a home care institution and a hospital collaborated closely and had joint responsibility for a transmural nurse clinic. All transmural nurse clinics were held by asthma community nurses at a hospital outpatient department. Extramural nurse clinics for asthmatic children were held by asthma community nurses at two locations in a building belonging to a home care organization. The home care organization bore the sole responsibility for the clinics.

Four nurses and five pediatricians involved in transmural nurse clinics as well as two nurses heading an extramural nurse clinic were interviewed. Parents of asthmatic children participated in the study in addition to professionals. (The term 'parent' will be used further to indicate both asthmatic children and their parents.) The following criteria were used for parents and their children in this study: (1) diagnosis of chronic non specific lung diseases (for example asthma or chronic obstructive pulmonary disease, COPD), (2) age below 14 years, (3) no previous contact with the nurse specialists, (4) one parent who speaks Dutch and (5) telephone access. Parents received a letter with information about the study. Those who chose to participate gave written consent.

Between April 1996 and February 1998, a total of 237 respondents were covered by the study. Of those, 152 attended a transmural nurse clinic while the remaining 85 visited an extramural nurse clinic. Thirteen of the 152 parents visiting a transmural nurse clinic and 22 of the 85 parents visiting an extramural nurse clinic dropped out of the study. This means that information is available about 139 parents visiting a transmural and 63 parents visiting an extramural nurse clinic ( $85 \%$ response).

The respondents visiting the two kinds of clinics were comparable on most of 
the background characteristics. In both groups, the children had a mean age of five years, 60 percent were male, and the mean duration of the disease was three years. Most of the parents had primary or secondary education, 95 percent were female and had contacted the specialist nurse about twice during the research period of six weeks. A significant difference in the severity of children's asthma was found between the two groups. Children visiting an extramural nurse clinic appeared to have less severe asthma than children visiting a transmural nurse clinic. About half the children (49\%) had moderate asthma.

\section{Measurement instruments}

For the first research question, semi-structured interviews were held with pediatricians involved in transmural nurse clinics and with specialist asthma nurses involved in transmural and extramural nurse clinics. Leading questions posed in the interviews were: (1) What are positive and negative aspects of the clinic? (2) What are inhibiting factors for running the clinics? and (3) Is it important to continue the clinic in the future? The interviews lasted about 45 minutes and were audio-taped.

Parents were approached for a telephone interview on two occasions. The interviews lasted from about 15 to 30 minutes. The first telephone interview with parents was conducted one to four days before the parent and child visited a nurse clinic (TO) while the second interview took place six weeks after their first visit at the nurse clinic (T1). To examine parents' perceptions of the quality of care, the Quality of Care through the Patient's Eyes for asthma and COPD patients (QUOTE-CNSLD) [4] was used. In the QUOTE-CNSLD, parents at TO are asked to rate the importance (I) of 16 health care service indicators (for example, 'health professionals should be fully conversant with my problems'; response range $1-4$ ). Parents at $T 1$, were asked to rate the perceived performance $(P)$ on each indicator in their perception (for example, 'the specialist nurse is fully conversant with my problems'; response range 14). The QUOTE-CNSLD has been shown to be a reliable and valid instrument for assessing the quality of health care services from the perspective of noninstitutionalized CNSLD patients [4].

To examine parents' perceptions of the continuity of care, the questionnaire on Continuity of care from the Clients' perspective (QCC) [10] was used. Analogous to the QUOTE-CNSLD, in the QCC questionnaire, parents were asked to rate, at $T 0$, the importance (I) and at $T 1$ the perceived performance $(P)$ of 15 continuity health care service indicators (score range 1-5). The QCC 
instrument has been shown to be a reliable and valid instrument for assessing the continuity of health care services from the perspective of CNSLD patients [10]. Because of the difference in score range, the importance and performance scores of the QUOTE-CNSLD and QCC are incomparable.

\section{Analyses}

The interviews with specialist nurses and pediatricians were analyzed using qualitative analysis techniques $[11,12]$. The interviews were transcribed and stored in Kwalitan, a computer program for practical support in qualitative analyses [13]. All interview fragments that were related to the first research question were given one or more key words. The interview fragments then were grouped by key word and compared with fragments with the same key words.

The quality and continuity of care in transmural and extramural nurse clinics was defined as "optimal" when parents' experiences with the clinics ( $P$ measured at $T 1$ ) were at least congruent with their individual importance scores (I measured at TO). For each indicator, average importance and performance scores were calculated to determine discrepancies between importance and performance score. Mean ratio scores $(R)$ then were calculated for each indicator by means of dividing perceived performance scores (T1) by importance scores (TO) for every individual patient. Mean ratio scores of 1.0 or higher indicate a positive score on a specific indicator. Mean ratio scores below 1.0 indicate a negative score on a specific indicator. If, for instance, a parent rated the importance of an indicator with score 3.0 and the performance with 2.0, the ratio score of $0.67(2.0 / 3.0)$ indicate a negative score on that specific indicator.

Differences in ratio scores between parents visiting a transmural or extramural nurse clinic were determined by ANCOVA with statistical adjustment for the baseline difference between the two groups in severity of the illness.

\section{RESULTS}

Specialist asthma nurses' and pediatricians' perceptions

Both specialist nurses and pediatricians are positive about the clinics involved. The accessibility of the clinics and the time available were experienced as strongly positive. In both types of nurse clinics, nurses have more time with the parents than the time available at a pediatricians' clinic. This gives nurses the option of providing parents with information additional to that given by 
pediatricians.

One pediatrician stated: 'In a medical clinic, the time is limited and it is only possible to provide limited information about illness-related aspects. The specialist nurse has more time during her clinic and can give additional information about, for instance, the inhalation method. According to them, parents discuss some problems (like not knowing how to use the medicines) more easily with a specialist nurse than with a pediatrician. (3-3-1) (These numbers indicate the place of the specific fragment in the Kwalitan program. The fist number refers to the work file, the second to the document code, and the third to the scene number).

In addition, all nurses and three of the five pediatricians interviewed mentioned that the clinic involved resulted in more accessible care. Impeding factors concerning transmural and extramural nurse clinics also were mentioned. In both kinds of clinics, the referral system to the clinics can be improved. For instance, in extramural nurse clinics, patient referrals from general practitioners and pediatricians seems to be made on an incidental rather than a structural basis. In the initial phase at transmural clinics, the way of referral was seen as an impediment.

A nurse stated: 'Several doctors can refer parents to my clinic. These doctors all have their own views on the care process. This has resulted in differences in referral patterns between doctors. These differences result in differences in the content of the care given, while parents' situations are comparable.' (4-218)

\section{Parents' perceptions of the quality of care}

Table 4.1 shows the scores on the 16 quality indicators. It appears that parents who visit transmural or extramural nurse clinics (at TO) attach great importance to most of the quality indicators. Parents rated indicator 4 , 'to be taken seriously by health professionals and institutions', of the highest importance, followed by indicator 8 , 'tell me what to do when I use other medicines besides the prescribed ones'; 11, 'physicians and nurses should know how my inhaler works' and 15, 'wards, waiting rooms and consulting rooms should be entirely smoke-free'.

Parents' perceptions $(P)$ of transmural and extramural nurse clinics was optimal as regards indicator 11 , 'physicians and nurses should know how my inhaler works' and 15, 'wards, waiting rooms and consulting rooms should be entirely smoke-free'. The performance score of 4.0 shows that all parents visiting a nurse clinic had an optimal positive judgement on these indicators. Parents also rated the quality of extramural nurse clinics optimal in regard to 
indicator 3, 'allow me to decide on what help to get'; 4, 'take me seriously'; 5 , 'keep their appointments' and 6 'allow me to choose another professional' (see Table 4.1).

Table 4.1 Mean Importance scores (I), mean Performance scores (P), mean Ratio scores $(R)$ and statistical test results on quality indicators"

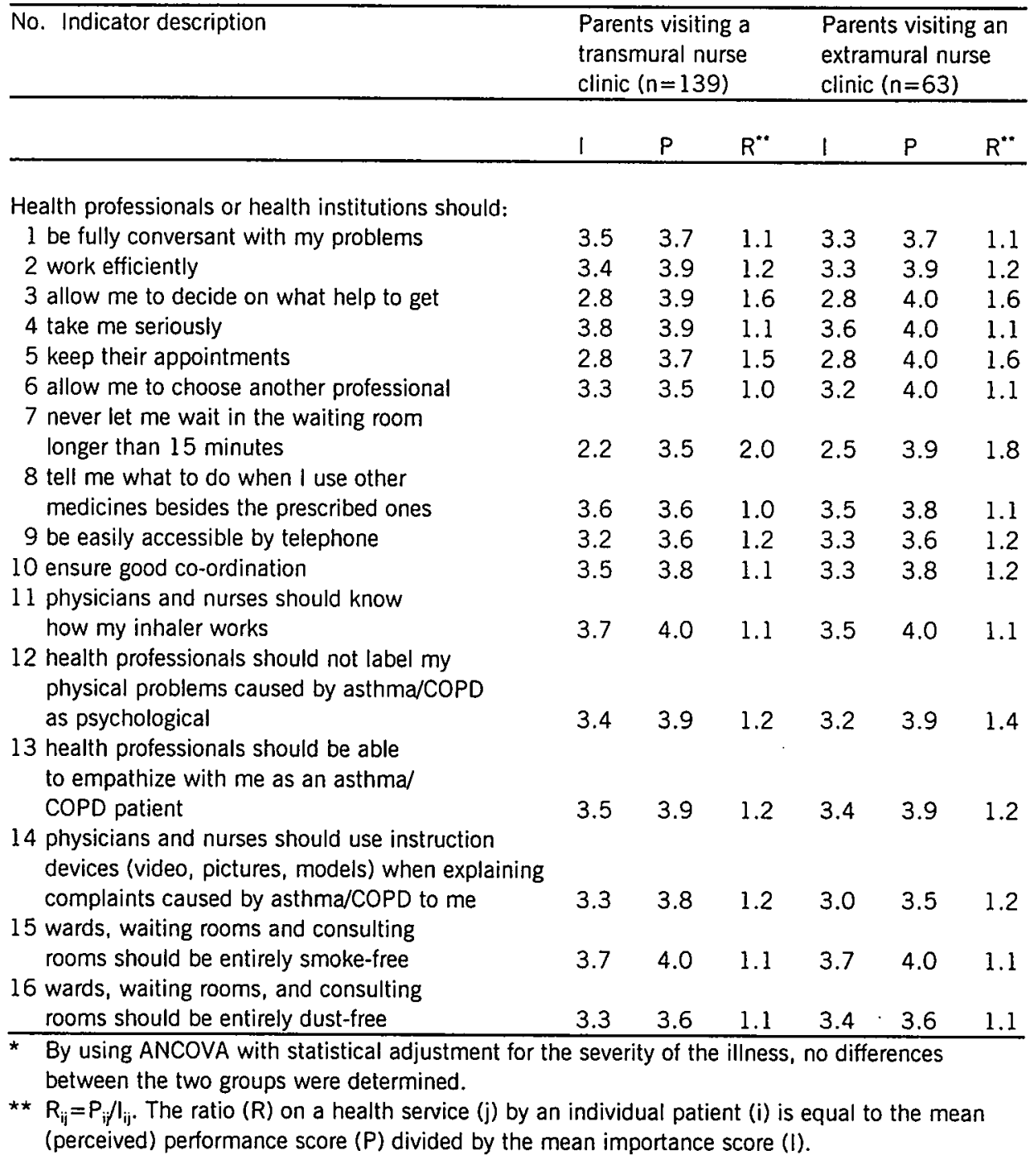


The optimal quality of care in transmural and extramural nurse clinics is also reflected in the mean ratio scores $(R)$ in Table 4.1. On all quality indicators a mean $\mathrm{R}$ score of 1.0 or higher appears. This indicates that on all quality of care indicators, parents' perceptions of nurse clinics are positive.

Finally, Table 4.1 shows that no significant differences were found between transmural and extramural nurse clinics with respect to the quality of care perceived by parents.

\section{Parents' perceptions of the continuity of care}

Table 4.2 displays indicators measuring the continuity of care, mean continuity importance scores $(I)$, mean perceived performance scores $(P)$ and mean ratio scores $(R)$ of the participating parents. It appears that parents who visited a transmural or extramural nurse clinic (TO) attached great importance to almost all continuity indicators. Parents rated the following continuity indicators as being of the greatest importance: 2 , 'adapt care when necessary in changing situations'; 3, 'provide care immediately during emergencies'; 7 'provide concurrent care' and 14 'give each other sufficient information concerning patients' situation'.

Parents' experiences relating to the continuity of care given at transmural and extramural nurse clinics can be deduced from the mean performance scores $(P)$ in Table 4.2. The performance of transmural nurse clinics was experienced as optimal regarding indicator 10 , 'give sufficient information to a substitute:. Parents visiting an extramural nurse clinic scored indicator 3 , 'provide care immediately during emergencies' and 5 ,'not cancel an appointment without reason' as optimal. Negative experiences with transmural nurse clinics occurred on indicator number 9 , 'have a locum in case of absence' and 13, 'refer me to another care provider when necessary'. Relatively poor experiences of extramural nurse clinics were reported for indicator 14, 'give each other sufficient information concerning patient's situation'.

The mean ratio scores show a positive score on most continuity indicators for both kinds of clinic. However, perceptions of parents visiting a transmural nurse clinic were less than optimal on continuity indicators 9 , 'have a locum in case of absence'; 13, 'refer me to another care provider when necessary' and 14, 'give each other sufficient information concerning patient's situation'. These indicators had a mean ratio score less than 1.0. Less positive mean ratio scores in extramural nurse clinics were found for continuity indicators 2 , 'adapt care when necessary in changing situations'; 6 ,'be reachable by 
telephone'; 9, 'have a locum in case of absence'; 10, 'give sufficient information to a substitute' and 14, 'give each other sufficient information concerning patient's situation'.

Table 4.2 Mean Importance scores (I), mean Performance scores (P), mean Ratio scores $(R)$ and statistical test results of the continuity indicators. ${ }^{1}$

No. Indicator description

$\begin{array}{ll}\text { Parents visiting a } & \text { Parents visiting an } \\ \text { transmural nurse } & \text { extramural nurse } \\ \text { clinic }(n=139) & \text { clinic }(n=63)\end{array}$

$\mathrm{P} \quad \mathrm{R}^{3}$

$l^{2} \quad P \quad R^{3}$

Health professionals or health institutions should:

1 provide the necessary care

2 adapt care when necessary in changing situations

3 provide care immediately during emergencies

4 keep to the time of appointment

$\begin{array}{llllll}4.5 & 4.7 & 1.1 & 4.8 & 4.7 & 1.0\end{array}$

5 not cancel an appointment without reason

6 be reachable by telephone

7 provide concurrent care

8 cooperate with each other

9 have a locum in case of absence

$\begin{array}{lll}4.8 & 4.8 & 1.0 \\ 4.9 & 4.9 & 1.0 \\ 4.1 & 4.6 & 1.3 \\ 4.3 & 4.9 & 1.5 \\ 4.6 & 4.5 & 1.0 \\ 4.9 & 4.8 & 1.0 \\ 4.8 & 4.7 & 1.0 \\ 4.6 & 2.8 & 0.6 \\ 4.8 & 5.0 & 1.0 \\ 4.4 & 4.5 & 1.2\end{array}$

$\begin{array}{lll}4.9 & 3.7 & 0.7\end{array}$

$\begin{array}{lll}4.9 & 5.0 & 1.0\end{array}$

10 give sufficient information to a substitute

11 give compatible advice

12 not provide care with too many different care providers

13 refer me to another care provider when necessary

14 give each other sufficient information concerning patients situation

$\begin{array}{llllll}4.2 & 4.8 & 1.5 & 4.0 & 4.9 & 1.6\end{array}$

$\begin{array}{llllll}4.3 & 2.8 & 0.6 & 4.4 & 4.3 & 1.0^{*}\end{array}$

15 visit patients at home when necessary

$\begin{array}{llllll}4.9 & 4.0 & 0.8 & 4.9 & 3.5 & 0.7\end{array}$

1 Differences in ratio scores between the two groups were determined by ANCOVA, with statistical adjustment for the severity of the illness.

2 The final version of the QCC does not contain importance indicators. Despite this, the authors chose to use importance scores because this gives the opportunity for giving practical advice to improve the continuity of care in transmural and extramural nurse clinics.

$3 \quad R_{i j}=P_{i j} / l_{i j}$. The ratio (R) on a health service ( $j$ ) by an individual patient (i) is equal to the mean (perceived) performance score $(P)$ divided by the mean importance score $(P)$. $p<0.05$ 
Significant differences between transmural and extramural nurse clinics occurred on two continuity indicators. Table 4.2 shows that parents consulting an extramural nurse clinic experienced the compatibility of advice given by different health professionals more positively than the positive experience with this indicator had of parents visiting a transmural nurse clinic. This significant difference in parents' positive experiences has no relevance in relation to a future continuity improvement program.

Another significant difference between the two kinds of clinics related to indicator 13, 'refer me to another care provider when necessary'. Parents visiting extramural nurse clinics scored this continuity indicator as positive while parents visiting a transmural nurse clinic gave this indicator a mean ratio score below 1.0, which indicates a negative perception.

\section{CONCLUSIONS AND DISCUSSION}

In the Netherlands and other European countries, nurse-run asthma clinics are used in order to face problems in the quality and continuity of care of asthmatics $[5,6,8,9]$. The content of such clinics consists mainly of giving patients information about their illness and supporting patients in dealing with their asthma. In the Netherlands two types of clinic, 'transmural' and 'extramural' nurse clinics are distinguished. 'Extramural' nurse clinics are the responsibility of a home care organization alone, while 'transmural' nurse clinics are the joint responsibility of a hospital and home care organization. In this study, parents were not assigned randomly to the two kinds of clinics distinguished by organizational structure. However, it appeared that the two groups did not differ on most background characteristics. There was a difference in the severity of children's asthma between the groups. This was taken into account in the statistical analyses.

To a large extent, the organizational differences between the two kinds of nurse clinics do not influence asthmatic children's parents' experiences with the quality and continuity of the care provided. The absence of large differences can be a result of the fact that parents do not attach much importance on the organization of the care provided, but focus mainly on the content of the care process. Because transmural and extramural nurse clinics do not differ in this respect, it is not surprising that differences between the perceived quality and continuity of care in the two kinds of clinics did not occur.

A choice made in the design of this study concerns the six-week period 
between measuring parents' expectations and experiences. If this period were extended to six months, it is possible that other differences between the two groups would be found.

As regards the quality of care, no negative quality judgements were found in either kind of clinic. It therefore can be concluded that future quality improvement programs in transmural and extramural nurse clinics are not necessary. However, it is important to maintain today's positive quality judgements in quality assurance programs.

With respect to the continuity of care, some aspects were shown to be relevant for improvement in Dutch transmural and extramural nurse clinics. Parents visiting transmural or extramural nurse clinic indicated that health professionals (such as specialist asthma nurses and pediatricians) do not always give each other sufficient information about a child's situation. Parents also indicated that in both transmural and extramural nurse clinics, a substitute specialist nurse was not always available in case of absence. Additionally, parents visiting a transmural nurse clinic had fewer positive experiences in the frequency with which they were referred by the specialist nurse to other care providers (such as a pediatrician) in cases where parents thought necessary. This result is incongruent with the goals of transmural nurse clinics in general. It is assumed that pediatricians and specialist nurses work closer in transmural nurse clinics and therefore will communicate more easily with each other than in the case of extramural nurse clinics. Parents who visited extramural nurse clinics noted fewer positive experiences regarding the way in which care was adapted in changing situations, the telephone access to the specialist nurses and whether specialist nurses gave sufficient information to a substitute or other professionals. These subjects are areas for special attention in continuity of care improvement of extramural nurse clinics.

This article also gave insight into specialist asthma nurses' and pediatricians' perceptions about transmural and extramural nurse clinics. Both specialist asthma nurses and pediatricians participating in this study share the opinion that nurse clinics are a positive innovation. Patients get additional information at the clinics and nurses are more accessible for patients than other providers such as pediatricians. However, professionals involved in both kinds of clinics plan to deal with impeding factors in the clinics. It is hoped that through this process, the positive influences of transmural and extramural nurse clinics will be strengthened. It therefore is recommended that in the future, a referral system to clinics is considered before using clinics in daily nursing practice. 


\section{REFERENCES}

[1] P. Ludwig-Beymer, S. Peterson, C. Gorman. "Improving care for adults with asthma across the continuum". Journal of Nursing Care Quality 12, no. 6 (1998):48-55.

[2] A.J. Eastwood and Sheldon. "Organization of asthma care: what difference does it make? A systematic review of the literature". Quality in Health Care 5, (1996): 134-143.

[3] A. Nocon and T. Booth. "The social impact of asthma". Family Practice 8, no. 1 (1990): 37-41.

[4] C. van Campen, H.J. Sixma, J.J. Kerssens, L. Peters. "Assessing Noninstitutionalized Asthma and COPD Patients' Priorities and Perceptions of Quality of Health Care: The development of the QUOTE-CNSLD Instrument". Journal of Asthma 34, no. 6 (1997): 531-538.

[5] I. Charlton, G. Charlton, J. Broomfield, M. Campbell. "An evaluation of a nurse-run asthma clinic in general practice using an attitudes and morbidity questionnaire". Family Practice 9, no. 2 (1992): 154-160.

[6] K.P. Jones and M.A. Mullee. "Proactive, nurse-run asthma care in general practice reduces asthma morbidity: scientific fact or medical assumption". British Journal of General Practice 45, (1995): 497-499.

[7] J. Droogan and K. Bannigan. "Organization of asthma care: what difference does it make?" Nursing Times 93, no. 34 (1997): 45-46.

[8] G. Barnes and M.R. Partridge. "Community asthma clinics: 1993 survey of primary care by the National Asthma Task Force". Quality in Health Care 3, (1994): 133-136.

[9] D. Temmink , A.L. Francke, A. Kerkstra, H. Huyer Abu-Saad . "Dutch transmural nurse clinics for chronic patients: a descriptive study". Patient Education and Counseling $2000 ; 39 ; 177-184$

[10] A.F. Casparie et al. Vragenlijst Continuïteit van zorg vanuit Cliëntperspectief (VCC) Handleiding en vragenlijsten. [Questionnaire continuity of care from the clients' perspecitive] Utrecht / Amsterdam / Groningen: NIVEL, VU, RUG, 1998.

[11] M.B. Miles and A.M. Huberman. Qualitative data analysis. An sourcebook of new methods (Beverly Hills: SAGE Publications, 1984).

[12] M.B. Miles and A.M. Huberman. Qualitative data analysis. An expanded sourcebook. $2^{\text {nd }}$ ed. (Newbuny park: SAGE Publications, 1994). 
chapter 4

[13] V. Peters, F. Wester, R. Richardson. Kwalitatieve analyse in de praktijk en handleiding bij Kwalitan [Qualitative analyze in practice and manual for Kwalitan]. SWI-reeks (Nijmegen: Katholieke Universiteit Nijmegen, 1989). 


\title{
QUALITY AND CONTINUITY OF CARE IN DUTCH NURSE CLINICS FOR PEOPLE WITH RHEUMATIC DISEASES
}

\author{
D. Temmink, J.B.F. Hutten, A.L. Francke, H. Huijer Abu-Saad, \\ J. van der Zee \\ International Journal for Quality in Health Care 2000; 12(2):89-95
}

\section{ABSTRACT}

Recently a new form of nurse clinic for people with rheumatic diseases has been introduced into Dutch health care. This study gives insight into: (i) patients' perceptions about the quality and continuity of care given at these (transmural) nurse clinics and (ii) specialized rheumatology nurses' and rheumatologists' perceptions about the quality and continuity of care in the clinics. Validated measurement tools (QUOTE and QCC) were used, before and after patients visited a clinic, to determine patient perceptions about the quality and continuity of care. Semi-structured interviews with professionals were used to gather information about their perceptions. The study was carried out at five locations in The Netherlands where a home care organization and a general hospital collaborated closely and had joint responsibility for a transmural rheumatology nurse clinic. A total of 128 patients, six specialist rheumatology nurses and four rheumatologists participated. In general, patients were positive about the quality and continuity of care given at the clinics. Some continuity aspects, like the presence of a locum nurse and providing the locum with sufficient information could be improved. Professionals were positive about the information given at the clinics, which is additional to the information given by a rheumatologist. Professionals were less positive about some of the clinics' preconditions. In this study, a control group (e.g. patients who received standard rheuma-tologist care) was not available. However, in comparison with patients' experiences of standard medical care in other (comparable) research, patients' experiences in this study were very positive. It was concluded that Dutch transmural nurse clinics, to a large extent, meet patients' and professionals' expectations and were a positive development in the care of rheumatic patients.

Keywords: continuity of care - nurse clinics - patient education - quality of care - rheumatic diseases - transmural care 
chapter 5 


\section{INTRODUCTION}

It appears to be difficult for health care organizations to provide people with a chronic illness with good quality care; for example the literature shows that few of those with rheumatoid arthritis are satisfied with the options available for the adaptation of the living environment as provided by standard medical services. In addition, people with rheumatoid arthritis often feel they do not receive enough information from standard medical care services [1], there is inadequate doctor-patient communication [2] and patients are often dissatisfied with the difficulty of unscheduled access to rheumatology outpatient clinics [3]. Furthermore, people with rheumatic diseases are often critical about waiting time when attending rheumatology outpatient clinics and about the co-ordination of care given by rheumatologists $[3,4]$.

People suffering from a chronic disease are often confronted with disabilities in their daily life and require help from several health care professionals in different settings [5]. Importance is therefore attached to communication, quality and continuity of care [6-9]. Consequently new forms of health care are being initiated in a number of countries to cope with demands for ongoing good quality care [10].

Dutch health care consists, traditionally, of a two-tiered system including both office-based primary care services, such as home care, and hospital-basedspecialty care services $[10,11]$. To bridge these two systems, 'transmural care' innovations have recently been implemented in The Netherlands.

'Transmural care' is defined as patient-tailored care provided on the basis of close collaboration and joint responsibility between hospitals and home care organizations [12]. One form of transmural care relates to transmural nurse clinics for people suffering from a rheumatic disease [13]; in 1996, 24 'transmural' nurse clinics were established in The Netherlands [13]. These clinics are often run by community nurses specializing in care for rheumatic patients. Most patients visiting a transmural nurse clinic are referred by their rheumatologist. The main activities of the specialist nurses at the clinics is to provide illness-related information and support patients in coping with the illness both practically and emotionally. Information can, for example, be given about how to acquire practical aids and adaptations for the living environment. Transmural rheumatology nurse clinics aim to improve quality and continuity of care [13]. For example, the quality of care could be improved because the rheumatologist who refers patients to the transmural nurse clinic now makes 
more use of the expertise of the specialist rheumatology nurse, and vice versa. The continuity of care is expected to be improved because the transmural nurse clinic is located at the same outpatient clinic at which the rheumatologist makes his consultations. Visits to the rheumatologist and the specialist nurse could thus be arranged on the same day [13].

The purpose of this study is to give insight into patient perceptions of the quality and continuity of care received at transmural nurse clinics, and also to give insight into specialist nurses' and rheumatologists' views about the positive and negative aspects of such clinics.

In this study, quality and continuity of care in transmural nurse clinics is defined as optimal, when patient perceptions of the clinics are at least congruent with their individual needs and expectations. Specialist nurses' and rheumatologists' views about transmural nurse clinics are defined as positive and negative factors experienced in the care process, related to quality and continuity of care.

The following research questions are addressed:

(1) are there, in the view of people with rheumatic diseases, quality or continuity of care aspects which need to be improved in Dutch transmural nurse clinics?

(2) what positive or negative factors, in the view of specialist rheumatology nurses and rheumatologists involved in Dutch transmural nurse clinics (such as organizational or social factors) had affected the quality or continuity of care?

\section{METHODS}

\section{Design and measurement points}

In order to answer the first research question, a quantitative research method was used. Patients were approached for a pre-structured telephone interview on two occasions during a 6 -week period. The first interview was conducted 1-4 days before patients attended a transmural nurse clinic (TO), and the second interview took place 6 weeks after their first contact at a transmural nurse clinic (T1). The telephone interviews were conducted by an independently trained pollster and lasted from about 20 to 40 minutes. To answer the second research question, a qualitative research method was used. The rheumatologists and specialist nurses, involved in the nurse clinics from which the patients were recruited for this study, were interviewed. The 
interviews lasted about 45 minutes and were tape recorded.

\section{Locations and sample}

The study was conducted at five locations in The Netherlands where transmural nurse clinics were operational. At all five locations, a home care institution and a general hospital collaborated closely and had joint responsibility for a transmural nurse clinic. All transmural nurse clinics were run in addition to the standard care of, for instance, rheumatologists, general practitioners and occupational therapists. The content of the five clinics was comparable.

The following patient inclusion criteria were used: (1) a diagnosis related to rheumatic disease (e.g. rheumatoid arthritis, osteoarthritis and others), (2) referral by a rheumatologist to a transmural nurse clinic, (3) no previous contacts with the specialist nurse, (4) ability to speak Dutch and (5) telephone access.

Permission for patient recruitment was obtained from ethical committees, the rheumatologists and specialist nurses. Patients who met the inclusion criteria were asked to participate by their rheumatologist. In addition to this direct request, patients were given an information letter in which the objectives and procedures of the study were explained. Those who chose to participate, gave their written consent and were approached for a telephone interview. The precise number of patients who refused to participate is not available; however, the rheumatologists and their assistants indicated that only in very exceptional cases did patients refuse to participate in the study beforehand (not more than one or two per location).

Between April 1996 and February 1998 a total of 144 people with rheumatic diseases were included in the study. Sixteen patients dropped out of the study for the following reasons: severity of illness or patient death $(n=8)$; patient refused to participate at the second time of measurement $(n=8)$. This means that information is available on 128 people with rheumatic diseases $(89 \%$ response).

Table 5.1 shows the background characteristics of the participating patients, which are comparable with the average Dutch population of people suffering from rheumatic diseases $[14,15]$. The mean age of the participating patients was 61 years, most of them had rheumatoid arthritis, were female, had primary education and most, despite their rheumatic disease, had adequate capacity for normal activities; class 2 in terms of Steinbröcker's classification 
[16]. The mean duration of patients' rheumatic disease was about 11 years and patients contacted the specialist nurse an average of one and a half times during the research period of 6 weeks (Table 5.1).

\section{Table 5.1 Background characteristics of participating patients at TO}

\begin{tabular}{|c|c|}
\hline & $\begin{array}{l}\text { People with rheumatic } \\
\text { diseases }(n=128)\end{array}$ \\
\hline Age (in years, mean (SD)) & $61.2(14.9)$ \\
\hline Gender (female) & $94(73 \%)$ \\
\hline Duration of complaints (years, mean (SD)) & $10.6(11.1)$ \\
\hline \multicolumn{2}{|l|}{ Kind of theumatic disease } \\
\hline Rheumatoid arthritis & $90(75 \%)$ \\
\hline Other & $30(25 \%)$ \\
\hline \multicolumn{2}{|l|}{ Functional impairment (Steinbröcker) } \\
\hline $\begin{array}{l}\text { Class I (complete functional capacity with ability to carry on all } \\
\text { usual duties without handicaps) }\end{array}$ & $8(6 \%)$ \\
\hline $\begin{array}{l}\text { Class II (functional capacity adequate to conduct normal activities } \\
\text { despite handicap of discomfort or limited mobility of one or } \\
\text { more joints) }\end{array}$ & $105(83 \%)$ \\
\hline $\begin{array}{l}\text { Class III (functional capacity adequate to perform only little or none } \\
\text { of the duties of usual occupation or of self care) }\end{array}$ & $11(9 \%)$ \\
\hline $\begin{array}{l}\text { Class IV (largely or wholly incapacitated with patient bedridden or } \\
\text { contined to wheelchair, permitting littie or no self care) }\end{array}$ & $2(2 \%)$ \\
\hline \multicolumn{2}{|l|}{ Level of education } \\
\hline Lower & $89(70 \%)$ \\
\hline Middle & $22(17 \%)$ \\
\hline Higher & $16(13 \%)$ \\
\hline \multicolumn{2}{|l|}{ Living situation } \\
\hline Alone & $24(19 \%)$ \\
\hline With others & $103(81 \%)$ \\
\hline $\begin{array}{l}\text { Number of contacts with the specialist nurse during the research period (mean } \\
\text { (SD)) }\end{array}$ & $1.4(0.7)$ \\
\hline
\end{tabular}

The background characteristics of patients who participated in the study were comparable with those who dropped out of the study. 
In addition, six specialist rheumatology nurses who run a transmural nurse clinic and four rheumatologists who referred rheumatics to transmural nurse clinics were interviewed. These professionals were all involved in the transmural nurse clinics from which patients were recruited for this study and are assumed to be representative of the 24 transmural nurse clinics for people with rheumatic diseases in The Netherlands.

\section{Variables and instruments}

In order to examine patients' perceptions of the quality of care, the Quality of Care Through the Patient's Eyes for rheumatic patients (QUOTE: RheumaticPatients) [4] was used. In the QUOTE procedure, at TO, patients are asked to rate the importance of 17 health care service indicators, e.g. 'health professionals should be conversant with my problems' (response range: 1 , unimportant; 2 , of little importance; 3, important; 4, extremely important). At $T 1$, patients were requested to rate the perceived performance on each indicator in their perception, e.g. 'the specialist nurse is conversant with my problems' (response range: 1 , no; 2 , not really; 3 , on the whole yes; 4 . yes). The instrument has been shown to be reliable (Cronbach's alpha $=0.92$ ) and was developed based on a literature review and focus group discussions with experts and patients [4]. Consequently, the validity of the QUOTE can be taken to be appropriate [4].

To examine patients' perceptions of the continuity of care, the Questionnaire on Continuity of care from the Clients' perspective (QCC) [17] was used. As for the QUOTE, in the QCC, at TO, patients were asked to rate the importance (response range: 1 , fully disagree; 2 , disagree; 3 , agree/disagree; 4 , agree; 5 , fully agree) and at $\mathrm{T} 1$ the perceived performance of 15 continuity health care service indicators (response range: 1 , no; 2 , not really; 3 , no/yes; 4 , on the whole yes; 5 yes). In order to assure the content validity, the QCC instrument was developed on the basis of a review of the literature, discussions in panel groups composed of clients and care providers and semi structured interviews with clients [16]. Furthermore, the QCC has been shown to be a reliable instrument for assessing the continuity of care from patient perspective [17]. Because of the difference in score range, the importance and performance scores of the QUOTE and QCC are incomparable.

To determine negative and positive factors (related to the quality or continuity of care) of transmural nurse clinics, the main questions posed in the interviews with rheumatologists and specialist nurses were: (1) what aspects of the clinic, related to the quality or continuity of care, were felt to be positive? 
(2) what aspects related to quality or continuity of care were felt to be negative in running the clinic? and (3) is it important to continue the clinic in future?

\section{Analyses}

For each indicator of both QUOTE and QCC questionnaire, average importance and performance scores and corresponding standard deviations were calculated to determine discrepancies between importance and performance scores. Mean ratio scores ( $R$ ) and standard deviations were then calculated for each indicator by dividing perceived performance scores (TI) by individual importance scores (TO) for every individual patient. Mean ratio scores of 1.0 or higher indicated a positive score on a specific indicator. Mean ratio scores below 1.0 indicated a negative score on a specific indicator. If, for instance, a patient rated the importance of an indicator with a score 3.0 and the performance with 2.0 , the ratio score of $0.67(2.0 / 3.0)$ indicated a negative score on that specific indicator.

The interviews with rheumatologists and specialist nurses were analysed using qualitative methods $[18,19]$. The tape recorded interviews were transcribed and stored in Kwalitan, a computer program for practical support in qualitative analyses [20]. All interview fragments which were related to the second research question, were given one or more keywords. The interview fragments were then grouped by keyword and compared with fragments with the same keywords. This comparison between interview fragments with the same keywords was facilitated by the Kwalitan program. The program provides an opportunity for selecting, grouping or printing qualitative material with simple computerized assignments. 


\section{RESULTS}

\section{Patients' perceptions of the quality of care}

Table 5.2 shows the importance, performance and ratio scores on the 17 quality indicators. It appears that people with a rheumatic disease who visit a transmural nurse clinic (at TO) attach great importance to most of these indicators. Patients rated indicator 4 , 'to be taken seriously by health professionals and institutions' of the highest importance, followed by indicator 1 , 'tell me what to do if I take other medication in addition to the prescribed ones'; 3 , 'buildings should be easily accessible for rheumatic patients' and 13 , 'health professionals are willing to learn about rheumatic patients' problems'.

Patients' experiences with transmural nurse clinics can be deduced from the performance scores in Table 5.2. The performance of transmural nurse clinics was, according to the patients, optimal on quality indicator 4 , 'take me seriously', 13 'be willing to learn about rheumatic patients' problems'; 14, 'pay attention to the psychosocial aspects of my illness' and 16, 'allow me to decide what help to get'. Patients' performance scores on the remaining quality indicators were also relatively positive.

The positive performance scores on the quality of care indicators are also reflected in the mean ratio scores, displayed in the right column in Table 5.2. All ratio scores are 1.0 or higher, which indicates that on all quality of care indicators, patients' perceptions of transmural nurse clinics are positive. 
Table 5.2 Patients' views on quality of care: importance scores, performance scores and ratio scores $(n=128)$

No. Indicator description

Importance scores
(mean, SD);
range 1-4

Performance scores
(mean, SD);

Ratio scores* (mean, SD)

Health professionals/the rheumatology nurse or health institutions should:

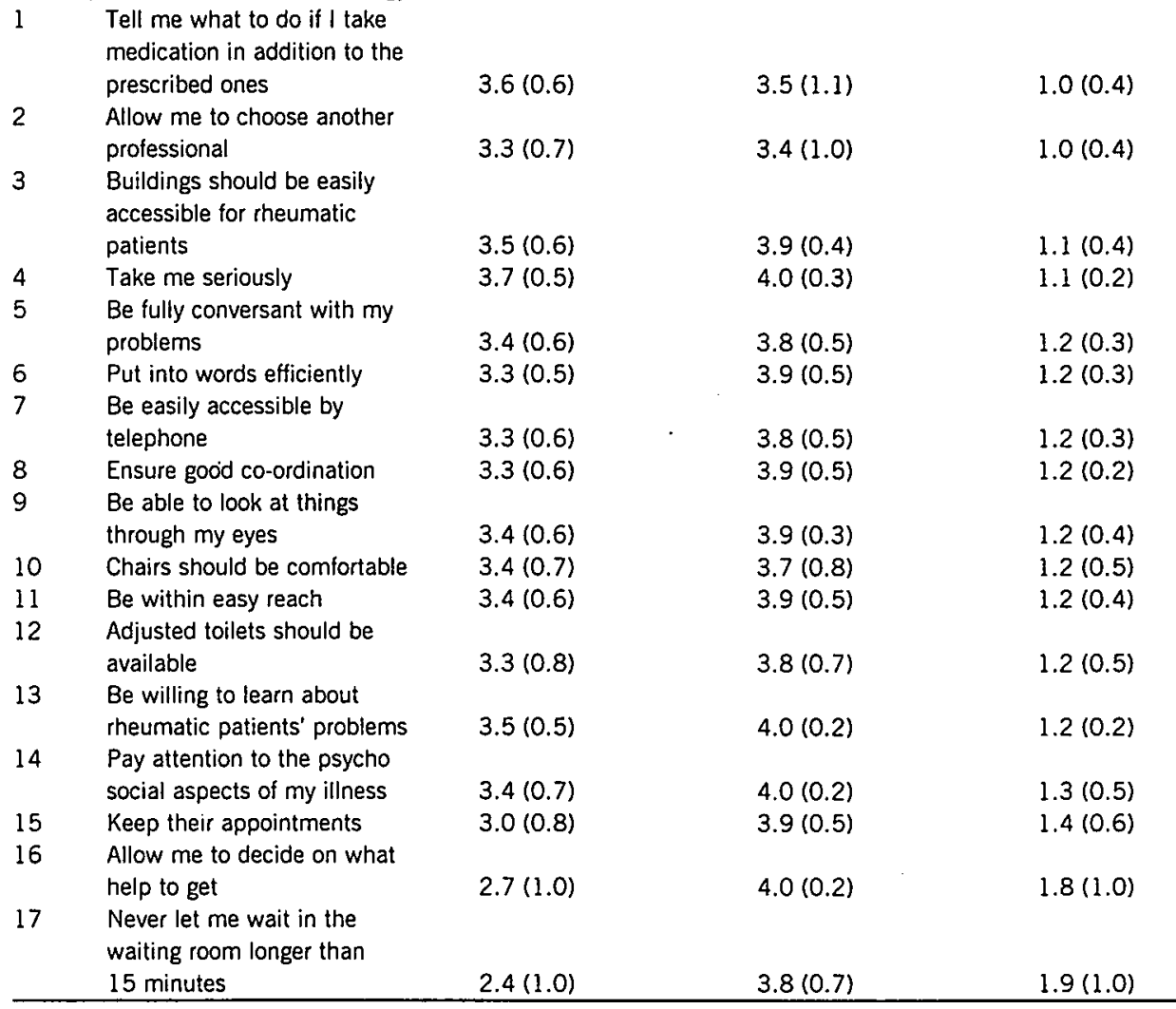

* $\quad R_{i j}=P_{i} / l_{11}$ The ratio $(R)$ on a health service (j) by an individual patient (i) is equal to the mean (perceived) performance score $(P)$ divideo by the mean importance score $(I)$. 


\section{Patients' perceptions of the continuity of care}

Table 5.3 shows indicators measuring the continuity of care, continuity importance scores, (perceived) performance scores and mean ratio scores for people with rheumatic diseases. It appears that patients who attended a transmural nurse clinic (TO) attached great importance to almost all continuity indicators. Rheumatics rated continuity indicator 3 , 'inform each other adequately about patients' situation'; 4 , 'adapt care when necessary in changing situations' and 7, 'cooperate with each other' as of the highest importance. Least important was indicator 15, 'visit patients at home when necessary'.

The experiences of continuity of care on the part of those suffering from rheumatic diseases can be deduced from the performance scores in Table 5.3. For almost all continuity indicators, the performance of the clinics was scored very positively. Highest performance scores were given to indicator 11 , 'give compatible advice' and 14; 'not provide care with too many different care providers'. Less positive performance scores were found at continuity indicator 1 , 'health professionals have a locum in case of absence'.

On most continuity indicators, the positive perceptions of the patients are reflected in the mean ratio scores. However, on indicator 1 , 'have a locum in case of absence'; 2, 'give sufficient information to the locum' and 3, 'adequate information on patients' situation' the mean ratio score is below 1.0. These low mean ratio scores indicate that the continuity of care in transmural nurse clinics could be improved on these aspects, according to the patients in this study. 
Table 5.3 Patients' view on continuity of care: importance scores, performance scores and ratio scores $(n=128)$

\begin{tabular}{|c|c|c|c|c|}
\hline No. & Indicator description & $\begin{array}{l}\text { Importance scores } \\
\text { (mean, SD); } \\
\text { range } 1-5 \text { * }\end{array}$ & $\begin{array}{l}\text { Performance scores } \\
\text { (mean, SD); } \\
\text { range } 1-5\end{array}$ & $\begin{array}{l}\text { Ratio } \\
\text { scores } \\
\text { (mean, SD) }\end{array}$ \\
\hline
\end{tabular}

Health professionals/the rheumatology nurse should:

1 Have a locum in case of

absence

$4.5(1.1)$

$3.2(1.9)$

$0.7(0.4)$

2 Give sufficient information to the locum

$\begin{array}{lll}4.8(0.6) & 4.6(0.8) & 0.9(0.2)\end{array}$

3 Inform each other adequately

about patients' situation

$\begin{array}{lll}4.9(0.2) & 4.2(1.7) & 0.9(0.4)\end{array}$

$4 \quad$ Adapt care when necessary in

changing situations

$\begin{array}{lll}4.9(0.5) & 4.8(0.7) & 1.0(0.2)\end{array}$

5 Provide care immediately

during emergencies

$4.8(0.5)$

$4.7(0.9) \quad 1.0(0.2)$

$4.8(0.5)$

$4.7(0.8)$

$1.0(0.3)$

$4.9(0.4)$

$4.5(0.9)$

$1.0(0.3)$

Cooperate with each other

$4.6(0.8)$

$4.6(0.9)$

$1.1(0.7)$

Be accessible by telephone

$4.7(0.7)$

$4.8(0.7)$

$1.1(0.6)$

10 Refer me to another care provider when necessary

$4.6(0.9)$

$4.8(0.9)$

$1.1(0.2)$

$4.5(1.0)$

$4.9(0.7)$

$1.2(0.7)$

12 Keep to the time of appointment

$4.3(1.0)$

$4.8(0.8)$

$1.3(0.9)$

13 Not cancel an appointment without reason

$4.5(1.1)$

$4.8(0.8)$

$1.3(1.0)$

14 Not provide care with too many different care providers

15 Visit patients at home when

$4.6(1.0)$

$4.9(0.5)$

$1.3(0.9)$ necessary

$3.9(1.3)$

$4.8(0.6)$

$1.8(1.3)$

The final version of the QCC does not contain importance indicators. Despite this, the authors chose to use importance scores because this gives the opportunity for giving practical advice to improve the continuity of care in transmural nurse clinics.

** $\quad R_{n}=P_{1} / /_{17}$ The ratio ( $R$ ) on a health service (j) by an individual patient (i) is equal to the mean (perceived) performance score $(\mathrm{P})$ divided by the mean importance score (1). 


\section{Positive factors regarding quality and continuity of care}

Both specialist rheumatology nurses and rheumatologists are positive about the quality and continuity of care provided in the transmural nurse clinic involved. The patient option to acquire additional information during a contact at the clinic and the available time at a nurse clinic are mentioned as particularly positive factors.

'During my medical rheumatology outpatient clinic, I can prescribe practical aids. In addition to a prescription, it can be meaningful for patients to give additional information about how and when to use the aids prescribed. At the transmural nurse clinic, the specialist nurse has the opportunity and time to give such information.'

According to the nurses and rheumatologists interviewed, patients view nurses as more accessible than rheumatologists. Patients may therefore discuss problems (like problems at work, sexual problems or the use of alternative care) more easily with the specialist nurse and the nurse is able to draw a more complete picture of patient care problems. This was felt to be a positive factor in the clinics. As a result of the transmural character of the clinics, in which home care organizations and hospitals work in a more integrated way, nurses have the option of following patients in several care settings (e.g. hospital and home care). This leads, in the view of the interviewees, to a more continuous nursing care process. In addition to this, the transmural character of the clinics leads to a more continuous interdisciplinary care process because the nurses who run the clinics have short lines of communication to care professionals in different settings.

The short lines from the specialist nurse to me, as a rheumatologist, and other health care professionals are an advantage of the clinic. It makes the total care process much more clear and I understand patients better when they tell me they feel worse, but I cannot find physical grounds.'

\section{Negative factors regarding quality and continuity of care}

Some negative or inhibiting factors relating to the quality and continuity of the care given in transmural nurse clinics were also mentioned by the interviewees. Three of the six specialist nurses and three of the four rheumatologists interviewed argued that the quality and continuity of care in a transmural nurse clinic would be improved if more nursing staff jobs were available. Often only one specialist nurse was available to run the clinic. In case of illness or holidays this was an inhibiting factor.

The rooms in which the clinics were held were said to be as unsuitable by the 
nurses interviewed. These particular rooms did not have windows or were also used by other professionals, which meant the specialist nurse had to bring her materials for every clinic. One nurse also mentioned that her room was not in the rheumatology outpatient clinic itself, but some way away from the medical outpatient clinic.

Despite the inhibiting factors experienced by specialist nurses and rheumatologists, all nurses and rheumatologists agreed that the positive factors of transmural nurse clinics were more important. Consequently, they all wanted to continue with the clinics in future.

\section{CONCLUSIONS AND DISCUSSION}

In The Netherlands 'transmural' nurse clinics for people with rheumatic diseases are being set up as a new form of health care. In these clinics, patient-tailored care is provided on the basis of close collaboration and joint responsibility between generalist primary care and specialist hospital care professionals. This article gives insight into patient perceptions about the quality and continuity of care received at transmural nurse clinics. In addition, views of professionals about these clinics are described.

Patient views on the quality and continuity of care have often been assessed by means of post-measurement patient satisfaction questionnaires only. However, such questionnaires often produce highly skewed scores $(90 \%$ or more of the respondents are satisfied) and absolute scores unrelated to respondents' individual levels of expectations and needs [4]. Apparently, the validity of the instruments used is often inadequate [21].

In this study we tried to overcome this difficulty by defining quality and continuity of care as optimal when patients' perceptions of the quality and continuity of clinics were at least congruent with their individual needs and expectations. Within this framework, validated and reliable measurement instruments (QUOTE and QCC) were used which scored not only patient's experiences, but also their needs and expectations. By using this method of pre- and post-measurement, a more valid insight into the quality and continuity of care can be given than by using information concerning patients' experiences only. Furthermore, both QUOTE and QCC questionnaires are specific enough to give direction to daily nursing practice. The results of this study show which aspects of quality and continuity can be used to improve 
transmural nurse clinics.

In general, patients in this study gave the quality and continuity of care in transmural nurse clinics a very positive rating. Only some continuity of care aspects were shown to be relevant for future improvement of transmural nurse clinics. Patients reported fewer positive experiences with regard to the availability of a locum in case of the absence of the specialist nurses and in giving sufficient information about patients' situation to a locum specialist nurse and other professionals, like the rheumatologist. Patients' less positive experience with the latter is at odds with the goals of transmural nurse clinics. It is assumed that rheumatologists and specialist rheumatology nurses involved in transmural nurse clinics work closely together and will therefore give each other the information required on the patients' situation. The aspects experienced as less positive by the patients are subjects which need special attention in the further continuation of transmural nurse clinics.

Patients' positive perceptions appeared to be comparable with those of professionals. Both nurses and rheumatologists agree that transmural nurse clinics are a positive innovation because patients get additional information at the clinics, nurses are (compared with rheumatologists) more approachable for patients and the transmural character stimulates inter- and intra-disciplinary co-operation. However, professionals also deal with some inhibiting factors in running transmural nurse clinics (e.g. the room available, limited staffing). It is to be supposed that, in dealing with these inhibiting factors, the positive influence of transmural nurse clinics will be strengthened. It is therefore recommended that in future transmural nurse clinics these preconditions be considered before setting up a clinic in practice.

\section{Limitations of the study}

A choice made in the design of this study is the 6-week period between measuring patients expectations and experiences. In interpreting the results of this study, it should be borne in mind that if this research period were extended to, for example, 6 months, it is possible that other results will be found. For instance, it seems plausible that in a 6 -month period, the relationship between the patient, the specialist nurse and other care professionals might be closer as they would have had more contact compared with the 6 -week period. This closeness of the care relationship might result in different perceptions of patients about the quality and continuity of care received. 
As a result of the character of the questionnaires used, this study does not give insight into differences between patients who were able and patients who were not able to attend a transmural nurse clinic. In the questionnaires used, indicators referring to the quality and continuity of care were often directed at the performance of the rheumatology nurse. Control patients who cannot attend a transmural nurse clinic cannot answer such indicators. However, the experiences of people with rheumatic diseases attending Dutch transmural nurse clinics in this study can be compared with patients' experiences with the standard care given by a rheumatologist in other studies. In the Dutch study of Van Campen et al. [4] the QUOTE questionnaire, which was used in this study, was developed and validated. On the basis of this study, it was concluded that people with rheumatic diseases often had negative experiences with the waiting time for an appointment at the rheumatology outpatient clinic. They also concluded that patients felt rheumatologists' co-ordination of care was less positive. Hill et al. [3], on the basis of a study in which both a premeasurement and a control group were lacking, drew comparable conclusions. In the Swedish cross-sectional study performed by Bendtsen and Bjurulf [1] both patient expectations and experiences concerning the care provided were measured. On the basis of this latter study, it was concluded that almost $20 \%$ of the patients indicated that physicians were not easily accessible [1]. Compared with these negative experiences in other comparable studies, patients' experiences in this study are very positive. It therefore can be concluded that Dutch transmural nurse clinics, to a large extent, meet the demands of those suffering from rheumatic diseases, for continuous care of sound quality. 


\section{REFERENCES}

[1] Bendtsen P, Bjurulf P. Perceived needs and patient satisfaction in relation to care provided in individuals with rheumatoid arthritis. Qual Assur Health Care 1993; 5: 243-253.

[2] Daltroy LH. Doctor-patient communication in rheumatological disorders. Baillieres Clin Rheumatol 1993; 7: 221-239.

[3] Hill J, Bird HA, Hopkins R, Lawton C, Wright V. Survey of satisfaction with care in a rheumatology outpatient clinic. Ann Rheum Dis 1992; 51: 195-197.

[4] van Campen C, Sixma HJ, Kerssens JJ, Peters L, Rasker JJ. Assessing patients' priorities and perceptions of the quality of health care: the development of the QUOTE-Rheumaticpatients instrument. Br J Rheum 1998; 37: 362-368.

[5] Bos, van den GAM. The burden of chronic diseases in terms of disability, use of health care and healthy life expectancies. Eur J Public Health 1995; 5; 29-34.

[6] Silvers IJ, Hovell MF, Weisman MH, Mueller MR. Assessing physician/patient perceptions in rheumatoid arthritis. Arthritis Rheum 1985; 28: 300-307.

[7] Smith $\mathrm{CH}$, Armstrong D. Comparison of criteria derived by government and patients for evaluating general practitioner services. BMJ 1989; 299: 494-496.

[8] Samuelsson A, AhImén M, Sullivan $M$. The rheumatic patient's early needs and expectations. Pat Educ Couns 1993; 20: 77-91.

[9] Waal van der MAE, Casparie AF, Lako CJ. Quality of care: a comparison of preferences between medical specialists and patients with chronic diseases. Soc Sci Med 1996; 42 : 643-649.

[10] Temmink D, Francke AL, Hutten JBF, Zee van der J, Huyer Abu-Saad H. Innovations in the nursing care of the chronically ill: a literature review from an international perspective. Journal of Advanced Nursing 2000;31(6):1449-1458.

[11] Linden, van der BA. Transmural care. Facts and future. In: Health and health care in the Netherlands. Utrecht: De Tijdstroom, 1997; 181-188.

[12] Nationale Raad voor de Volksgezondheid \& College voor Ziekenhuisvoorzieningen. Transmurale somatische zorg: Advies van de Nationale Raad voor de Volksgezondheid en het College voor Ziekenhuisvoorzieningen [Somatic Transmural Care: Advice of the National Council for Public Health and National Board for Hospital Facilities] (in Dutch). Zoetermeer: NRV/CVZ, 1995. 
[13] Temmink D, Francke AL, Kerkstra A, Huyer Abu-Saad H. Dutch transmural nurse clinics for chronic patients: a descriptive study. Pat Educ Couns 2000; 39:177-184.

[14] Ministerie van Welzijn, volksgezondheid en cultuur. Reumabeleid [Rheumatology Policy] (in Dutch). Den Haag: SDU-uitgeverij, 1989.

[15] Taal E, Seydel ER, Rasker JJ, Wiegman O. Psychosocial Aspects of Rheumatic Diseases: Introduction. Pat Educ Couns 1993; 20: 55-61.

[16] Steinbröcker $\mathrm{O}$, Traeger $\mathrm{CH}$, Batterman RC. Therapeutic criteria in rheumatoid arthritis. The Jour Am Med Ass 1949; 140: 659-662.

[17] Casparie AF, Foets M, Raaijmakers MF, Bakker DH de, Schneider MJ, Sterkenburg PS, Janssen CGC, Bijman-Schulte AM, Bakker RH, Moorer P, Dassen THWN, Suurmeijer NCG . Vragenlijst Continuiteit van zorg vanuit Cliëntperspectief (VCC) Handleiding en vragenlijsten. [Questionnaire continuity of care from the clients' perspective] (in Dutch) Utrecht/Amsterdam/Groningen: NIVEL, VU, RUG, 1998.

[18] Miles MB, Huberman AM. Qualitative data analysis. An sourcebook of new methods. Beverly Hills: SAGE Publications, 1984.

[19] Miles MB, Huberman AM. Qualitative data analysis. An expanded sourcebook (second edition). Newbury park: SAGE, 1994.

[20] Peters V, Wester F, \& Richardson R. Kwalitatieve analyse in de praktijk en handleiding bij Kwalitan [Qualitative analyze in practice and manual for Kwalitan] (in Dutch). SWI-reeks. Nijmegen: Katholieke Universiteit Nijmegen, 1989.

[21] Wensing $M$, Grol R, Smits A. Quality judgements by patients on general practice care: a literature analysis. Soc Sci Med 1994; 38: 45-53. 


\section{CONTENT AND OUTCOMES OF DUTCH NURSE CLINICS FOR CHILDREN WITH ASTHMA}

D. Temmink, A.L. Francke, J.B.F. Hutten, P. Spreeuwenberg,

J. van der Zee, H. Huijer Abu-Saad

Journal of Asthma (in press)

\section{ABSTRACT}

Dutch specialist asthma nurses run 'extramural' and 'transmural' nurse clinics for children with asthma. Extramural clinics are run under the responsibility and in the premises of a home care organization. Transmural clinics are run in an outpatient clinic in close collaboration and joint responsibility between home care organizations and hospitals. Effects of and differences between these clinics were determined using a quasi-experimental design. Visiting a nurse clinic appears to result in a reduced information need and use of health care services. Parents of asthmatic children visiting transmural nurse clinics appeared to have a lower information need than those attending extramural nurse clinics.

Keywords: children with asthma - health care utilisation - information needs - patient education - nursing care - nurse clinics 
chapter 6

108 


\section{INTRODUCTION}

In the Netherlands, there are a growing number of nurses who have a specific focus on care for asthmatic children [1,2]. These nurses are often employed by home care organizations and one of their tasks is to run nurse clinics for such children. In these clinics, specialist nurses provide illness-related information about topics such as inhaler techniques and asthma preventers and relievers.

Dutch health care is, traditionally a two-tiered system including both officebased primary care services, like home care, and hospital-based specialty care services $[3,4]$. In keeping with this health care system, nurse clinics in the Netherlands are implemented in both home care and hospital. 'Extramural' nurse clinics have a rather long tradition in Dutch health care and are run at the responsibility and in the premises of a home care organization. So-called 'transmural' nurse clinics are more recent and have been implemented in Dutch hospital outpatient departments in the last five years. In 1996, eleven of such clinics were established in the Netherlands [5]. In transmural nurse clinics, care is provided on the basis of close collaboration and joint responsibility between home care organizations and hospitals [5].

Implementing transmural nurse clinics, depends to a large extent on the existing health care facilities for children with asthma. Regions in which extramural nurse clinics are operational, will not establish transmural nurse clinics as well. However, in regions where there are no nurse clinics for asthmatic children, a transmural nurse clinic may be established due to the current interest in transmural care innovations in the Dutch health care system.

Despite the organizational differences between extramural and transmural nurse clinics, both kinds of clinics have comparable objectives. Extramural and transmural nurse clinics aim to provide asthmatic children and their parent's with information on, for instance, how to deal with asthma in daily life or how to use the medication.

In the United Kingdom and Ireland, nurse clinics for asthmatics have also been established. [6-12]. These clinics are often implemented in general practice and are, just like Dutch extramural and transmural nurse clinics, 
primarily designed to provide patients with information about how to deal with their complaint in daily life.

Several studies generally record a positive impact when providing education to asthmatics. For instance, Taggart et al. [13] using a quasi-experimental design, evaluated an inpatient hospital-based self-management education program comprising written and audio-visual materials and interpersonal communication with a nurse. This study showed that inpatient hospital-based education reduces asthmatic children's use of health care services. A quasiexperimental evaluation study by Pérez et al. [14] showed that a selfmanagement education program, (with separate sessions for parents and asthmatic children) given by a (nurse) allergy specialist in the hospital, resulted in significant positive effects on children's and parents' asthma knowledge.

Whether the comparable objectives of Dutch transmural and extramural nurse clinics translate into comparable patients attending the clinics and comparable content in the nursing care provided, remains unclear. Furthermore, it is doubtful whether the positive results of asthma education programs in general, also apply to asthma nurse clinics. Nurse clinics run by specialist asthma nurses are regarded as providing more time and opportunity for patients to increase their knowledge of the disease $[6,11]$. In addition, attending a nurse clinic is expected to reduce asthmatic children and their parents' use of health care services. The number of contacts with general practitioners, for example, might be reduced following attendance at a nurse clinic. However, reliable insight in the content and effectiveness of asthma nurse clinics on patients' need for information and their use of health care services, is lacking $[6,10]$. Moreover, there is no evidence as to the preferred organizational structure for nurse clinics $[6,15]$.

Consequently, the aim of this study is to explore differences in children attending the clinics and differences in the content of care given by Dutch specialist nurses running the transmural or extramural clinics. The effects of visiting such a clinic on (parents of) asthmatic children's need for asthmarelated information and their use of health care services are also determined. Finally, this study explores differences in outcomes between Dutch extramural and transmural nurse clinics. 
The following research questions are addressed in this article:

1. Do transmural and extramural nurse clinics differ with regard to the characteristics of the attending asthmatic children and their parents?

(e.g. age, gender, duration of complaints, severity of asthma and level of education)

2. Do transmural and extramural nurse clinics differ with regard to the nursing care provided (e.g. referral to the clinic, number and duration of contacts, care demands and activities)?

3. What is the effect of visiting a nurse clinic on (parents of) asthmatic children:

- $\quad$ need for asthma-related information?

- $\quad$ use of health care services, more specifically:

- $\quad$ the number of contacts with other health care professionals?

- the number of admissions in hospitals and other institutions?

4. Is there a difference in outcomes between transmural and extramural nurse clinics with regard to: parents' need for asthma-related information and asthmatic children's use of health care services?

\section{METHODS}

\section{Design and measurement points}

In order to answer the research questions a pretest-post test, non-randomized control group design was used. Two groups of parents ${ }^{*}$ participated in the study. The first group comprised parents who attended a transmural nurse clinic; while the other group comprised parents who attended an extramural nurse clinic. Both groups were approached for three telephone interviews within six months. The first telephone interview with parents was conducted one to four days before parent and child were to attend a nurse clinic (TO). The second interview took place six weeks after their first appointment at the nurse clinic (T1), while the third interview was conducted six months after their first appointment at the nurse clinic (T2). The duration of the telephone interviews ranged from about fifteen to thirty minutes.

* The term 'parent' will be used further to indicate both asthmatic children and their parents. 


\section{Locations and sample}

The study was conducted at six locations in the Netherlands. At four of the locations, a home care organization and a hospital collaborated closely and had joint responsibility for a transmural nurse clinic. All four transmural nurse clinics were held at a hospital outpatient department by specialist asthma nurses who were employed by a home care organization. At two of the locations (each with three sub-locations) six extramural nurse clinics for asthmatic children were held by specialist asthma nurses who were also employed by a home care organization. The home care organization bore the sole responsibility for the extramural clinics.

The following inclusion criteria were used in this study: 1 . the child has a diagnosis of Chronic Non Specific Lung Diseases (e.g. asthma or Chronic Obstructive Pulmonary Disease, COPD), 2. the child is under fourteen. 3. parents and child have had no previous contact with a specialist asthma nurse 4. at least one parent is able to speak Dutch and 5. there is telephone access.

Permission for patient recruitment was obtained from ethical committees and the professionals involved. Parents who met the inclusion criteria were invited to participate in the study by the secretariat of the particular clinic, at the time they made an appointment at the clinic. In addition to this direct request, the parents were given an information letter in which goals and procedures of the study were explained. Those who chose to participate, gave their written consent and were approached for a telephone interview.

Between April 1996 and February 1998 a total of 237 respondents were included in the study; 152 attended a transmural nurse clinic and 85 attended an extramural nurse clinic. Thirteen of the 152 parents attending a transmural nurse clinic and twenty-two of the 85 parents attending an extramural nurse clinic dropped out of the study. The reasons for dropping out were: they did not want or could not be interviewed by telephone for post-test measurement $(n=18)$; it appeared that parents had not attended the clinic during the study $(n=14)$; illness or other family circumstances $(n=3)$. Consequently, information is available about 139 (91\% response) and 63 parents ( $74 \%$ response) attending a transmural or extramural nurse clinic respectively. 
Variables and instruments

During the first measurement (TO) the following background characteristics of parents and their asthmatic children were gathered: age and gender, duration of the child's asthma-related complaints, gender and educational level of the parent (see Table 6.1).

During the research period of six months, specialist asthma nurses running either a transmural or extramural nurse clinic, filled in a registration form for each child. The specialist nurse registered information on the content of the nursing care provided, namely the referral to the nurse clinic, the number and duration of contacts with the child and parent, care demands made upon the nurse and the nursing carried out (see Table 6.2).

The severity of the child's asthma was registered by the nurse during the first contact with the child. Following Van Es [16], four categories based on the degree of exacerbation, the prescribed amount and type of medication, were used: mild (stable with less than six levels of exacerbation annually), moderate (stable with $\leq 400 \mu \mathrm{g}$ inhaled corticosteroids per day), severe ( $>400 \mu \mathrm{g}$ inhaled corticosteroids per day) or the severity is not known by the nurse (see Table 6.2).

To gain insight into parents' need for asthma-related information, at all measurements, parents were asked about the topics for which they required asthma-related information. The response categories used in this question are displayed in Table 6.3.

To determine asthmatic children's use of health care facilities, parents were asked at $\mathrm{TO}$ and $\mathrm{T} 2$ to rate their child's number of asthma-related contacts with health care professionals (general practitioner, physiotherapist or paediatrician) during the last six months. Parents were also asked to give the number of times their child had been admitted to hospital or other health care institutions during the last six months. Reason for not asking this question at T1 was that changes in patients' use of health care facilities could not be expected in the six weeks period between TO and T1.

\section{Analyses}

Differences between the two groups in patient characteristics (Table 6.1) and the content of the care provided (Table 6.2) were determined by using Student's t-test for continuous data, Chi-square test for nominal data and Mann-Whitney test for ordinal data.

To determine differences between measurements and research groups in information needs and use of health care facilities, multiple linear regression analyses and MANCOVAs for repeated measures were used for continuous data. Since multiple linear regression analyses and MANCOVAs showed 
comparable results, only the output of linear regression analysis will be reported in this article. Dichotomous data was analysed by using multiple logistic regression analyses. In all analyses differences between the two groups and measurements were tested after controlling for children's and parents' background characteristics as displayed in Table 6.1 and interaction terms between measurements and condition.

\section{RESULTS}

\section{Patient characteristics}

Table 6.1 shows that the two groups were comparable in most patient characteristics. The children had a mean age of five years, $60 \%$ were male and the mean duration of the disease was three years in both groups. Most of the parents had primary or secondary education, $95 \%$ were female. A significant difference in the severity of children's asthma was found between the two groups. Children attending an extramural nurse clinic appeared to have less severe asthma than children attending a transmural nurse clinic. Furthermore it appeared that nurses running an extramural nurse clinic more frequently did not know the severity of the child's asthma (Table 6.1).

\section{Nursing contacts}

The person who referred children to the specialized nurse was significantly different for the two groups. Most of the parents attending a transmural nurse clinic were referred by a paediatrician, while parents attending an extramural nurse clinic were referred by either their paediatrician, a general practitioner or had contacted the nurse on their own initiative (Table 6.2).

As regards the mean number of contacts between parents and specialist nurses, no significant difference was found. Parents in both groups contacted the specialist nurse more than twice on average (Table 6.2). However, the duration of these contacts appeared to be significantly longer in the extramural situation. Parents attending a transmural nurse clinic visited the specialist nurse for forty minutes on average, while for parents attending an extramural nurse clinic this duration was more than fifty minutes on average. 
Table 6.1 Background characteristics of parents and their children in both research conditions ${ }^{1}$

\begin{tabular}{|c|c|c|c|}
\hline & $\begin{array}{l}\text { Transmural condition } \\
(n=139)\end{array}$ & $\begin{array}{l}\text { Extramural condition } \\
(n=63)\end{array}$ & $p$ \\
\hline Age child in years ${ }^{2}$ & $4.5(3.1)$ & $5.1(3.5)$ & n.s. \\
\hline Gender child (male) & $81(58 \%)$ & $36(57 \%)$ & nis. \\
\hline Gender parent (female) & $131(94 \%)$ & $56(89 \%)$ & n.s. \\
\hline Duration of complaints in years ${ }^{2}$ & $2.7(2.3)$ & $3.3(2.9)$ & n.s. \\
\hline Severity of asthma: & & & * \\
\hline mild & $13(9 \%)$ & $11(17 \%)$ & \\
\hline moderate & $71(51 \%)$ & $18(29 \%)$ & \\
\hline severe & $45(32 \%)$ & $3(5 \%)$ & \\
\hline unknown & $1(1 \%)$ & $26(41 \%)$ & \\
\hline Level of education parent: & & & n.s. \\
\hline lower & $60(43 \%)$ & $24(38 \%)$ & \\
\hline middle & $59(42 \%)$ & $29(46 \%)$ & \\
\hline higher & $19(14 \%)$ & $10(16 \%)$ & \\
\hline
\end{tabular}

'Missing values: Age child in years ( 1 in transmural group, 4 in extramural group), Gender child ( 4 in transmural group, 1 in extramural group), Gender parent ( 3 in transmural group, 1 in extramural group), Duration of complaints (10 in transmural group), Severity of asthma ( 9 in transmural group, 5 in

2 Mean (sd) extramural group), Level of education parent ( 1 in transmural group).

n.s. not significant

* $p \leq 0.05$

Both similarities and differences between the two groups were found with regard to the care demands made upon the specialist nurses. In both groups parents made more than one care request relating to their living environment, for example: Do we have adequate curtains or bedcovers in my child's bedroom. However, it appeared that parents attending a transmural nurse clinic made significantly more frequent care demands relating to the use of medication, dealing with asthma in daily life (for instance during holidays or at school) and smoking (Table 6.2). 
chapter 6

Table 6.2 Content of the nursing care provided in transmural and extramural nurse clinics

\begin{tabular}{llll}
\hline & $\begin{array}{l}\text { Transmural } \\
\text { condition } \\
(n=139)\end{array}$ & $\begin{array}{l}\text { Extramural } \\
\text { condition } \\
(n=63)\end{array}$ & $p$ \\
\hline
\end{tabular}

Referral to the nurse clinic:

$$
\begin{aligned}
& \text { paediatrician } \\
& \text { general practitioner } \\
& \text { contacted on own } \\
& \text { initiative }
\end{aligned}
$$

Number of contacts per child

$(M, S d)$

Duration of contacts in minutes

(M, Sd)

Topics of care demands posed to the nurse $(M, S d)$ :

$\begin{array}{llll}\begin{array}{l}\text { living } \\ \text { environment/housing } \\ \text { improvement }\end{array} & 1.6(0.7) & 1.5(0.8) & \text { n.s. } \\ \begin{array}{l}\text { medication use } \\ \text { dealing with asthma }\end{array} & 1.8(0.7) & 1.0(0.8) & \text { * } \\ \text { smoking } & 0.9(0.8) & 0.5(0.8) & \text { * } \\ \text { family situation } & 0.4(0.8) & 0.3(0.5) & \text { n.s. } \\ \text { others } & 0.4(0.7) & 0.4(0.8) & \text { n.s. }\end{array}$

Care activities at the nurse clinic $(\mathrm{M}, \mathrm{Sd})$ :

\begin{tabular}{llll} 
education/advice & $2.0(0.6)$ & $1.8(0.8)$ & n.s. \\
psycho-social support & $1.5(1.0)$ & $0.6(0.9)$ & $\star$ \\
history taking & $1.0(0.7)$ & $1.0(0.6)$ & n.s. \\
others & $0.07(0.3)$ & $0.06(0.3)$ & n.s. \\
\hline
\end{tabular}

${ }^{\star} p \leq 0.05$

n.s. not significant 
With respect to the care activities of the specialist nurses, it was found that nurses running transmural nurse clinics more often provided psycho-social support to parents and their children compared to those running extramural nurse clinics (Table 6.2).

\section{Need for asthma-related information}

Table 6.3 shows that $62 \%$ of the total number of parents participating, indicated at TO, that they needed some kind of additional information about asthma. This percentage decreased during the research period to $23 \%$ at $\mathrm{T} 1$ and decreased further to $10 \%$ at T2. Topics about which parents needed more information included, for example, how to request practical aids or adaptations, asthma itself or how to handle their child's asthma in daily life. The mean number of asthma-related topics mentioned by the total group of parents at TO was 1.3, while this mean number declined at T1 and T2 to 0.3 and 0.2 respectively.

Logistic regression analysis showed that the differences in time with respect to parents' need for information about requesting practical aids or adaptations, asthma in general, asthma in daily life and the use of medication were significant (Table 6.3). Logistic regression analysis also indicated a significant difference between parents in the two conditions, with respect to their need for information about requesting practical aids or adaptations in the living environment and information about asthma in general. Parents who attended a transmural nurse clinic reported significantly fewer needs concerning this kind of information.

Furthermore, regression analyses showed that the total number of topics about which parents needed information was significantly lower for parents in the transmural group (Table 6.5). 
Table 6.3 Information needs of parents at T0, T1 and T2 for the two conditions separate and for the total group

\begin{tabular}{|c|c|c|c|c|c|c|c|c|c|}
\hline & \multicolumn{3}{|c|}{$\begin{array}{l}\text { Transmural condition } \\
\qquad(n=139)\end{array}$} & \multicolumn{3}{|c|}{$\begin{array}{l}\text { Extramural condition } \\
\qquad(n=63)\end{array}$} & \multicolumn{3}{|c|}{$\begin{array}{l}\text { Total group } \\
(n=202)\end{array}$} \\
\hline & TO & $\mathrm{T} 1$ & $\mathrm{~T} 2$ & TO & $\mathrm{T} 1$ & $\mathrm{~T} 2$ & ro & $\mathrm{Tl}$ & $\mathrm{T} 2$ \\
\hline $\begin{array}{l}\text { Need for some kind of } \\
\text { information about asthma } \\
\end{array}$ & $55 \%$ & $25 \%$ & $9 \%$ & $76 \%$ & $19 \%$ & $13 \%$ & $62 \%$ & $23 \%{ }^{*}$ & $10 \% *$ \\
\hline Need for information about: & & & & & & & | & & \\
\hline $\begin{array}{l}\text { Requesting practical } \\
\text { aids/adaptations }\end{array}$ & $27 \%$ & $10 \%$ & $2 \%$ & $54 \%$ & $11 \%$ & $5 \%$ & $36 \%$ & $10 \% *$ & $3 \% *$ \\
\hline Asthma in general $\diamond$ & $22 \%$ & $4 \%$ & $3 \%$ & $41 \%$ & $3 \%$ & $5 \%$ & $28 \%$ & $4 \%^{\star}$ & $4 \% *$ \\
\hline Asthma in daily life & $33 \%$ & $4 \%$ & $4 \%$ & $19 \%$ & $2 \%$ & $3 \%$ & $29 \%$ & $3 \%{ }^{\star}$ & $4 \% \star$ \\
\hline Medication use & $17 \%$ & $8 \%$ & $4 \%$ & $19 \%$ & $0 \%$ & $2 \%$ & $18 \%$ & $5 \%$ & $4 \% *$ \\
\hline Side-effects of medication & $5 \%$ & $2 \%$ & $1 \%$ & $10 \%$ & $0 \%$ & $0 \%$ & $6 \%$ & $2 \%$ & $1 \%$ \\
\hline Other & $12 \%$ & $5 \%$ & $1 \%$ & $19 \%$ & $6 \%$ & $2 \%$ & $14 \%$ & $5 \% *$ & $1 \% *$ \\
\hline $\begin{array}{l}\text { Total number of topics } s, \varepsilon, \\
\Theta(M, S d)\end{array}$ & $\begin{array}{l}1.2 \\
(1.3)\end{array}$ & $\begin{array}{c}0.3 \\
(0.6)\end{array}$ & $\begin{array}{c}0.2 \\
(0.6)\end{array}$ & $\begin{array}{r}1.6 \\
(1.5)\end{array}$ & $\begin{array}{c}0.2 \\
(0.5)\end{array}$ & $\begin{array}{c}0.2 \\
(0.4)\end{array}$ & $\begin{array}{c}1.3 \\
(1.4)\end{array}$ & $\begin{array}{l}0.3^{*} \\
(0.6)\end{array}$ & $\begin{array}{l}0.2^{\star} \\
(0.5)\end{array}$ \\
\hline
\end{tabular}

\footnotetext{
$\mathrm{p}<0.05$ in comparing $\mathrm{T} 1$ or $\mathrm{T} 2$ with T0 for the total group main effect of condition $p<0.05$ interaction effect condition $* 1<0.05$ interaction effect condition ${ }^{\star} T 2<0.05$
}

\section{Use of health care services}

Table 6.4 displays childrens' average number of contacts with professionals (exclusively the specialist asthma nurse) and their average number of hospital admissions for the research conditions separately and for the total group. It appeared that children attending either a transmural or extramural nurse clinic contacted health care professionals at $\mathrm{T} 2$ less frequently compared to TO. Linear regression analyses indicated that the total number of contacts with health care professionals and, more specifically, general practitioners significantly decreased in the total group of children. Furthermore, it appeared that this drop of the number of contacts with health care professionals did not significantly differ between the transmural and extramural condition (Table 6.5).

With regard to the average number of hospital admissions, it appeared that children in this study were seldom admitted to a hospital during the research 
period (Table 6.4). Significant differences in this respect were not found, neither among the measurements nor among research conditions.

Table 6.4 Average (and Sd) number of contacts with other health care professionals and number of hospital admissions at TO and T2 for the two conditions separate and for the total group

\begin{tabular}{|c|c|c|c|c|c|c|}
\hline & \multicolumn{2}{|c|}{$\begin{array}{l}\text { Transmural condition } \\
(n=139)\end{array}$} & \multicolumn{2}{|c|}{$\begin{array}{l}\text { I Extramural condition } \\
(n=63)\end{array}$} & \multicolumn{2}{|l|}{$\begin{array}{l}\text { Total group } \\
(n=202)\end{array}$} \\
\hline & TO & $\mathrm{T} 2$ & To & $\mathrm{T} 2$ & To & $\mathrm{T} 2$ \\
\hline $\begin{array}{l}\text { Total number of } \\
\text { contacts with } \\
\text { professionals }\end{array}$ & $7.5(7.8)$ & $3.7(4.5)$ & $7.1(6.5)$ & $4.3(6.0)$ & $7.4(7.4)$ & $3.9(5.0)^{\star}$ \\
\hline $\begin{array}{l}\text { general } \\
\text { practitioner }\end{array}$ & $4.8(6.2)$ & $1.6(4.1)$ & $5.0(5.4)$ & $2.1(3.6)$ & $1_{4.9(5.9)}$ & $1.8(4.0)^{*}$ \\
\hline paediatrician & $1.9(1.7)$ & $1.8(1.1)$ & $1.7(3.1)$ & $1.5(3.1)$ & $1.8(4.0)$ & $1.7(1.9)$ \\
\hline $\begin{array}{l}\text { physical } \\
\text { therapist }\end{array}$ & $0.04(0.4)$ & $0.2(0.9)$ & $0.02(0.1)$ & $0.3(2.0)$ & $0.04(0.3)$ & $0.2(1.4)$ \\
\hline others & $0.7(3.0)$ & $0.2(0.7)$ & $0.4(1.3)$ & $0.5(1.5)$ & $0.6(2.6)$ & $0.3(1.0)$ \\
\hline $\begin{array}{l}\text { Hospital } \\
\text { admissions }\end{array}$ & $0.2(0.6)$ & $0.1(0.3)$ & $0.2(0.6)$ & $0.1(0.6)$ & $0.2(0.6)$ & $0.06(0.4)$ \\
\hline
\end{tabular}

$\mathrm{p}<0.05$ in comparing $\mathrm{T} 2$ with TO for the total group 
Total number of topics about which information

is needed

Beta
Total number of contacts

with professionals

Beta

Variables in the equation:

Condition

(transmural nurse clinic)

$-0.18^{\star *}$

$-0.08$

Measurement moment

(TO)
T1
$-0.63^{* *}$
not applicable
$\mathrm{T} 2$
$-0.66^{\star \star}$
$-0.21 *$

Condition*Tl

$0.22^{\star \star}$

not applicable

Condition ${ }^{\top}$ T2

$0.18^{*}$

$-0.07$

Duration of complaints

0.01

0.00

Level of education parent

(middle)

lower
higher
$-0.01$

0.02

0.04

$-0.06$

Severity of asthma

(moderate)

$\begin{array}{lcc}\text { mild } & 0.06 & -0.01 \\ \text { severe } & 0.06 & 0.11^{*} \\ \text { unknown } & 0.05 & -0.09\end{array}$

Gender parent

(male)

0.04

0.04

Gender child

(female)

0.02

0.05

Age child in years

0.01

$-0.22$

$\mathrm{R}^{2}$

0.27

0.14

Adjusted $\mathrm{R}^{2}$

0.25

0.11

${ }^{*} p \leq 0.05,{ }^{* *} p \leq 0.01$ 


\section{CONCLUSIONS AND DISCUSSION}

In the Netherlands two kinds of nurse clinics for children with asthma have been established. The first kind are so-called 'extramural' nurse clinics which are run under the responsibility and in the premises of a home care organization. Secondly, so-called 'transmural' nurse clinics have only recently been established in the Netherlands. These transmural nurse clinics are provided on the basis of close collaboration and joint responsibility between home care organizations and hospitals. This article gives insight into whether the patients attending these two kinds of clinics and the content of the nursing care provided in these clinics is comparable.

Furthermore, we determined whether attending Dutch nurse clinics results in changes in parents of asthmatic children's need for asthma-related information and asthmatic children's use of health care services. Finally, insight is given into whether the organizational difference between transmural and extramural nurse clinics leads to different outcomes.

In this study almost no differences were found between children with asthma and their parents attending transmural or extramural nurse clinics. However, it appeared that in extramural nurse clinics children had less severe asthma and the severity of the children's asthma was often not known by the nurses running the clinics. In line with these results, it was found that the content of the care provided in transmural and extramural nurse clinics appeared to differ depending on the person referring to the clinic (paediatrician in transmural clinic vs. general practitioner, paediatrician or own initiative). Also with respect to the duration of the nursing contacts (significant longer in extramural clinics), parents' care demands (in transmural nurse clinics more frequent demands concerning the use of medication, dealing with asthma and smoking) and nurses' care activities (in transmural nurse clinics nurses provided more often psycho-social support) differences were found.

Especially the fact that in extramural nurse clinics parents contact the specialist nurse at their own initiative seems to be related to the, by the nurse, unknown severity of the child's asthma. These two results, combined with the fact that the population of asthmatic children in regions in which extramural and transmural nurse clinics are operational is comparable, point in the direction that structural referrals of children with asthma to an extramural nurse clinic could be improved in the future. 
In line with our expectation, this study indicated that after attending a nurse clinic, parents' needs for asthma-related information had significantly decreased. Furthermore, it appeared that this decline in parents' needs for asthma-related information was greater in transmural than in extramural nurse clinics. In other research too, in which information was provided to children with asthma or their parents, positive effects on information requirement were found. For instance, Mesters [17] evaluated a multidisciplinary education protocol for primary care professionals (general practitioners, community nurses, asthma nurses and doctors in child health centers). In this experimental study it was concluded that when the protocol was used, parents' knowledge about asthma improved significantly. Research in hospital settings also indicated positive effects of asthma-related information given by specialist nurses. Donaghy [12] compared a group of asthmatics who received only instruction from a doctor with a comparable group who received an additional individual education program conducted by an asthma nurse specialist. The latter study demonstrated that additional asthma education provided by a nurse specialist improves patients' understanding of asthma. When interpreting these results of others, it should be kept in mind that in the current study parents' needs for information was measured, while in other research parents' knowledge about or understanding of asthma was determined.

The expectation that attending a nurse clinic would lead to a decrease in asthmatic children's use of health care services is also confirmed in this study. However, with respect to the organizational differences between transmural and extramural nurse clinics, no differences were found with regard to the decline in the number of hospital admissions and number of contacts with health care professionals. In the study of Colland [18] it was also concluded that asthmatic children who followed a behavioural self-management program (consisting of ten weekly one-hour education sessions with a group of six to eight children) had a lower health care consumption. Other research also indicated that the implementation of an education program for asthmatic patients, which are mainly informative, resulted in a decline in the use of health care services $[13,17,19-22]$. Consequently, on the basis of the current underlying study and other research, it can be concluded that education programs for asthmatics in general and nurse clinics for asthmatic children in particular result in a decline in asthmatic patients' use of health care services. The organizational context in which the education is provided does not seem to influence this use. 
These results bring us to the question of why transmural nurse clinics for children with asthma have recently been implemented in Dutch health care. Reasons given by policy-makers are often formulated in terms such as improvement of quality and continuity of care and efficiency (reduction of health care costs). In this study health care costs were not measured. However, our results on patients' use of health care services do not point in the direction of lower cost for the care provided in transmural nurse clinics compared with the care provided in traditional extramural nurse clinics. With respect to the quality and continuity of care it should be noted that from another part of this study, that it was concluded that there were no significant differences between the two kinds of nurse clinics in parents' positive perceptions about the quality and continuity of the care provided [23]. It seems therefore, that the characteristics of health care regions are the decisive factors for implementing or continuing transmural or extramural nurse clinics.

\section{Limitations of the study}

It should be remembered that the comparison of the outcomes in this study was based on the data of a limited number of transmural and extramural nurse clinics. However, in 1996 only eleven transmural nurse clinics for children with asthma, with comparable content, were established in the Netherlands [4]. Consequently, the results for transmural nurse clinics probably apply to all Dutch transmural nurse clinics. The precise number of extramural nurse clinics established in the Netherlands is unclear. However, it is assumed that this number is low and it can therefore be stated that the results of the six extramural nurse clinics in this study also apply to other extramural nurse clinics for children with asthma in the Netherlands.

In this study, data about parents and children with asthma who cannot attend a nurse clinic, but receive regular care only, was not available. However, such information can give insight into additional positive effects of visiting a nurse clinic. Accordingly, it is recommended a control group receiving regular care only be included in future research.

Furthermore, the data obtained in this study could, as a result of including all children with asthma instead of making a distinction in the severity of their asthma, not be used for analysing differences between children who suffered severe, moderate or mild asthma. It is assumed that the severity of the illness influences patients' demands. Consequently, future research in which the effects of visiting nurse clinics on specific groups of children with asthma can be tested is recommended. 


\section{Acknowledgement}

This study was supported by a grant from the Dutch Ministry of Health,

Welfare and Sport Affairs. We thank the parents of asthmatic children, nurses and paediatricians for participating in this study and Anneke Kaper for her help in collecting and entering the data. 


\section{REFERENCES}

[1] Ketelaars C. Aftercare and specialised community nursing: Implications for patients with chronic obstructive pulmonary disease. PhD-thesis. Maastricht: Rijksuniversiteit Limburg, 1996.

[2] Wiegers TA. Evaluatie van modellen voor aansluiting tusen intramurale specialistische en extramurale verpleegkundige CARA-zorg voor kinderen [Evaluation of models for a connection between hospital and home nursing care] (in Dutch). Utrecht: NIVEL, 1991.

[3] Linden, van der BA. Transmural care. Facts and future. In: Health and health care in the Netherlands. Utrecht: De Tijdstroom, 1997; 181-188.

[4] Temmink, D, Francke, AL, Hutten JBF, Zee van der J, Huyer Abu-Saad H. Innovations in the nursing care of the chronically ill: a literature review from an international perspective. J Adv Nurs 2000;31(6):1449-1458.

[5] Temmink, D, Francke AL, Kerkstra, A, Huyer Abu-Saad, H. Dutch transmural nurse clinics for chronic patients: a descriptive study. Pat Educ Couns 2000;39:177-184.

[6] Eastwood AJ, Sheldon TA. Organisation of asthma care: what difference does it make? A systematic review of the literature. Qual Health Care 1996;5:134-143.

[7] Charlton I, Charlton G, Broomfield J, Mullee MA. Audit of the effect of a nurse run asthma clinic on workload and patient morbidity in a general practice. $\mathrm{Br} J \mathrm{Gen}$ Prac $1991 ; 41: 227-231$.

[8] Charlton I, Charlton G, Broomfield J, Campbell M. An evaluation of a nurse-run asthma clinic in general practice using an attitudes and morbidity questionnaire. Fam Prac $1992 ; 9(2): 154-160$.

[9] Jones KP, Mullee MA. Proactive, nurse-run asthma care in general practice reduces asthma morbidity: scientific fact or medical assumption? Br J Gen Prac 1995;45:497-499.

[10] Barnes G, Partridge MR. Community asthma clinics: 1993 survey of primary care by the National Asthma Task Force. Qual Health Care 1994; 3:133-136.

[11] Dickinson J, Hutton S, Atkin A, Jones K. Reducing asthma morbidity in the community: the effect of a targeted nurse-run asthma clinic in an English general practice. Respir Med 1997;91(10):634-640.

[12] Donaghy D. The asthma specialist and patient education. Prof Nurse 1995;11:160-162. 
[13] Taggart VS, Zuckerman AE, Sly RM, Steinmueller C, Newman G, O'Brien RW, Schneider S, Bellanti JA. You can control asthma: evaluation of an asthma education program for hospitalized inner-city children. Pat Educ Couns 1991;17:35-47.

[14] Pérez MG, Feldman L, Caballero F. Effects of a self-management educational program for the control of childhood asthma. Pat Educ Couns 1999;36:47-55.

[15] Droogan J, Bannigan D. Organisation of asthma care: what difference does it make? Nurs Times 1997; 34:45-46.

[16] Es, SM van. Adherence to asthma medication in adolescents. PhD-thesis. Amsterdam: Vrije Universiteit, 1999.

[17] Mesters I. Infants with asthma. Towards a multidisciplinary education protocol for primary care. Phd-thesis. Maastricht: Rijksuniversiteit Limburg, 1993.

[18] Colland Vr. Leren omgaan met astma. Interventiemethoden voor kinderen en ouders. Phdthesis. Amsterdam: Universiteit van Amsterdam, 1993. (Learning to cope with asthma. Intervention programs for children and parents).

[19] Ghosh CS, Ravindran P, Joshi M, Stearns SC. Reductions in hospital use from self management training for chronic asthmatics. Soc Sci Med 1998;8:1087-1093.

[20] Maslennikova GY, Morosova ME, Salman NV, Kulikov SM, Oganov RG. Asthma education programme in Russia: educating patients. Pat Educ Couns 1998;33:113-127.

[21] Osman LM, Abdalla MI, Russel IT, Fiddes J, Friend JAR, Legge JS, Douglas JG. Integrated care for asthma: matching care to the patient. Eur Resp J 1996;9:444-448.

[22] Campbell Haggerty M, Stockdale-Woolley R, Nair S. Respi-care, an innovative home care program for the patient with chronic obstructive pulmonary disease. Chest $1991 ; 100(3): 607-612$.

[23] Temmink, D, Hutten JBF, Zee van der J, Huyer Abu-Saad $H$. Dutch nurse clinics for children with asthma: views of professionals and parents. J Nurs Care Qual 1999;14(1):63-71 


\section{RHEUMATOLOGY OUTPATIENT NURSE CLINICS: A VALUABLE ADDITION?}

D. Temmink, J.B.F. Hutten, A.L. Francke, J.J. Rasker,

H. Huijer Abu-Saad, J. van der Zee

Submitted for publication

\section{ABSTRACT}

Recently 'transmural nurse clinics', where nursing care is provided under the joint responsibility of a home care organization and a hospital, were introduced into Dutch health care. This article gives insight into outcomes of transmural rheumatology nurse clinics.

Rheumatic patients who attended a transmural nurse clinic in addition to regular care and rheumatic patients who received regular care only were compared on: the need for rheumatology-related information, use of aids and adaptations, use of health care services and daily functioning. Attending a transmural nurse clinic appeared not to influence rheumatic patients' need for information, the application of practical aids and adaptations or the functional capacity. However, attending a transmural nurse clinic does result in more contacts with rheumatologists and occupational therapists. It is concluded that attending transmural nurse clinics does not result in major differences in outcomes compared with regular care. Further studies are needed to appreciate the long term effects of transmural nurse clinics.

Keywoords: nurse clinics - outcome - patient education - rheumatic patients transmural care 
chapter 7

128 


\section{INTRODUCTION}

Western health care systems are increasingly being confronted with chronic patients, like people with rheumatic diseases, who need complex interventions tailored to their individual needs [1]. However, it seems that today's health care professionals, organizations and budgets are not sufficiently prepared to. provide this kind of care. Consequently, health care policy in many countries targets innovations anticipating the increasing number of chronic patients and their need for adequate health care.

In such innovations, specialist nurses play a central role. Yet, there is limited evidence about whether such nursing-related innovations result in improvement of health care. In a database maintained at the University of Sheffield about six hundred nursing-related innovations were identified, but most have not been adequately evaluated [2]. In the Netherlands, the same conclusion was drawn about innovations in which care was provided across the organizational boundaries of hospitals and home care organizations [3].

However, some studies specifically investigated the value of nursing-related innovations for chronic patients' demand for information, use of health care services or daily functioning [4-13]. Rheumatic patients participated in two of these studies $[4,5]$. These two studies show an increase in knowledge in patients consulting a rheumatology nurse practitioner compared with those consulting rheumatologists in the United Kingdom.

In the Netherlands, rheumatology nurse clinics are often provided in so-called 'transmural' settings. The term 'transmural' refers to care provided in close collaboration and joint responsibility between generalist primary care and specialist hospital care professionals [14]. Transmural nurse clinics are often held at hospital outpatient clinics, by specialist rheumatology nurses employed by a home care organization.

The content and organization of Dutch transmural nurse clinics is partly comparable with the nurse clinic described by Hill [4] and Hill et al. [5]. One difference is that in the studies of Hill, there was substitution of rheumatology nurse practitioners for rheumatologists. In contrast, Dutch transmural nurse clinics are run in addition to the regular care provided by rheumatologists and others. Another difference between Dutch transmural nurse clinics and the clinic described by Hill [4] and Hill et al. [5] is that transmural nurse clinics 
are run under the joint responsibility of a hospital and home care organization, while Hill [4] and Hill et al. [5] studied a clinic run under the sole responsibility of a hospital. As a result of these differences, it is unclear whether the positive results of nurse clinics in the United Kingdom would also apply to Dutch transmural nurse clinics. Consequently, we are addressing the following research questions in this article: What is the effect of attending a transmural nurse clinic in addition to the regular care provided for rheumatic patients' on the:

1. need for rheumatology-related information?

2. use of practical aids and adaptations?

3. use of health care services, more specifically:

a. the number of contacts with health care professionals?

b. the number of admissions in hospitals, nursing homes, rehabilitation centres or other institutions?

4. daily functioning?

Our hypothesis is that attending a transmurat nurse clinic will better meet rheumatic patients' information needs, as patient education is an important aspect in transmural nurse clinics. Furthermore, it is expected that, after attending a transmural nurse clinic, rheumatic patients will use practical aids, like can-openers or long shoehorns, and adaptations in their home environment, like adjustable beds, toilets or chairs, more often as the information given at the clinics often includes telling patients the importance of practical aids or adaptations and how to acquire these. It is assumed that rheumatic patients who attend transmural nurse clinics will be better able to deal with the activities of daily life because of the expected increase in knowledge and the use of practical aids and adaptations. It is also expected that the activities of a specialist nurse at a transmural nurse clinic will reduce contacts with rheumatologists and increase contacts with other health professionals, such as physical and occupational therapists. For instance, occupational or physical therapists may be consulted more often after patients have attended a transmural nurse clinic, because they need more specific information about how to use practical aids. 


\section{METHODS}

\section{Design}

Effects of transmural nurse clinics for rheumatic patients were measured in a pre-test post-test control group design. Patients were recruited from nine comparable community hospitals in the Netherlands. At hospital level two groups of patients were recruited for the study. The intervention group consisted of rheumatic patients, recruited from five hospitals, who attended a transmural nurse clinic in addition to the regular care provided. Patients in the control group, recruited from four other hospitals, could not attend a nurse clinic as such a clinic was not (yet) available at that hospital, and only received regular care. Both groups of patients were approached for two pre-structured telephone interviews in six months.

\section{Sample}

Rheumatic patients in both the intervention and control group were invited by their rheumatologist to participate in the study. The selection of cases in the intervention group was made before they received the intervention and the following criteria were used to include patients in the intervention and control group: 1. diagnosis related to rheumatic diseases (e.g. rheumatoid arthritis, osteoarthritis or others), 2. ability to speak Dutch 3. accessible by telephone and 4. no previous contact with a specialist rheumatology nurse. In both groups, patients had problems regarding their disease and their rheumatologist indicated that they needed more information and/or support. Patients who met the inclusion criteria received a letter from their rheumatologist with information about the study. Patients who choose to participate, gave their written consent and were approached for a first telephone interview. The patients in the intervention group were, by their rheumatologist, referred to a specialist nurse running a transmural nurse clinic, while those in the control group only received regular care.

The transmural nurse clinics were held by nurses who, following their basic training, had followed an additional course in the nursing care for people with a rheumatic disease. This additional training program was mainly focused on giving patients with rheumatic disorders support and advice about how to deal with their disease in daily life. 


\section{Measurement moments and tools}

Patients in both conditions were approached for a telephone interview on two occasions. The first telephone interview with patients was one to four days after they had consulted their rheumatologist and given written consent (TO). The second interview took place six months after the first interview (T1). The telephone interviews were conducted by an independently trained pollster and lasted from about twenty to forty minutes.

Patients were asked what rheumatology information they needed for an insight into rheumatic patients' need for rheumatology related information, at both measurement moments. Response categories used in this question are displayed in Table 7.2.

Patients' use of practical aids and adaptations was measured by asking 'Which practical aids or adaptations do you use in daily life?' at both measurement moments. In answering this question, fifteen response categories (see Table 7.3), all representing an aid or adaptation, were presented to the patient.

To determine rheumatic patients' use of health care facilities, at both interviews patients were asked to list the number of rheumatology related contacts with health care professionals like general practitioners, physiotherapists, occupational therapists, rheumatologists etc. during the last six months (see Table 7.4). Furthermore, patients were asked to rate their admissions during the last six months in a hospital, nursing home, rehabilitation centre or other health care institutions.

To examine differences in patients' daily functioning, the questionnaire 'Capacities of daily life for patients with rheumatoid arthritis' (Vragenlijst Dagelijks Functioneren, VDF [16]) was used for both measurements. This questionnaire is a Dutch version of the English language Health Assessment Questionnaire. In the VDF patients are asked to rate their level of dependency in terms of twenty daily activity indicators such as: 'Were you able to get on and off the toilet?' These indicators cover eight fields of activity as displayed in Table 7.5. Each field consists of two to four questions with a score range from 0 (=completely dependent) to 3 (=independent). The instrument has been shown to be valid and reliable [16].

\section{Analyses and statistics}

Differences in background characteristics between the two groups were determined by using Student's t-test for continuous data, Chi-square test for nominal data and Mann-Whitney test for ordinal data.

To analyse the VDF questionnaire, the reliability of the eight fields of activity at 
T0 was specified. Multiple linear regression analyses for continuous data and multiple logistic regression analyses for dichotomous data were used to determine differences in outcomes between the two research groups. In all regression analyses, differences between the two groups were tested after controlling for patients' background characteristics as displayed in Table 7.1 and baseline scores for the concerning outcome variable.

Difference scores concerning rheumatic patients' total number of rheumatology related information subjects, practical aids and adaptations used, contacts with health care services and daily functioning score were calculated for every individual patient. The sum score on TO was subtracted from the sum score at $\mathrm{T} 1\left(\sum \mathrm{T} 1-\sum \mathrm{T} 0\right)$ to calculate these difference scores. If, for instance, a patient needed about three subjects at TO information and about one at $T 1$, his difference score will be -2 (1-3). A negative difference score indicates a decrease, while a positive score refers to an increase. In addition to analysing differences in total scores, differences in specific information needs, use of practical aids, contacts with health care professionals/admissions and fields of daily functioning were analysed by using multiple linear regression analyses for continuous data and multiple logistical regression analyses for dichotomous data.

\section{RESULTS}

In the period between April 1996 and April 1998, a total of 227 patients were included in the study. The precise number of patients who refused to participate is not available. However, the rheumatologists and their assistants indicated that only in very exceptional cases did patients refuse to participate in the study beforehand (not more than one or two per location). Of the 227 approached patients, a total of 144 were referred to a transmural nurse clinic, while the remaining 83 control patients received regular care only.

Sixteen of the patients attending a transmural nurse clinic dropped out of the study. Reasons for dropping out were: too severely ill to visit the clinics or death $(n=8)$; patient refused to participate at the second measurement moment $(n=8)$. Two patients in the control group were not accessible by telephone at the second measurement moment and thus dropped out of the study. Consequently, information is available about 128 and 81 patients respectively ( $92 \%$ response) who either did or did not attend a transmural nurse clinic. 
The respondents in the intervention and control group were comparable on most of the background characteristics (Table 7.1).

Table 7.1 Background characteristics of intervention and control patients at $\mathrm{TO}^{1}$

\begin{tabular}{|c|c|c|}
\hline & Intervention group $(n=128)$ & Control group $(n=81)$ \\
\hline Age (in years) ${ }^{2}$ & $61.2(14.9)$ & $57.6(14.1)$ \\
\hline Gender (female) & $94(73 \%)$ & $56(69 \%)$ \\
\hline $\begin{array}{l}\text { *Duration of complaints (in } \\
\text { years) }{ }^{2}\end{array}$ & $10.6(11.1)$ & $7.1(8.0)$ \\
\hline \multicolumn{3}{|l|}{ Kind of rheumatic disease } \\
\hline rheumatoid arthritis & $90(75 \%)$ & $64(79 \%)$ \\
\hline other & $30(25 \%)$ & $17(21 \%)$ \\
\hline \multicolumn{3}{|l|}{ Functional impairment } \\
\hline class 1 & $8(6 \%)$ & $10(13 \%)$ \\
\hline class 11 & $105(83 \%)$ & $52(67 \%)$ \\
\hline class III & $11(9 \%)$ & $13(17 \%)$ \\
\hline class IV & $2(2 \%)$ & $3(3 \%)$ \\
\hline \multicolumn{3}{|l|}{ Level of education } \\
\hline lower & $89(70 \%)$ & $54(68 \%)$ \\
\hline middle & $22(17 \%)$ & $18(22 \%)$ \\
\hline higher & $16(13 \%)$ & $8(10 \%)$ \\
\hline \multicolumn{3}{|l|}{ Living situation } \\
\hline alone & $24(19 \%)$ & $14(17 \%)$ \\
\hline with others & $103(81 \%)$ & $67(83 \%)$ \\
\hline
\end{tabular}

${ }^{1}$ Missing values: Age in years ( 1 in intervention group), Duration of complaints (4 in control group), Classification of functional impairment ( 2 in intervention group, 3 in control group), Kind of rheumatic disease ( 8 in intervention group), Level of education ( 1 in intervention group, 1 in control group), Living situation ( 1 in intervention group)

${ }^{2}$ Mean (sd)

* Difference between groups, $p<0.05$

In both groups, patients had a mean age of sixty years, most of them were female, had rheumatoid arthritis and an adequate capacity for normal 
activities; class 2 according to Steinbröcker's classification [15]. The majority had a lower educational level and lived with a partner and/or children. However, the intervention and control group differed with regard to the duration of rheumatology-related complaints. Patients in the intervention group had suffered from rheumatic disease for a significantly longer period than patients in the control group (Table 7.1). No differences in background characteristics were found across the locations participating in the study as intervention and control group respectively.

Description of nurse contacts in the intervention group

Across the five locations in which patients did attend a nurse clinic, the care provided was comparable. Patients attending a transmural nurse clinic were referred to the clinic by their rheumatologist. Reasons for referral were: problems or questions in coping with their rheumatic disease (38\%), a request of the rheumatologist for further analysis of problems/history taking $(28 \%)$, requesting practical aids or adaptations (13\%) or other reasons $(21 \%)$. Patients in the intervention group contacted the specialist nurse about three times during the study period of six months. All intervention patients attended the transmural nurse clinic. Most of the contacts intervention patients had with the specialist nurse (67\%) were at the clinic itself, $24 \%$ by telephone and the others during house calls by the nurse to the patient at home or at the home care organization. Contacts between specialist nurses and patients at the transmural nurse clinics had a mean duration of 34 minutes; while telephone contacts had a mean duration of about a quarter of an hour. Care demands discussed during contacts at a transmural nurse clinic related to dealing with rheumatic disease in daily life (58\%), patients' living situation (54\%), requesting practical aids or adaptations (44\%) and use of medication ( $8 \%$ ). The principal activities of the specialist nurses in meeting patients' care demands during transmural nurse clinics were: education (73\%), psychosocial support (62\%) and analyzing problems/history taking (17\%). Care demands and activities during contacts outside the transmural nurse clinics (e.g. home visits or telephone contacts) were comparable with those during contacts at the clinics. 
Need for rheumatology related information

About $52 \%$ of the intervention group and $32 \%$ of controls indicated that they did need additional information at TO. At T1, these percentages decreased to $20 \%$ and $7 \%$ respectively (Table 7.2 ).

Table 7.2 Information needs of intervention and control patients at TO and T1

\begin{tabular}{|c|c|c|c|c|}
\hline & \multicolumn{2}{|c|}{ Intervention $(n=128)$} & \multicolumn{2}{|c|}{ Control $(n=81)$} \\
\hline & TO & $\mathrm{T} 1$ & TO & $\mathrm{Tl}$ \\
\hline $\begin{array}{l}\text { Need for more information in } \\
\text { general }\end{array}$ & $52 \%$ & $20 \%$ & $32 \%$ & $7 \%$ \\
\hline Need for information about: & & & & \\
\hline $\begin{array}{l}\text { Rheumatic disease in } \\
\text { general }\end{array}$ & $18 \%$ & $5 \%$ & $12 \%$ & $2 \%$ \\
\hline $\begin{array}{l}\text { Requesting practical } \\
\text { aids/adaptations }\end{array}$ & $22 \%$ & $3 \%$ & $11 \%$ & $1 \%$ \\
\hline Rheumatic disease in daily life & $12 \%$ & $3 \%$ & $4 \%$ & $4 \%$ \\
\hline Medication use & $7 \%$ & $3 \%$ & $4 \%$ & $1 \%$ \\
\hline Side-effects of medication & $5 \%$ & $2 \%$ & $2 \%$ & $1 \%$ \\
\hline Other & $11 \%$ & $6 \%$ & $10 \%$ & $5 \%$ \\
\hline $\begin{array}{l}\text { Number of subjects mentioned } \\
(M ; S d)\end{array}$ & $0.7(1.1)$ & $0.2(0.7)$ & $0.4(0.9)$ & $0.1(0.6)$ \\
\hline
\end{tabular}

Subjects about which rheumatic patients required more information concerned for instance the rheumatic disease itself, how to acquire practical aids or adaptations or how to handle their disease in daily life. The mean number of subjects mentioned by rheumatic patients in the intervention and control group at TO was 0.7 and 0.4 respectively. At T1 these averages decreased to 0.2 in the intervention group and 0.1 in the control group (Table 7.2).

From multiple linear regression analyses, it appeared that the change in total number of subjects about which patients' needed more information, did not 
significantly differ between patients who did attend a transmural nurse clinic and patients who received regular care (Table 7.6). Furthermore, logistical regression analysis did not show significant differences between the two groups with respect to the need for specific information (not in table).

Use of practical aids and adaptations

At T0, $56 \%$ of the patients in the intervention condition and $46 \%$ of the controls made use of practical aids or housing adaptations. At $\mathrm{Tl}$, all patients in both conditions (100\%) used some kind of aids or adaptations (Table 7.3).

Table 7.3 Use of practical aids and adaptations in intervention and control patients at TO and $\mathrm{TI}$

\begin{tabular}{|c|c|c|c|c|}
\hline & \multicolumn{2}{|c|}{ Intervention $(n=128)$} & \multicolumn{2}{|c|}{ Control $(n=81)$} \\
\hline & TO & $\mathrm{Tl}$ & то & $T 1$ \\
\hline $\begin{array}{l}\text { Use of practical } \\
\text { aids/adaptations }\end{array}$ & $56 \%$ & $100 \%$ & $46 \%$ & $100 \%$ \\
\hline \multicolumn{5}{|l|}{ Use of: } \\
\hline heightened toilet & $28 \%$ & $33 \%$ & $28 \%$ & $35 \%$ \\
\hline adjusted taps & $18 \%$ & $27 \%$ & $27 \%$ & $31 \%$ \\
\hline handles in the bathroom & $18 \%$ & $23 \%$ & $27 \%$ & $28 \%$ \\
\hline shower-chair & $12 \%$ & $13 \%$ & $20 \%$ & $20 \%$ \\
\hline adjusted bed & $13 \%$ & $15 \%$ & $16 \%$ & $11 \%$ \\
\hline adjusted chair & $6 \%$ & $11 \%$ & $14 \%$ & $9 \%$ \\
\hline adjusted cutlery & $7 \%$ & $7 \%$ & $7 \%$ & $10 \%$ \\
\hline pot-opener & $11 \%$ & $11 \%$ & $1 \%$ & $7 \%$ \\
\hline wheelchair & $2 \%$ & $4 \%$ & $10 \%$ & $9 \%$ \\
\hline stick & $6 \%$ & $4 \%$ & $6 \%$ & $6 \%$ \\
\hline crutches & $1 \%$ & $2 \%$ & $1 \%$ & $4 \%$ \\
\hline long stick to pick things up & $2 \%$ & $3 \%$ & $1 \%$ & $1 \%$ \\
\hline walking frame & $2 \%$ & $2 \%$ & $1 \%$ & $0 \%$ \\
\hline aids for dressing & $2 \%$ & $1 \%$ & $0 \%$ & $1 \%$ \\
\hline others & $0 \%$ & $2 \%$ & $5 \%$ & $3 \%$ \\
\hline $\begin{array}{l}\text { Number of aids/adaptations } \\
(M ; S d)\end{array}$ & $1.3(1.8)$ & $1.6(2.1)$ & $1.7(2.5)$ & $1.8(2.5)$ \\
\hline
\end{tabular}


Rheumatic patients mostly used appliances like heightened toilets, adjusted taps, handles in the bathroom, shower-chairs or adjusted beds. Rheumatic patients in the intervention and control group used at TO respectively 1.3 and 1.7 practical aids on average, while this average at $\mathrm{T} 1$ was 1.6 and 1.8 respectively (Table 7.3).

Multiple linear regression analyses showed, after controlling for patients' background characteristics and baseline scores, no significant difference between the two groups in this increase (Table 7.6). Also in the use of the most frequently mentioned specific aids no significant differences between the two groups were found (not in table).

\section{Use of health care services}

The average number of contacts with professionals and the average number of admissions in health care institutions during the last six months are summarized in Table 7.4. Patients who attended a transmural nurse clinic appeared to contact most health care professionals more frequently at $T I$ than at TO. The opposite is found in control patients; they contacted most health care professionals less frequently at $\mathrm{Tl}$ compared to TO. This finding is reflected in the total number of contacts with health care professionals; in the intervention and control group at TO 19.0 and 21.8 respectively. At T1 these average numbers were 22.1 and 17.4 respectively.

With regard to the average number of admissions, it appeared that rheumatic patients in this study were hardly admitted to a nursing home or rehabilitation centre during the half year follow up period. The mean number of hospital admissions was also low. Differences between the two research groups in this respect were small. It appeared that intervention patients were, on average, admitted to a hospital 0.06 times at both measurement moments, while this number was 0.03 at both moments for patients in the control group.

Results of multiple linear regression analyses on the change in rheumatic patients' number of admissions did not show significant differences between intervention and control patients. However, differences in the total number of contacts with health care professionals did occur. The difference score on the number of contacts with health care professionals of patients who attended a transmural nurse clinic was significantly higher compared with patients who could not attend a transmural nurse clinic (Table 7.6). This indicates that at $\mathrm{Tl}$, intervention patients more often contacted health care professionals than the control patients did. 
Table 7.4 Average (and Sd) number of contacts with health care professionals and admissions, during the last six months, in intervention and control patients at TO and T1

\begin{tabular}{|c|c|c|c|c|c|}
\hline & & \multicolumn{2}{|c|}{ Intervention $(n=128)$} & \multicolumn{2}{|c|}{ Control $(n=81)$} \\
\hline & & TO & $\mathrm{T} 1$ & TO & $T 1$ \\
\hline \multicolumn{6}{|c|}{ Generalist professionals: } \\
\hline \multicolumn{2}{|c|}{ general practitioner } & $1.6(3.6)$ & $1.1(3.3)$ & $1.4(2.3)$ & $0.6(1.6)$ \\
\hline \multicolumn{2}{|c|}{ physical therapist } & $9.0(14.4)$ & $11.7(16.6)$ & $10.7(17.8)$ & $9.8(17.0)$ \\
\hline \multicolumn{2}{|c|}{ * occupational therapist } & $0.06(0.5)$ & $0.8(3.7)$ & $0.4(1.4)$ & $0.2(0.7)$ \\
\hline \multicolumn{2}{|l|}{ welfare worker } & $0.2(2.3)$ & $0.04(0.3)$ & $0.07(0.7)$ & $0.05(0.3)$ \\
\hline \multicolumn{2}{|l|}{ psychologist } & $0.2(2.1)$ & $0.2(2.3)$ & $0.2(1.4)$ & $0.06(0.6)$ \\
\hline \multicolumn{2}{|c|}{$\begin{array}{l}\text { home care professionals exclusive the } \\
\text { specialised rheumatology nurse }\end{array}$} & $4.4(13.0)$ & $4.6(13.9)$ & $3.8(10.9)$ & $2.9(9.2)$ \\
\hline \multicolumn{2}{|c|}{ WVG consultant } & $0.03(0.2)$ & $0.06(0.2)$ & $0.0(0.0)$ & $0.1(0.5)$ \\
\hline \multicolumn{2}{|l|}{ others } & $0.7(3.8)$ & $1.0(5.7)$ & $0.3(2.9)$ & $0.9(4.2)$ \\
\hline \multicolumn{6}{|c|}{ Specialist professionals: } \\
\hline \multicolumn{2}{|c|}{ * rheumatologist } & $2.4(1.3)$ & $2.2(1.3)$ & $3.0(1.6)$ & $2.1(0.9)$ \\
\hline \multicolumn{2}{|l|}{ internist } & $0.02(0.2)$ & $0.04(0.3)$ & $0.05(0.3)$ & $0.04(0.2)$ \\
\hline \multicolumn{2}{|l|}{ orthopedist } & $0.1(0.7)$ & $0.1(0.5)$ & $0.2(0.7)$ & $0.1(0.4)$ \\
\hline \multicolumn{2}{|c|}{ rehabilitation specialist } & $0.02(0.2)$ & $0.1(0.6)$ & $0.09(0.6)$ & $0.06(0.3)$ \\
\hline \multicolumn{2}{|l|}{ others } & $0.1(0.6)$ & $0.3(1.1)$ & $1.6(5.7)$ & $0.5(3.0)$ \\
\hline \multicolumn{2}{|c|}{$\begin{array}{l}\text { Total number of contacts with health } \\
\text { care professionals }\end{array}$} & $19.0(22.8)$ & $22.1(27.4)$ & $21.8(25.7)$ & $17.4(22.5)$ \\
\hline \multirow[t]{4}{*}{ Admission to: } & hospital & $0.06(0.2)$ & $0.06(0.3)$ & $0.03(0.2)$ & $0.03(0.2)$ \\
\hline & nursing home & $0.0(0.0)$ & $0.0(0.0)$ & $0.0(0.0)$ & $0.0(0.0)$ \\
\hline & $\begin{array}{l}\text { rehabilitation } \\
\text { centre }\end{array}$ & $0.0(0.0)$ & $0.01(0.01)$ & $0.0(0.0)$ & $0.0(0.0)$ \\
\hline & others & $0.0(0.0)$ & $0.0(0.0)$ & $0.0(0.0)$ & $0.0(0.0)$ \\
\hline \multicolumn{2}{|c|}{ Total number of admissions } & $0.06(0.2)$ & $0.07(0.3)$ & $0.03(0.2)$ & $0.03(0.2)$ \\
\hline
\end{tabular}

* $p<0.05$ 
More specifically, from further analyses, it appeared that the difference scores in the number of contacts with both an occupational therapist and rheumatologist were significantly higher in the intervention group than in the control group. In the intervention group, the average number of contacts with an occupational therapist increased during the research period, while the average number of contacts between these patients and a rheumatologist decreased (Table 7.4). In control patients a decrease was measured for both the mean number of contacts with an occupational therapist and a rheumatologist.

\section{Effects on patients' change in functional capacity}

The functional capacity score on the eight main fields of activity at TO and $\mathrm{Tl}$ are summarized in Table 7.5. Rheumatic patients who did attend a transmural nurse clinic performed slightly better in all fields of activities at $\mathrm{T} 1$ compared with TO. This is reflected in the total score of intervention patients. This score was 35.5 at TO and 36.3 at T1 respectively (Table 7.5) indicating that they were generally able to function independently with little difficulty.

For control patients, the fact that their scores in most of the fields of activity increased during the research period of six months also counts (Table 7.5). Total scores in the control group appeared to be a little higher compared with the total scores in the intervention group, indicating slightly better functional ability in daily life. However, multiple linear regression analysis revealed no significant differences between the intervention and control group with regard to patients' change in total functional capacity (Table 7.6); neither did analyses of the fields of activity show significant differences between the two groups. 
Table 7.5 Average (and Sd) functioning on daily activities fields of intervention and control patients at T0 and TI

\begin{tabular}{|c|c|c|c|c|c|c|}
\hline & & \multirow{2}{*}{$\begin{array}{l}\text { Scale } \\
\text { reliability } \\
\text { (alpha) at TO }\end{array}$} & \multicolumn{2}{|c|}{ Intervention $(n=128)$} & \multicolumn{2}{|c|}{ Control $(n=81)$} \\
\hline & & & TO & $\mathrm{T} 1$ & TO & $\mathrm{Tl}$ \\
\hline \multicolumn{7}{|c|}{ Field of activity (range $0-3$ ): } \\
\hline 1. & $\begin{array}{l}\text { Dressing and } \\
\text { grooming }\end{array}$ & 0.94 & $1.8(1.0)$ & $1.9(1.1)$ & $2.2(0.9)$ & $2.3(0.9)$ \\
\hline 2. & Arising & 0.82 & $1.8(1.0)$ & $1.9(1.0)$ & $2.3(0.8)$ & $2.3(0.8)$ \\
\hline 3. & Eating & 0.84 & $1.8(1.0)$ & $1.9(1.0)$ & $2.2(0.8)$ & $2.3(0.8)$ \\
\hline 4. & Walking & 0.84 & $1.7(1.1)$ & $1.8(1.1)$ & $2.0(1.0)$ & $2.1(1.1)$ \\
\hline 5. & Hygiene & 0.81 & $1.9(1.0)$ & $2.0(1.0)$ & $2.3(0.8)$ & $2.3(0.8)$ \\
\hline 6. & Reach & 0.19 & $1.4(0.8)$ & $1.5(0.8)$ & $1.8(0.9)$ & $1.6(0.9)$ \\
\hline 7. & Grip & 0.79 & $2.0(0.8)$ & $2.0(0.9)$ & $2.3(0.7)$ & $2.3(0.7)$ \\
\hline 8. & Activity & 0.67 & $1.5(0.9)$ & $1.5(0.9)$ & $1.7(1.0)$ & $1.8(1.0)$ \\
\hline \multicolumn{2}{|c|}{$\begin{array}{l}\text { Total score } \\
\text { (range } 0-60 \text { ) }\end{array}$} & 0.94 & $\begin{array}{l}35.5 \\
(14.9)\end{array}$ & $\begin{array}{l}36.3 \\
(16.0)\end{array}$ & $\begin{array}{l}42.0 \\
(14.7)\end{array}$ & $\begin{array}{l}43.0 \\
(14.3)\end{array}$ \\
\hline
\end{tabular}


Table 7.6 Results of Multiple linear regression analyses $(n=209)$

\begin{tabular}{|c|c|c|}
\hline $\begin{array}{l}\text { Change in } \\
\text { need for } \\
\text { information }\end{array}$ & $\begin{array}{c}\text { Change in use } \\
\text { of practical } \\
\text { aids and } \\
\text { adaptations }\end{array}$ & $\begin{array}{l}\text { Change in } \\
\text { number of } \\
\text { contacts with } \\
\text { professionals }\end{array}$ \\
\hline
\end{tabular}

Beta Beta Beta Beta

Variables in the equation:

Condition:

(transmural nurse

0.04

0.07

$0.17 *$

$-0.06$

clinic)

Duration of

$-0.02$

$-0.02$

0.08

$-0.05$

complaints

Kind of rheumatic

disease:

(other than RA)

0.02

$-0.01$

$-0.01$

$-0.09$

Level of education:

(lower)

$\begin{array}{lllll}\text { middle } & -0.07 & 0.01 & 0.06 & 0.09 \\ \text { higher } & -0.02 & 0.02 & -0.02 & 0.07\end{array}$

Functional

impairment:

(class I)

$\begin{array}{llccc}\text { class II } & -0.06 & 0.06 & 0.00 & -0.13 \\ \text { class III } & -0.06 & 0.33^{*} & 0.03 & -0.13 \\ \text { class IV } & -0.01 & 0.02 & 0.19 & -0.22^{\star}\end{array}$

Living situation:

(with others)

$-0.07$

$-0.05$

$-0.03$

0.05

Age in years

$-0.08$

0.07

$-0.10$

$-0.11$

Gender:

(female)

0.04

$-0.09$

0.12

$-0.01$

Outcome variable at

$-0.84^{*}$

$-0.24^{*}$

$-0.39 *$

$-0.36^{*}$

TO

$\mathrm{R}^{2}$

0.68

0.13

0.20

0.16

Adjusted $\mathrm{R}^{2}$

0.66

0.08

0.15

0.10

Significance: ${ }^{\star} p<0.01$ 


\section{DISCUSSION}

In the Netherlands 'transmural' nurse clinics for rheumatic patients are being set up as a new form of health care service. In these clinics, patient-tailored care is provided on the basis of close collaboration and joint responsibility between generalist primary care and specialist hospital professionals.

Contrary to our expectations, no significant differences were found in rheumatic patients' need for rheumatology-related information between patients who attended a transmural nurse clinic and those who received regular health care alone. This result is in line with an experimental study by Riemsma et al. [17], in which the effect of an educational program for people with rheumatoid arthritis was evaluated. During a six-month period, patients received disease-related information from nurses, rheumatologists, general practitioners and physiotherapists by discussing chapters from a self-help guide during their regular consultations with the patients. Riemsma et al. [17] concluded that the individual education program had no effect on rheumatic patients' knowledge about the disease. However, other studies did indicate a positive influence of patient education on rheumatic patients' knowledge of their disease [4, 5, 18, 19]. For instance, in Hill [4] and Hill et al. [5] after consulting a rheumatology nurse practitioner, six times in 48 weeks, rheumatic patients knew significantly more about their disease than patients attending a rheumatologist's clinic. When comparing the results of our study with Hill's [4, 5] and Riemsma's [17] results, it should be borne in mind that in our study patients' need for information was measured, while Riemsma et al. [17], Hill [4] and Hill et al. [5] measured rheumatic patients' level of knowledge. Another difference concerns the fact that in this study, the specialist nurses provide care which is additional to the regular care, while in the studies of Hill [4] and Hill et al. [5] patients went to either a rheumatology nurse practitioner or a rheumatologist. Furthermore, the research period and number of contacts with the specialist nurse should be remembered; in this study patients were followed for a six month period in which they contacted the nurse about three times, while in Hill's study [4] this period was twice as long and the number of contacts was twice as high.

The lack of disparity between the two groups, with regard to information needs, in the study presented might be caused by the fact that patients were asked about information needs after six months. Yet, most rheumatic patients contacted a specialist nurse running a transmural nurse clinic in the first two 
months of the research period of six months. It is therefore plausible that effects on patients' information needs occurred shortly after their first contact with the nurse. These effects may have faded away at the six-month measurement. Furthermore, during the contacts with the specialist nurses patients may have become aware of more questions than the controls, who did not have the occasion to visit a specialist nurse.

This study did not show significant differences in the use of practical aids and adaptations between patients who attended and patients who did not attend a transmural nurse clinic. This is a surprising result because a significant number of the rheumatic patients attending a transmural nurse clinic in our study required practical aids or adaptations. $A$ reason for not finding a difference might be that a procedure for acquiring aids and adaptations often takes longer than the six month period used in this study.

The expectation that attending a transmural nurse clinic would positively influence rheumatic patients' functional capacity was also not met. Vliet Vlieland et al. [20] compared the effects of in-patient multidisciplinary treatment (also including nursing care) with standard out-patient care in patients with active rheumatoid arthritis. On the basis of this latter study, it was also concluded that improvement in functional measures did not differ between the groups. In the Riemsma's experimental study too [17] it was concluded that individual education for people with rheumatoid arthritis had no effect on health status. On the results of this study and the studies of Vliet Vlieland [20] and Riemsma [17], it seems clear that education-oriented interventions alone cannot positively influence the functional abilities of people with rheumatic diseases.

However, attending a transmural nurse clinic did result in a significant difference in the number of contacts between rheumatic patients and rheumatologists. In both research groups, a decrease in the number of contacts with rheumatologists was found. Yet, this decrease was significantly greater in the control group than in the intervention group. Furthermore, it appeared that attending a transmural nurse clinic leads to a significant increase in the number of contacts between intervention patients and occupational therapists. A possible reason for these results is that a specialist rheumatology nurse might specify patients' care problems more extensively and be directed to co-ordinate the care optimally. This might result in care demands requiring the competence of other professionals like a rheumatologist or occupational therapist and, consequently, in referrals. However, also 
the alternative may apply. It might have been that an extensive specification of patients' care problems in patients attending a transmural nurse clinic resulted in a higher insecurity level of patients, which might have resulted in a greater need for reassurance of occupational therapists. But, this latter explanation of a greater number of contacts with occupational therapists seems, also on the basis of the positive results of nurse clinics in other studies $[4,5,13]$, less likely.

For instance, Mazzuca et al. [13] showed partially opposite results, for the effects of patient education by a specialist arthritis nurse. Mazzuca and colleagues [13] assessed a decrease in care utilization for patients with osteoarthritis of the knee. Reasons for somewhat contradictory results concerning contacts with health care professionals can be that in our study nurses only carried out nursing tasks in providing information or psychosocial support to patients; while in Mazzuca et al. [13] substitution of medical tasks also took place. If a substitution of medical tasks were also to take place in Dutch transmural nurse clinics, it would seem reasonable to expect that rheumatic patients' health care utilization might be reduced.

An advantage of our study was that we had the opportunity to compare the situation in community hospitals, with and without nurse clinics. We chose for the comparison of the two settings rather than to randomise within the settings, as from own experience it appears to be very difficult if not impossible to do so without contaminating the results. Patients will talk with each other in the waiting rooms and will soon know about the existence of a specialist nurse and ask to visit her.

This study comprised a six month period between pre- and post measurement. It seems plausible that if the period had been extended to one year, other results would be found regarding the outcome variables chosen. In the present study we did not measure the influence of attending a transmural nurse clinic on rheumatic patients' pain, morning stiffness and fatigue. The main reason for not measuring such outcomes was that the intervention of transmural nurse clinics consisted mainly of providing patient education about the disease and giving psychosocial support. It does not therefore seem plausible for a transmural nurse clinic to influence the physical aspects described above. Consequently, in future research also, the influence of rather limited interventions, such as transmural nurse clinics, on more physical outcomes does not seem indicated. However, further studies are needed to measure the long-term effects of attending transmural rheumatology nurse clinics on, for instance, efficiency, effectiveness and patient well being. 
chapter 7

\section{Acknowlegements}

We thank the patients, nurses and rheumatologists for participating in this study and the pollster Anneke Kaper for her cooperation. 


\section{REFERENCES}

[1] Temmink D, Francke AL, Hutten JBF, Van der Zee J, Huyer Abu-Saad H. Innovations in the care of the chronically ill: a literature review from an international perspective. Journal of Advanced Nursing 2000;31(6):1449-1458.

[2] Hobbs R, Murray ET. Specialist liaison nurses. Evidence for their effectiveness is limited. BMJ 1999;318:683-684.

[3] Persoon A, Francke A, Temmink D, Kerkstra A. Transmurale zorg in Nederland: een inventarisatie op basis van bestaande gegevensbestanden. Utrecht: NIVEL, 1996. ('Transmural care in the Netherlands: an inventarisation based on existing databases').

[4] Hill J. Patient satisfaction in a nurse-led rheumatology clinic. J Adv Nurs 1997;25:347354.

[5] Hill J, Bird HA, Harmer R, Wright V, Lawton C. An evaluation of the effectiveness, safety and acceptability of a nurse practitioner in a rheumatology outpatient clinic. Br J Rheumatol $1994 ; 33: 283-288$.

[6] Grahame R, West J. The role of the rheumatology nurse practitioner in primary care: an experiment in the further education of the practice nurse. $\mathrm{Br} J$ Rheumatol 1996;35:581588.

[7] Campbell Haggerty M, Stockdale-Woolley R, Nair S. Respi-care, an innovative home care program for the patient with chronic obstructive pulmonary disease. Chest 1991;100(3):607-612.

[8] Smeenk FWJM. Transmural care of terminal cancer patients. An evaluation study in the Eindhoven region. PHd-thesis. Maastricht: Universiteit Maastricht, 1998.

[9] Witteveen E. Home care technology for patients with cancer or serious infections. PHdthesis. Utrecht: Universiteit Utrecht, 1998.

[10] Häggmark C, Nilsson B. Effects of an intervention programme for improved discharge-planning. The frequency of re-admissions, problems and treatments of cancer patients receiving repeated treatments in hospital. Vård I Nord 1997;17:4-8.

[11] Osman LM, Abdalla MI, Russel IT, Fiddes J, Friend JAR, Legge JS, Douglas JG. Integrated care for asthma: matching care to the patient. Eur Respir J 1996;9:444-448.

[12] Rich MW, Beckham V, Wittenberg C, Leven CL, Freedland KE, Carney RM et al., A multi disciplinary intervention to prevent the readmission of elderly patients with congestive heart failure. N Engl J Med 1995;333:1190-1195. 
[13] Mazzuca, SA, Brandt KD, Katz BP, Hanna M, Chambers M, Byrd DJ. Self-care education reduces health care utilization and costs for patients with osteoarthritis (OA) of the knee. Arthritis and Rheum 1996;39 (Supplement 9):S168.

[14] Nationale Raad voor de Volksgezondheid \& College voor Ziekenhuisvoorzieningen. Transmurale somatische zorg: Advies van de Nationale Raad voor de Volksgezondheid en het College voor Ziekenhuisvoorzieningen [Somatic Transmural Care: Advice of the National Council for Public Health and National Board for Hospital Facilities] (in Dutch). Zoetermeer: NRV/CvZ, 1995.

[15] Steinbröcker $\mathrm{O}$, Traeger $\mathrm{CH}, \&$ Batterman RC. Therapeutic criteria in rheumatoid arthritis. The Jour Am Med Ass 1949; 140: 659-662.

[16] Bijlsma JWJ, Oude Heuvel CHB, Zaalberg A. Development and validation of the Dutch questionnaire capacities of daily life (VDF) for patients with rheumatoid arthritis. J Rehabilitation Sciences 1990;3:71-74.

[17] Riemsma RP, Taal E, Brus HLM, Rasker JJ, Wiegman O. Co-ordinated individual education with an arthritis passport for patients with rheumatoid arthritis. Arthritis care and Research 1997; 10: 238-249.

[18] Taal E, Rasker JJ, Wiegman O. Group education for rheumatoid arthirits patients. Seminars in Arthritis and Rheumatism 1997; 26: 805-816.

[19] Hirano PC, Laurent DD, Lorig K. Arthritis patient education studies, 1987-1991: a review of the literature. Pat Educ and Couns $1994 ; 24: 9-54$.

[20] Vliet Vlieland TPM. Multi disciplinary team care in rheumatoid arthritis. 1996. PhD-thesis. Leiden: Rijksuniversiteit Leiden. 


\section{SUMMARY}

Cultural, financial and health (care) related developments offer a challenge to the health care system and often result in the implementation of innovations in health care. Such innovations are often directed at erasing traditional boundaries between primary and secondary care and encouraging substitution of care from hospital to home care professionals.

In the Netherlands, part of the substitution-related innovation falls under the concept of 'transmural care'. Transmural care refers to care which breaks down the traditional barriers between hospital and primary care, is tailored to patient needs and provided on the basis of close collaboration and joint responsibility by primary care and hospital organizations (NRV/CVZ, 1995).

In this thesis, one kind of transmural care, namely transmural nurse clinics, is studied. At the core of the thesis insight is provided into whether attending a transmural nurse clinic influences the quality and continuity of care, patient information needs, use of practical aids and adaptations, daily functioning and the use of health care facilities.

In the first chapter of the thesis the background to the studies, the research methods and the major findings are described. Furthermore, in chapter 1 the limitations of the studies and recommendations for practice, policy and research are formulated. The most important recommendation for practice and policy concerns the further implementation of transmural nurse clinics. Where health care professionals or policy makers pursue improvement of the quality and continuity of care for the chronically ill, further implementation would seem useful. However, when a reduction in the use of health care facilities, an improvement in daily functioning or changes in the use of practical aids and adaptations are the main goals, further implementation of transmural nurse clinics is not so self-evident. Chapter 1 recommends further research on:

- the effects of substituting medical tasks to specialist nurses,

- the impact of transmural nurse clinics on other patient groups (like diabetics) or subgroups of asthma- and rheumatic patients,

- the impact of transmural nurse clinics on other outcome measures like patients' knowledge, self-care behaviour, adherence to regimes and cost-effectiveness,

- the effectiveness of other substitution-related innovations. 
In chapter 2, a literature study concerning substitution-related innovations in the nursing care of the chronically ill is described. In this chapter it is hypothesized that characteristics of substitution-related innovations differ among countries because their health care systems differ. To test this hypothesis, on the basis of financial and organizational characteristics, three categories of country are distinguished. These are: primary-care-oriented countries, secondary-care-oriented countries and countries that do not have a specific orientation towards either primary or secondary care. On the basis of the literature, three types of substitution-related innovation are distinguished in chapter 2 . These types are: advanced nursing practice, hospital-at-home care and integrated care. The main conclusion of this chapter is that integrated care innovations are implemented in both primary care as well as in secondary-care-oriented countries. Innovations concerning hospital-at-home-care and advanced nursing practice are primarily implemented in primary-care-oriented countries. On the basis of existing literature, it is still unclear whether substitution-related innovations positively influence the quality of care, costs of care or patients' use of health care facilities.

Chapter 3 of this thesis presents the results of a descriptive inventory study concerning transmural nurse clinics in the Netherlands. In this study insight is given into the characteristics of Dutch transmural nurse clinics and evaluation studies conducted. Information on a total of 62 transmural nurse clinics for chronic patients has been collected. Most of these clinics are held by specialist community nurses at a hospital outpatient clinic. The principal tasks of the specialist nurses at the clinics are providing illness-related information and supporting patients in dealing with the illness. Only a few unpublished evaluations of Dutch transmural nurse clinics have been conducted (in all cases by the professionals involved). However, due to the research methods used, firm conclusions about the impact of transmural nurse clinics cannot be inferred. It is therefore concluded that further research has to be carried out to determine the impact of transmural nurse clinics.

The impact of transmural nurse clinics is described in chapters 4-7. Chapter 4 outlines the results regarding the quality and continuity of care in transmural and extramural asthma-nurse clinics. Transmural nurse clinics are run under the joint responsibility of a home care organization and a hospital; while extramural nurse clinics are run under the sole responsibility of a home care organization. Chapter 4 gives insight into the opinions of professionals and parents of asthmatic children on the quality and continuity of care given at 
these clinics. It is concluded that parents judge the quality and continuity of care positively at both kinds of clinic. The organizational differences between transmural and extramural nurse clinics do not influence the positive perceptions. According to professionals, nurse clinics are a positive innovation because patients get additional information and nurses are more accessible to patients than other care providers, such as pediatricians. Professionals involved in both kinds of clinics plan to deal with impeding factors in the clinics, such as the unstructured way of referring patients from medical specialists and general practitioners to the clinics. It is hoped that as a result of this process, the positive influences of transmural and extramural nurse clinics will be strengthened.

In chapter 5 the quality and continuity of care in transmural rheumatology nurse clinics is presented. In comparison with chapter 4 , the quality and continuity of care is measured from the perspective of both patients and professionals. On the basis of this study, it is also concluded that both patients and professionals assess the quality and continuity of care in transmural nurse clinics positively.

Chapter 6 deals with the characteristics of patients and the nursing care delivered in transmural and extramural nurse clinics for children with asthma. Furthermore, this chapter deals with the effects of transmural and extramural clinics on the information needs and the use of health care services of (parents of) children with asthma. In this chapter it is concluded that children attending a transmural nurse clinic suffer more severe asthma in comparison with children attending extramural nurse clinics. It also appeared that nurses participating in this research and running extramural nurse clinics often were unaware of the severity of the children's asthma. It is further concluded that both transmural and extramural nurse clinics result in a decline of parents' needs for asthma-related information. This decline was greater in transmural than in extramural nurse clinics. Subsequently, chapter 6 shows that both transmural and extramural nurse clinics result in a decrease in asthmatic children's use of health care facilities. The organizational differences between transmural and extramural nurse clinics do not influence this outcome.

In chapter 7, a comparison is made between rheumatic patients attending a transmural nurse clinic and rheumatic patients only receiving regular care. This chapter shows that attending a transmural nurse clinic does not influence patients' needs for information, use of practical aids and adaptations and daily 
functioning. However, attending a transmural nurse clinic does result in increased contact with rheumatologists and occupational therapists.

\section{Literature}

Nationale Raad voor de Volksgezondheid \& College voor Ziekenhuisvoorzieningen (1995).

Transmurale somatische zorg: Advies van de Nationale Raad voor de Volksgezondheid en het College voor Ziekenhuisvoorzieningen. [Somatic Transmural Care: Advise of the National Council for Public Health and the National Board for Hospital Facilities]. Zoetermeer: NRV/CvZ. 


\section{SAMENVATTING}

Culturele, financiële en gezondheids(zorg) ontwikkelingen leiden er toe dat er tegenwoordig veel zorginnovaties worden ingevoerd. Dergelijke innovaties zijn er vaak op gericht om de traditionele scheiding tussen thuis- en ziekenhuiszorg op te heffen en substitutie van ziekenhuis- naar thuiszorgmedewerkers te bevorderen.

In Nederland wordt een deel van de substitutie-gerelateerde innovaties aangeduid met de term 'transmurale zorg'. Transmurale zorg wordt vaak als volgt gedefinieerd: 'vormen van zorg die, toegesneden op de behoefte van de patiënt, verleend worden op basis van afspraken over samenwerking, afstemming en regie tussen generalistische en specialistische zorgverleners, waarbij sprake is van een gemeenschappelijk gedragen verantwoordelijkheid met expliciete deelverantwoordelijkheden' (NRV/CvZ, 1995).

In dit proefschrift staat één vorm van transmurale zorg, namelijk transmurale verpleegkundige spreekuren, centraal. In de kern van dit proefschrift wordt inzicht gegeven in hoeverre het bezoeken van een transmuraal verpleegkundig spreekuur invloed heeft op de kwaliteit en continuïteit van zorg, de informatiebehoefte, het gebruik van hulpmiddelen, dagelijks functioneren en gebruik van zorgvoorzieningen door patiënten.

In het eerste hoofdstuk van dit proefschrift wordt de achtergrond van de verrichte studies, de gebruikte onderzoeksmethoden en de belangrijkste bevindingen beschreven. Ook worden in dit hoofdstuk de beperkingen van de studies benoemd en aanbevelingen voor de praktijk, beleid en onderzoek geformuleerd. De belangrijkste aanbeveling voor praktijk en beleid is gericht op de verdere implementatie van transmurale verpleegkundige spreekuren. Indien zorgverleners of beleidsmakers een verbetering van de kwaliteit en continuïteit van zorg voor chronisch zieken nastreven lijkt grootschaliger implementatie gewenst. Wanneer echter vermindering van zorggebruik, verbetering van het dagelijks functioneren of verandering in het gebruik van hulpmiddelen de primaire doelstelling is lijkt invoering op grotere schaal echter niet relevant. In het eerste hoofdstuk wordt tevens aanbevolen om toekomstig onderzoek te richten op:

- de effecten van substitutie van medische taken naar gespecialiseerde verpleegkundigen,

- de impact van transmurale spreekuren op andere groepen patiënten (zoals diabetici) of subgroepen van astma- en reumapatiënten, 
- de impact van transmurale spreekuren op andere uitkomstmaten zoals het kennisniveau van patiënten, zelfzorg, therapietrouw en kosteneffectiviteit van transmurale spreekuren,

- de effectiviteit van andere substitutie-gerelateerde innovaties.

In hoofdstuk 2 wordt verslag gedaan van een literatuurstudie naar substitutiegerelateerde innovaties in de verpleegkundige zorg voor chronisch zieken. De veronderstelling die in dit hoofdstuk centraal staat is dat gezondheidszorgsystemen verschillen tussen landen. Door deze verschillen worden in landen andere soorten innovaties ingevoerd. Om deze veronderstelling te onderzoeken zijn, op basis van organisatorische en financiële kenmerken, zes landen ingedeeld in drie groepen, namelijk: thuiszorg-georiënteerde landen, ziekenhuis-georiënteerde landen en landen die geen specifieke oriëntatie op de thuiszorg of het ziekenhuis hebben. Op basis van de literatuur zijn er drie typen van substitutie-gerelateerde innovaties te onderscheiden. Deze drie typen zijn: ziekenhuisverplaatste zorg, geïntegreerde zorg en gespecialiseerde verpleging. Innovaties die gericht zijn op de integratie van zorg worden in zowel thuiszorg- als ziekenhuisgeoriënteerde landen ingevoerd. Innovaties gericht op ziekenhuisverplaatste zorg en gespecialiseerde verpleging worden vooral ingevoerd in thuiszorggeoriënteerde landen. Op basis van de bestaande literatuur is nog weinig inzicht in hoeverre de voornoemde innovaties de kwaliteit van zorg, kosten van zorg en het zorggebruik beïnvloeden.

Hoofdstuk 3 van dit proefschrift presenteert de resultaten van een inventariserend onderzoek naar transmurale verpleegkundige spreekuren in Nederland. In deze studie is nagegaan hoe in Nederland invulling wordt gegeven aan transmurale verpleegkundige spreekuren. Daarnaast wordt inzicht gegeven in reeds uitgevoerde evaluatiestudies naar transmurale verpleegkundige spreekuren. Van in totaal 62 transmurale verpleegkundige spreekuren voor chronisch zieken in Nederland zijn gegevens verzameld. Het merendeel van deze spreekuren wordt door gespecialiseerde wijkverpleegkundigen gehouden in de polikliniek van een ziekenhuis. De hoofdtaak van de verpleegkundige is meestal gericht op het geven van informatie over ziekte en behandeling en op het bieden van ondersteuning bij het omgaan met de ziekte. Van de bestaande spreekuren zijn er enkele geëvalueerd (in alle gevallen door de betrokken hulpverleners of medewerkers). Door beperkingen in de gehanteerde evaluatiemethoden is het moeilijk om stellige conclusies over de meerwaarde van transmurale spreekuren te formuleren. Op basis hiervan wordt geconcludeerd dat 
toekomstig onderzoek nodig is om de impact van transmurale spreekuren vast te stellen.

Naar aanleiding van het inventariserend onderzoek uit hoofdstuk 3 is de impact van transmurale spreekuren onderzocht en beschreven in de hoofdstukken 4 tot en met 7 . Hoofdstuk 4 beschrijft de resultaten met betrekking tot kwaliteit en continuïteit van zorg in transmurale en extramurale astma-spreekuren. Transmurale spreekuren worden gehouden onder gezamenlijke verantwoordelijkheid van de thuiszorg en een ziekenhuis. Extramurale spreekuren worden gehouden onder de verantwoordelijkheid van enkel een thuiszorgorganisatie. In dit hoofdstuk zijn de percepties van ouders van kinderen met astma die respectievelijk transmurale of extramurale spreekuren bezoeken met elkaar vergeleken. Het blijkt dat in beide typen spreekuren de kwaliteit en continuïteit van zorg erg positief beoordeeld wordt. De organisatorische verschillen tussen transmurale en extramurale spreekuren blijken dit positieve oordeel van ouders niet te beïnvloeden. Naast het oordeel van ouders wordt in hoofdstuk 4 ook het oordeel van gespecialiseerde verpleegkundigen en kinderartsen over deze spreekuren beschreven. Deze professionals zijn van mening dat verpleegkundige spreekuren een positieve innovatie zijn omdat patiënten aanvullende informatie krijgen tijdens een spreekuurbezoek. Daarnaast zijn, volgens de professionals, spreekuren van verpleegkundigen meer laagdrempelig dan spreekuren van medisch specialisten. Hierdoor zullen ouders hun twijfels of vragen over de ziekte van hun kind eerder uitspreken. Volgens de professionals zouden de positieve punten van verpleegkundige spreekuren echter versterkt kunnen worden indien een aantal belemmerende factoren, zoals het niet structureel verwijzen van medisch specialisten en huisartsen naar de spreekuren, in de toekomst worden weggenomen.

In hoofdstuk 5 wordt de kwaliteit en continuïteit van zorg in transmurale verpleegkundige reuma-spreekuren beschreven. Net als in hoofdstuk 4 is kwaliteit en continuïteit van zorg gemeten vanuit het perspectief van patiënten en professionals. Ook uit deze studie blijkt dat zowel patiënten als professionals een positief oordeel hebben over de kwaliteit en continuïteit van zorg in transmurale verpleegkundige spreekuren.

Hoofdstuk 6 is gewijd aan de kenmerken van patiënten en de verleende verpleegkundige zorg in transmurale en extramurale verpleegkundige astma spreekuren. Daarnaast is dit hoofdstuk gewijd aan de effecten van transmurale en extramurale verpleegkundige astma-spreekuren op de 
informatiebehoefte en het zorggebruik van (ouders van) kinderen met astma. In dit hoofdstuk wordt geconcludeerd dat kinderen die een transmuraal verpleegkundig spreekuur bezoeken een ernstiger vorm van astma hebben dan kinderen die een extramuraal spreekuur bezoeken. Daarnaast blijkt dat verpleegkundigen die in dit onderzoek participeerden en een extramuraal spreekuur houden vaak niet op de hoogte zijn van de ernst van de astma van kinderen die hun spreekuur bezoeken. Een andere conclusie uit dit hoofdstuk is dat zowel transmurale als extramurale spreekuren voorzien in de informatiebehoefte van ouders van kinderen met astma. Dit effect bleek echter groter in transmurale dan in extramurale spreekuren. Tenslotte blijkt uit hoofdstuk 6 dat zowel transmurale als extramurale spreekuren leiden tot een afname in het zorggebruik van kinderen met astma. De organisatorische verschillen tussen transmurale en extramurale spreekuren hebben op deze uitkomst geen invloed.

In hoofdstuk 7 wordt een vergelijking gemaakt tussen reumapatiënten die een transmuraal verpleegkundig spreekuur bezochten en reumapatiënten die enkel reguliere zorg ontvingen. Uit dit hoofdstuk blijkt dat het bezoeken van een transmuraal verpleegkundig spreekuur geen invloed heeft op de informatiebehoefte, het gebruik van hulpmiddelen en het dagelijks functioneren van reumapatiënten. Een verschil tussen de twee onderzoeksgroepen is echter wel gevonden met betrekking tot het zorggebruik van reuma-patiënten. Het blijkt namelijk dat als mensen met een reumatische aandoening een transmuraal spreekuur bezoeken zij vaker een reumatoloog en ergotherapeut consulteren.

\section{Literatuur}

Nationale Raad voor de Volksgezondheid \& College voor Ziekenhuisvoorzieningen (1995).

Transmurale somatische zorg: Advies van de Nationale Raad voor de Volksgezondheid en het College voor Ziekenhuisvoorzieningen. Zoetermeer: NRV/CvZ. 


\section{DANKWOORD}

Dit proefschrift is de neerslag van het werk, de inzet en motivatie van velen. Uiteraard was de medewerking van de vele patiënten, verpleegkundigen, kinderartsen, reumatologen en assistentes onontbeerlijk. De ontvangst in de diverse ziekenhuizen en thuiszorginstellingen was altijd hartelijk en ik heb met veel plezier met jullie samengewerkt.

Daarnaast een woord van dank voor mijn promotoren. Huda en Jouke, tijdens onze besprekingen kreeg $i k$ altijd voldoende ruimte om m'n eigen ideeën te ventileren en door te voeren in de artikelen die samen dit proefschrift vormen. Bedankt voor de fijne samenwerking in de afgelopen periode. Anneke, je hebt als copromotor een belangrijke bijdrage geleverd aan de opzet van het evaluatie-onderzoek naar de spreekuren. Jij hebt het onderzoek gestart en was nauw betrokken bij de uitvoering van mijn dagelijkse onderzoekswerkzaamheden. Ik kon altijd bij je aankloppen met de meest uiteenlopende vragen en opmerkingen. Bedankt voor je luisterend oor, goede tips en praktische en inhoudelijke steun.

Jack, jouw rol had geen officiële titel maar is ondanks dat zeer waardevol voor mij geweest. Je verfrissende blik op het onderzoek en opbouwende adviezen bij het schrijven van de artikelen heb ik ontzettend gewaardeerd. Naast de inhoudelijke ondersteuning die je me hebt gegeven was het erg prettig om met je samen te werken.

Mw. Bal, mw. Bos, mw. Kruyt, dhr. Rasker en mw. Van Vliet vormden samen de begeleidingscommissie van het onderzoek naar transmurale reumaspreekuren. Bedankt voor jullie kritische blik naar de relevantie en praktische haalbaarheid van het onderzoek.

Ada Kerkstra was als voorzitter van de begeleidingscommissie, projectleider en later als afdelingshoofd betrokken bij de opzet en uitvoering van de onderzoeken die in dit proefschrift zijn beschreven. Ada, bedankt voor je interesse in de vorderingen van het onderzoek en de stand van zaken van de publicaties.

Het spreekt voor zich dat niet alleen de begeleiding bij het onderzoek betekenisvol is geweest. Ook in de uitvoering heb ik veel ondersteuning gehad van diverse mensen. Allereerst heeft Anneke Kaper alle telefonische enquêtes bij patiënten die meededen aan het onderzoek afgenomen en ingevoerd in de computer. Anneke, je hebt een berenklus geklaard. Ik heb altijd graag met je samengewerkt, ontzettend bedankt.

Jan Gravestein bedank ik voor het opzetten van de SPSS invoerprogramma's voor de astma- en reuma-studie uit dit proefschrift. Jan, de programma's die 
jij hebt gemaakt zaten erg goed in elkaar, wat er voor zorgde dat het analyseren van alle gegevens vlot verliep.

Bij het analyseren was Peter Spreeuwenberg altijd beschikbaar om mijn vragen te beantwoorden en een deel van mijn analyses te controleren op juistheid. Peter bedankt voor je goede ideeën en de fijne samenwerking. Marcelle van der Meulen en Richard van Kruysdijk hebben zich gebogen over het uiterlijk van mijn proefschrift. Bedankt voor jullie werk, het mag gezien worden!

Gelukkig waren er tijdens het onderzoek ook nog mensen om me heen die niets of weinig inhoudelijks van mijn proefschrift op zich wisten en gewoon over andere dingen konden praten. Mijn kamergenoten en andere collega's: Arjen, Nienke, Johan, Corina, Hanneke, Janice, Saskia, Irma, Suzanne, Mireille, Annie, Geertjan, Wienke, Emmy, Greet en Ria is het gelukt om het onderzoek te relativeren en mij te verleiden met een ijsje op de Oude Gracht, een drankje in de Steeg, een heerlijke kop soep of een wandelwerkbespreking. Naast de genoemde 'Nivellers' zijn er natuurlijk nog ontzettend veel anderen die gedurende mijn Nivel-tijd relativerende opmerkingen hebben gemaakt, waar ik met veel plezier aan terug denk. Allemaal bedankt voor de gezellige sfeer en de collegialiteit! En..... er is nog leven naast het Nivel. Lieve Willem, jij bent er altijd van overtuigd geweest dat ik m'n proefschrift tot een goed eind zou brengen. Bedankt voor je liefde, humor, zorgzaamheid en kookkunst. Ik hoop dat we daar samen nog een lange tijd van kunnen genieten.

Bas, het leek wel of jouw komst mijn onderzoekswerk in de vierde versnelling zette. Toen je nog in m'n buik zat rolde het ene na het andere artikel van mijn hand uit de printer en twee dagen voor je geboorte lag daar 'zomaar' een proefschrift. Het is heerlijk dat je bij ons bent!

En dan zijn er natuurlijk nog mijn overige familieleden, de 'Kwirido-vrienden', de 'meiden uit Maastricht' en mijn paranimfen Annemarie en Katinka. Lieve allemaal, bedankt voor jullie steun, interesse en de gezellige en ontspannende weekenden, avonden en middagen! 


\section{CURRICULUM VITAE}

Denise Temmink is op 6 juli 1971 in Wormerveer geboren. Na het Middelbaar Algemeen Voortgezet Onderwijs (1983-1987) rondde zij in 1989 het Hoger Algemeen Voortgezet Onderwijs af. Vervolgens heeft zij in Alkmaar de HBOVerpleegkunde in 1993 met goed gevolg afgesloten. In de periode 1993-1994 heeft Denise met een VSB-beurs geparticipeerd in een uitwisselingsprogramma van de Universitas Gadjah Mada (YogyakartaIndonesië) en Hogeschool Midden Nederland (Utrecht). In het kader van dit uitwisselingsprogramma heeft zij gedurende een jaar als verpleegkundige in Indonesië (Yogyakarta/Java en Maumere/Flores) gewerkt. Na haar werkzaamheden in Indonesië is Denise Gezondheidswetenschappen gaan studeren. Deze opleiding rondde zij in 1996 af. Vanaf september 1996 is Denise werkzaam bij het Nivel in Utrecht. Een deel van haar onderzoekswerkzaamheden bij het Nivel zijn opgenomen in dit proefschrift. Daarnaast heeft Denise bij het Nivel onderzoek gedaan naar transmurale zorg in het algemeen, palliatieve zorg en kwaliteitszorg.

Denise Temmink was born on July 6, 1971 at Wormerveer, the Netherlands. After completing high school in 1989, she studied at the Academy for Health Care and received her Bachelor's degree in Nursing in 1993. In 1993-1994, Denise participated with the help of a VSB-grant, in an exchange programme between Universitas Gadjah Mada (Yogyakarta-Indonesia) and Hogeschool Midden Nederland (Utrecht-the Netherlands). She worked as a nurse in Indonesia (Yogyakarta/Java and Maumere/Flores) within this programme. After her return from Indonesia, Denise studied the Health Sciences at Maastricht University. She received her Masters degree in 1996 and then worked at the Nivel foundation in Utrecht (the Netherlands). A part of her work at the Nivel is reflected in this dissertation. In addition Denise carried out research into the fields of general transmural care, palliative care and quality of care. 
